\title{
MOTOR CARRIER PRICING IN AN UNREGULATED ENVIRONMENT
}

\author{
By \\ RUSSELL WYANT JONES \\ Bachelor of Science \\ Oklahoma State University \\ Stillwater, Oklahoma \\ 1955 \\ Master of Science in Business \\ Administration \\ Boston University \\ Boston, Massachusetts \\ 1977
}
Submitted to the Faculty of the Graduate College of the Oklahoma state University in partial fulfillment of the requirements for the Degree of DOCTOR OF PHILOSOPHY December, 1992




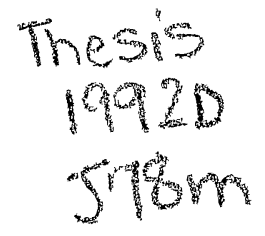




\section{MOTOR CARRIER PRICING IN AN \\ UNREGULATED ENVIRONMENT}

Thesis Approved:

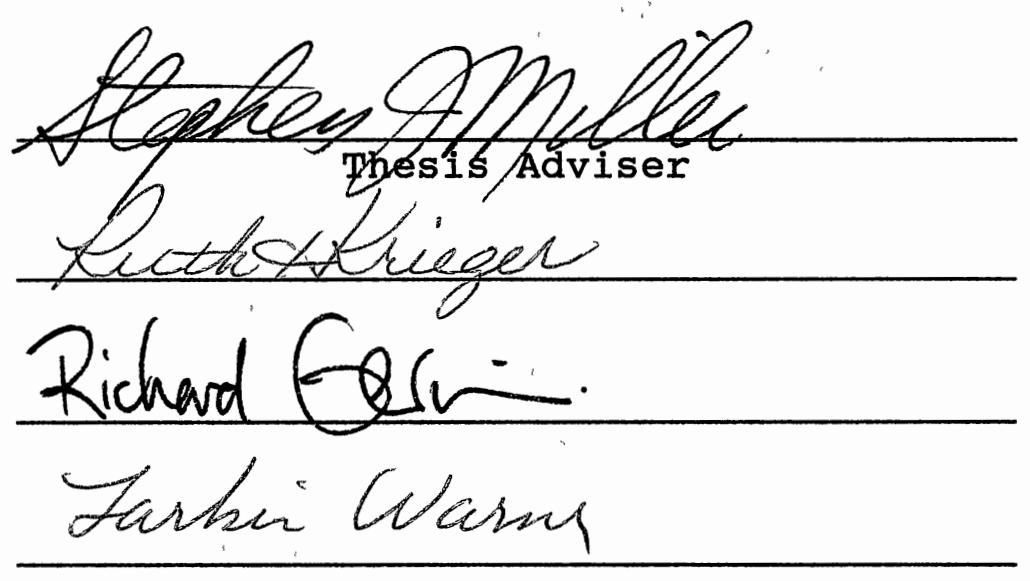

$\frac{\text { Thoman C. Preme }}{\text { - Dean of the Graduate college }}$ 


\section{PREFACE}

Data for over 5000 individual motor carrier shipments were collected for analysis. The shipments originated in 46 states and were destined for a single destination, Tinker Air Force Base, Oklahoma. Information was available for state and city of origin, type of equipment used, motor carrier company or companies involved in each shipment, shipment weight, shipment charges, and pick-up and delivery dates. The shipment data were supplemented with geographic, product attribute, and motor carrier attribute data gathered from secondary sources. Nine hypotheses about motor carrier pricing behavior were developed. These hypotheses were tested for statistical significance using the expanded database and a standard statistical analysis package. The conclusions reached about motor carrier pricing behavior as a result of the analysis of the data are reported.

I wish to thank the members of my dissertation committee for their support and assistance in the preparation of this paper. In particular, I wish to thank Dr. Stephen Miller, my committee chairman, for the guidance he provided during a long and difficult process. My thanks to Dr. Larkin Warner who originally sparked my interest in the field of motor carrier pricing and regulation. Dr. Ruth 
Krieger deserves many thanks for her helpful comments on the multiple drafts of this paper and for her personal support. I would also like to give special thanks to Dr. Richard Germain, a newcomer to my committee, for the interest he has shown in this project, his insightful comments, and his enthusiasm and encouragement.

I would also like to recognize the support of the College of Business Administration at the University of Central Oklahoma. The computer time and facilities they provided made many long trips to Stillwater unnecessary. Ms. Kay Tevebaugh of the Transportation Operations Division at Tinker Air Force Base also contributed a great deal to this research effort. During the data gathering process her help was invaluable.

Finally, I owe Marilyn, my wife of thirty eight years, many special thanks. She provided extensive moral support and always believed in my abilities. She spent many hours sitting at the typewriter trying to read my scribbling. She endured my foul moods when things did not go well and shared my elation when some, often minor, breakthrough occurred. 
TABLE OF CONTENTS

Chapter

Page

I. INTRODUCTION. . . . . . . . . . . . . . .1

Transportation and Industrial Societies. . . .1

Transportation and Marketing. . . . . .2

Transportation Rates and Research. . . 3

Transportation Rates and Markets. . . . 4

Transportation Rates and Competition. . .5

Freight Rate Modeling. . . . . . . 7

Deregulation and Freight Rates. . . . 8

Deregulation and Freight Classification 10

Recent Motor Carrier Pricing Studies. . 12

Research Methodology... . . . . . . . .13

Research Objectives. . . . . . . . .14

Product Attributes. . . . . . . 16

Hypothesis 1. . . . . . ..16

Hypothesis 2. . . . . . . . 17

Hypothesis 3. . . . . . . 17

Hypothesis $4 .$. . . . . . 17

Geographic Attributes. . . . . 17

Hypothesis 5. . . . . . . 17

Hypothesis 6. . . . . . . . 17

Carrier Attributes. . . . . . .18

Hypothesis 7. . . . . . 18

Hypothesis 8. . . . . . 18

Service Attributes. . . . . . . 18

Hypothesis 9. . . . . . 18

Database. . . . . . . . . . . . . . 18

Contributions. . . . . . . . . . . 20

Report Organization. . . . . . . . . . 21

II. MOTOR CARRIER INDUSTRY STRUCTURE AND HISTORY.....22

The United States Transportation System. • . 22

Roadway Development. . . . . . . . .23

The Motor Carrier Industry. . . . . . . .25

Industry Structure and Size. . . . . . .26

Motor Carrier Market Competition. . . 29

Motor Carrier Revenues. . . . . . 30

Motor Carrier Historical Development. . . . 31

Motor Carrier Industry 1900-1935. • . . 32

Motor Carrier Industry 1935-1980. • . 37

Motor Carrier Industry 1980-Present. . .47

Effects of Deregulation. . . . . 48 
III. MOTOR CARRIER INDUSTRY PRICING, REGULATION, AND RATE RESEARCH. . . . . . . . . . . . . . 52

Regulated Motor Carrier Pricing. . . . . ..52 Transportation Pricing Problems. . . . .53 Freight Classification Factors and

Freight Classes. . . . . . . . . .54

Railroad Industry Pricing. . . . . . .57

Adoption of Railroad Pricing by Motor

Carriers. . . . . . . . . . 59

Value-of-Service Pricing. . . . . . 60

Value-of-Service Pricing Studies. . . 63

Legal and Legislative Actions Affecting Pricing. . . . . . . . . . . .65

Collective Ratemaking. . . . . . . . 69 Impact of Motor Carrier Regulation. . 73 Transportation Cost Studies. . . . . .75 Effects of Motor Carrier Regulation

on Pricing. . . . . . . . . . . 77

Exempt Carrier Studies. . . . . 78

Cross Sectional Studies. . . . 79

Canadian Studies. . . . . . . . 80

European and Australian Studies. $\bullet 81$

New Jersey Study. . . . . . . . .83

Weaknesses in Rate Level Research. . . .84

Rate Adequacy Measures. . . . . . 87

Return on Investment. . . . . . .88

Operating Ratio. . . . . . . 91

Return on Equity. . . . . . . . .92

IV. DEREGULATION AND MOTOR CARRIER PRICING BEHAVIOR. .94

Rate Studies and the Deregulated Motor

Carrier Industry. . . . . . . . . . . . . .94

Survey, Case Studies, and Empirical

Investigations. . . . . . . . 95

Case Studies. . . . . . . . .95

Surveys. . . . . . . . . . 97

Empirical Investigations. . . 100

The Blair, Kasserman, and McClave Study. . . . . 101

The Beilock and Freemen

Study. . . . . . . . 106

Conclusions . • . . . . . . 113

Need for More Empirical Studies. . . 114

Government Freight Transportation. . . . .116

History of Government Freight

Transportation. . . . . . . . .117

Section 22 Rates. . . . . . . . . . .118

DOD Freight Shipments versus Commercial

Freight Shipments. . . . . . . 123 
A Disaggregated Military Traffic

Database. . . . . . . . . . . 125

The Freight Information System. 127

Motor Carrier Rate Modeling. . . . . . . .128

Distance, Weight and Cost

Relationships . . . . . . . . . 129

Motor Carrier Rate Models. . . . . 130

Problems Caused by Inconsistent

Variable Selection. . . . . . . .132

Deregulation and Motor Carrier Rates. .133

V. METHODOLOGY. . . . . . . . . . . . . 136

Research Hypotheses. . . . . . . . . .136

Product Attributes. . . . . . . . .137

Hypothesis 1. . . . . . . . . 139

Hypothesis 2. . . . . . . . . 139

Hypothesis 3. . . . . . . . . 140

Hypothesis 4. . . . . . . . . 141

Geographic Factors. . . . . . . . 142

Hypothesis 5. . . . . . . . . 142

Hypothesis 6. . . . . . . . . 143

Carrier Attributes. . . . . . . . .144

Hypothesis 7. . . . . . . . 145

Hypothesis 8. . . . . . . . . 146

Service Factors. . . . . . . . . 146

Hypothesis 9. . . . . . . . . . 147

Research Database. . . . . . . . . . . 147

Database Selection Criteria. . . . 148

Database Content. . . . . . . . . .151

Supplemental Database Information. . 152

Measures. . . • . . . . . . . . . 156

Commodity Attribute Measures. . . . .156

Geographic Measures. . . . . . . 159

Motor Carrier Attribute Measures. . . .163

Service Measures. . . . . . . . . .165

Distance, Weight and Charge Measures. .169

Hypotheses Tests. . . . . . . . . . 170

Hypothesis 1 Test. . . . . . . . . . 171

Hypothesis 2 Test. . . . . . . . . 172

Hypothesis 3 Test. . . . . . . . . . 173

Hypothesis 4 Test................174

Hypothesis 5 Test. . . . . . . . . . 174

Hypothesis 6 Test. . . . . . . . 175

Hypothesis 7 Test. . . . . . . . . 176

Hypothesis 8 Test. . . . . . . . 176

Hypothesis 9 Test. . . . . . . . . 177

VI. DAta ANALYSis. . . . . . . . . . . . 179

Introduction. . . . . . . . . . . . 175

Product Attributes. . . . . . . . . . . . 189 
Hypothesis 1 Findings. . . . . . . 189

Hypothesis 2 Findings. . . . . . . . 192

Hypothesis 3 Findings. . . . . . . . 196

Hypothesis 4 Findings. . . . . . . 198

Geographic Attributes. . . . . . . . .200

Hypothesis 5 Findings. . . . . . 201

Hypothesis 6 Findings.'. . . . . . 204

Carrier Attributes. . . . . . . . . . 207

Hypothesis 7 Findings. . . . . . . 208

Hypothesis 8 Findings. . . . . . . 210

Service Attributes. • . • . . . . . . . 213

Hypothesis 9 Findings. . . . . . . 214

Data Analysis Summary. . . . . . . . . . 217

Motor Carrier Rate Models. . . . . . . .218

Reduced Database Analysis. . . . . 219

VII. SUMMARY AND CONCLUSIONS. • • • • • • . . . . 227

Introduction. . . . . . . . . . . . . 227

Research Findings Summary . . . . . . . 228

Limitations ofthe Study . . . . . . . . 231

Implications of the Study . . . . . . . 233

Future Research Efforts . . . . . . . . 236

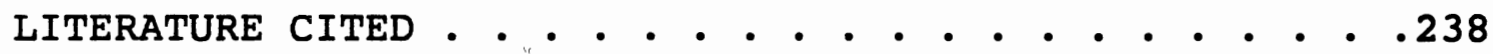




\section{LIST OF TABLES}

Table

Page

1. Product Classification Criteria . . . . . . . 157

2. State Regional Assignments . . . . . . . . . 160

3. Size of Shipment Origin Points'. . . . . . . 163

4. Motor Carrier Size by Sales (1984) . . . . . . 166

5. Service Standards in Days . . . . . . . . 168

6. Correlation Matrix, Reduced Database . . . . . 182

7. Regression Analysis, Hypothesis 1. . . . . . . 191

8. Regression Analysis, Hypothesis 2. . . . . . . 194

9. Regression Analysis, Hypothesis 3. • . . . . . 197

10. T-Test Summary, Hypotheses 4 . . . . . . . . 199

11. One-way ANOVA, Hyopthesis 5 . . . . . . . 202

12. Regression Analysis, Hypothesis 6. . . . . . 206

13. T-Test Summary, Hypotheses 7 . . . . . . . 209

14. Regression Analysis, Hypothesis 8. . . . . . .212

15. Regression Analysis, Hypothesis 9. . . . . . .215

16. General Linear Model Regression Results, Dependent Variable, RTM . . . . . . . . 221

17. General Linear Model Regression Results, Dependent Variable, Charge. . . . . . . 222

18. Stepwise Regression Results . . . . . . . . 224

19. Stepwise Regression Results . . . . . . . . 225 


\section{LIST OF FIGURES}

Figures

Page

1. Structure of the Motor Carrier Industry . . . . . 27

2. Regional Differences, Full Database . . . . . . 203

3. Regional Differences, Reduced Database . . . . 203 
CHAPTER I

INTRODUCTION

Transportation and Industrial Societies

Transportation is a universal input - perhaps the only one in economic terms. As such, transportation warrants special attention from governments, from private enterprises in both the transportation and non-transportation sectors of the economy, and from all persons interested in the welfare of a particular company, city, region, nation; in fact, the welfare of the world (Gellman, 1967, p. 62).

An efficient logistical system, in which transportation plays a vital part, is essential to the economic development of a country. Without transportation, mass production as we know it could not take place and the standard of living enjoyed in industrialized countries would be significantly lower. A primitive transportation system has often been identified as a major reason for the lack of economic development in many countries. In industrialized countries, transportation becomes more important as the logistic concept and just-in-time inventory control techniques become more widely accepted.

The logistic concept holds that for a given level of customer service, logistical system costs should be minimized. Transportation is the major logistical cost; therefore, it is vital to know how transportation prices are 
set and what factors affect these prices. In a just-in-time inventory control system, efficient transportation is usually substituted for inventory.

\section{Transportation and Marketing}

Despite the importance of transportation, the field of marketing has largely ignored the subject. Marketers claim that channels of distribution, of which physical

distribution and transportation are parts, fall within their domain. Yet the amount of attention paid to transportation by those in marketing is extremely limited. To confirm the previous statement, one only has to examine a basic marketing text, indices of articles published in leading marketing journals, and marketing curriculum structures.

In most marketing texts, channels of distribution are discussed within the context of the institutions involved, the relationships between the institutions, and the management of the institutional relationships. Physical distribution, which involves transportation, generally receives very little attention. Although transportation might be mentioned as a distribution facilitating function, that is the extent of the coverage. In marketing journals, articles which address either practical or theoretical problems in the field of transportation rarely appear.

Perhaps this lack of attention could be justified in the past when much of the transportation industry was extensively regulated. Most marketing mix elements of 
transportation companies were effectively controlled by the regulators. Transportation research, under these conditions, was the study of economic regulation, not marketing. At this point it is necessary to point out that there are three forms of regulation, economic, safety, and financial. This paper is only concerned with economic regulation of transportation at the federal and to some degree the state government levels.

Transportation has, in the past, been viewed as being closer to the operations management field, rather than the field of strategic marketing. However, by 1980 legislation was enacted that deregulated most of the transportation industry. A deregulated transportation environment has enabled firms, both transportation companies and shippers, to develop the principal of logistical competitive advantage. Deregulation should make the field of transportation research more attractive to marketing scholars. Significant research activity in this area would help strengthen the claim that transportation falls within the domain of the marketing discipline.

\section{Transportation Rates and Research}

Rates are one area of transportation which should attract the marketing researchers' interest. Rates are the prices which transportation companies charge for their services, and price is one of the basic elements of a firm's marketing mix. Research is needed to describe the present 
rate structure and to determine what factors underlie the structure. Rate research would contribute to the understanding of pricing behavior in an industry which provides a service in an unregulated environment. Rate research would benefit individual firms and economic development agencies. The amount of post-deregulation transportation rate research has been very limited, but the research done by marketers has been almost non-existent. The lack of transportation rate research by the marketing discipline adds credence to the arguments of those who feel that transportation has not truly been accepted as part of the marketing domain.

\section{Transportation Rates and Markets}

Transportation rates to and from a particular area have a major impact on economic activity within that area. Transportation rates basically define the boundaries of the area where a firm can look for raw materials. They also define the boundaries of the area where a firm can market its finished products. If two firms produce identical products and have identical production costs, the natural market boundary between them could be described by a series of points where transportation costs are equal. At these points neither firm would have a competitive advantage in product landed price. ${ }^{1}$ If one firm enjoys a transportation 1.Most logistic texts point out that the customers of a firm are concerned with the landed price of the goods they purchase, not the price of the goods at the factory. The landed price of the product is its price at its source plus 
rate advantage, its market area will expand. The market area served by the firm with the rate disadvantage will contract. This expansion and contraction of the market areas is not, however, linear. If a firm pays a rate equal to 50 percent of that paid by the competition, it can transport products twice as far for the same transportation dollar. If the operational radius of a firm doubles, the market area served is four times larger. It can be seen from the above example that any firm currently located at or considering locating at a specific geographic point would be interested in transportation rates.

\section{Transportation Rates and Competition}

As previously discussed, transportation rates are one of the major factors which determine feasible market areas for firms. Transportation rates also assist firms in defining their competition. ${ }^{2}$ It is beneficial to any group of firms, located in a specific geographic area, to know the rates for both inbound and outbound freight shipments. Under regulation, they could, with some effort, acquire this information. Under deregulation, rate information is not available. The firms know the inbound and outbound shipment rates they pay or, if they operate their own private fleets,

the transportation charges to wherever the product is delivered.

2. There is an extensive body of literature which deals with the relationship between transportation, facility location, and regional economic development. For a summary of early locational theory development see Melvin L. Greenhut, Plant Location in Theory and Practice (Chapel Hill, NC: University of North Carolina Press, 1956). 
they know their fleet operating costs. They do not have, however, exact knowledge of the rates paid by their competitors.

If a product, produced by a local firm, is being imported into the community, it is probable that the local firm has a capacity constraint, a production cost disadvantage, a marketing disadvantage, or is seeking to achieve a profit margin which is unrealistic. If the local firm considers its profit margin to be competitive, and its production assets are being used at less than capacity, knowledge of the transportation rates paid by the competition would be beneficial. This information could be used by the local firm to assess its production or marketing disadvantage.

If a local firm had no significant transportation cost in serving a local market, then the local firm should be the supplier of preference in the local market. If, however, a locally demanded product can be produced elsewhere and imported to compete with the locally made product, the locational competitive advantage enjoyed by the local firm has disappeared. Based on this line of reasoning, local firms and economic development agencies should be willing to expend considerable effort to develop an understanding of freight rates for their community. Interest would naturally focus on the rates for products which are imported to compete with locally produced products. 
Freight Rate Modeling

Any research that produces a model of freight rates and explores the factors which underlie the model should prove useful in developing the competitive strategy of a firm. The model would also be useful in establishing an area economic development program. If such a model could be discovered and validated, it would contribute significantly to the understanding of transportation services pricing in a deregulated environment. Recent studies which take a freight rate modeling approach to the problem of deregulated transportation pricing are noteworthy, but extremely limited. One major limitation is that studies do not use individual shipment data. From a review of transportation literature, it quickly becomes obvious that additional research in the area of freight rate modeling is needed to develop a deeper understanding of the impact of deregulation. Rate research is also needed to meet the requirements of local businesses and economic development agencies .

Using modern statistical analysis packages, the development of a model of transportation freight rates would be an easy task if the proper data were available. A major problem which precludes the development of post-deregulation freight rate models has been, however, the lack of a suitable disaggregated database. ${ }^{3}$ The Interstate Commerce

3.Databases in transportation related articles are often described as aggregated or disaggregated databases. A disaggregated database is one which uses an individual 
Comission (ICC) does draw a one-percent sample from the waybills of the railroad industry but no similar effort has been made for the motor carrier industry.

For a single firm or a local economic development agency, the development of a transportation rate model alone might be sufficient. From an academic point of view such research would need to be carried beyond model construction to contribute significantly to transportation pricing theory development. The development of a transportation rate model can only be considered the first step in the academic research process. Transportation rate model development would have to be extended to identifying and analyzing the factors underlying the model for the research to have academic significance. These underlying factors would have to be described and examined for situation specific variation and statistical significance. If situation specific variation does exist, then the issue of why it exists must be examined as well as the stability of the variation as situations are altered.

\section{Deregulation and Freight Rates}

Deregulation of the motor carrier industry in 1980 changed most aspects of a pricing system which had been utilized for the previous 45 years. Before deregulation, everyone understood how the motor carrier industry set

shipment as the unit of observation. An aggregated database is one which combines a number of individual shipments into a single observation. 
prices. Pricing was completely controlled by a series of specific regulations, laws, and court decisions. Exactly what the regulated motor carriers could or could not do in the area of pricing was a matter of public record. Every product regularly involved in commerce was assigned a class rating and everyone knew exactly what factors were considered by the classification board in assigning a product classification. Arguments about a product's classification occurred frequently, but eventually all products recieved classification numbers.

Product class rating, shipment weight and the distance between origin/destination points basically determined what a regulated motor carrier could charge for its service. Other factors did affect the rates charged but the major ones are listed above. Under the same or similar conditions every shipper paid exactly the same price for transportation services from a common carrier. Since everyone paid the same price under the same conditions, transportation was not considered a competitive factor by firms which depended on regulated motor carriers.

Before deregulation a firm might choose not to operate its own motor carrier fleet and depend on common or contract carriers to supply transportation services. Under these conditions the firm could determine the freight rates paid by its competition for comparable transportation services to or from a location. These rates were a matter of public record, available to everyone who wished to expend the 
energy to seek them out. Firms could determine if they had a product landed price advantage on which to make their marketing appeal, or if they would have to employ a different marketing mix strategy.

Deregulation resulted in a previously known competitive factor, transportation costs, being replaced by a largely unknown one. Most firms in today's deregulated transportation environment make every effort to hide their transportation costs from competitors. These costs are treated as proprietary information to conceal any competitive advantage a firm might enjoy due to reduced transportation rates. An individual firm might make an educated guess about transportation rates paid by its competition, but the risks associated with guessing wrong probably outweigh the rewards associated with guessing right. At this time a significant number of transportation rate studies, which might reduce the risk of guessing wrong, have not been compiled. Further research in the unregulated transportation rate area is obviously needed.

\section{Deregulation and Freight Classification}

The pricing behavior of most privately owned, unregulated industries in this country is only constrained by broad legal guidelines and the forces of market competition. Unregulated companies are not required to reveal the factors used to make pricing decisions. Now that motor carriers have basically become part of the unregulated 
sector, can we, through research, determine how they set the price they charge for their services?

Initially the pricing constraints which had been imposed under motor carrier industry regulation were only relaxed, not removed. During the two years following its passage, the pricing provisions of the Motor Carrier Act of 1980 became operable. At the end of this period the pricing behavior of the formerly regulated motor carrier industry had approached that of an industry which had never been regulated. By the end of three years the ICC had removed all product classification criteria, other than those based on cost, from the list of product classification criteria. The ICC ruled that product demand-oriented factors could be used in ratemaking, but not in classification. If product demand factors were to be considered in setting a transportation rate, they were to be considered by individual motor carriers, not by classification committees collectively.

The ICC also ruled that it was improper for different class ratings to be assigned to the same product shipped in different volumes. This did away with the two-tiered, lessthan-truckload (LTL) and truckload (TL), product classification system which had been in effect for years. The ICC determined that when rates differed strictly because of the volume of the shipment, this was a volume discount. Volume discounting was to be the responsibility of the motor carrier, not a collective rate-making body. The individual 
motor carrier was also assigned the responsibility of determining where the individual minimum shipment and volume discount weight breaks would be.

\section{Recent Motor Carrier Pricing Studies}

With deregulation, motor carriers were forced to develop their own individual pricing expertise in three short years. They could no longer depend on the type of group pricing which had been practiced under regulation. As individual companies they had to determine how much to charge for their services in a multitude of different circumstances. Would they be market price takers as they had been in the highly competitive pre-regulation motor carrier industry or would they attempt to differentiate their product and be price makers? Presently little is known about how the motor carriers went about solving their individual pricing problems. Very few studies have examined deregulated motor carrier pricing behavior. The majority of the small number of pricing studies done examined motor carrier costs and tried to correlate pricing behavior with cost recovery.

Most of the published pricing studies are based either on case studies or surveys. The number of studies based on individual shipment data are extremely limited. Studies based on surveys report motor carrier and shipper perceptions about the changes that have taken place in motor carrier pricing behavior under deregulation. With this type 
of research, feelings or perceptions of the subjects surveyed might not represent the feelings of the general population. In this case rate study findings would reflect the respondent's perceptions about changes in rates and not the actual rate changes themselves.

Feelings and perceptions are very abstract concepts that are extremely difficult to measure. They vary from person to person, from situation to situation, and from time to time. For these reasons it is unlikely that motor carrier pricing studies based on surveys will contribute significantly to progress toward defining a general theory of deregulated motor carrier pricing. Case studies are also limited in explanatory and predictive power. They often report what has happened to the rates paid by a single firm, shipping a single or limited line of products over fixed routes.

\section{Research Methodology}

Both surveys and case studies of deregulated motor carrier pricing have produced interesting results which are helpful in promoting an understanding of current motor carrier pricing behavior. These studies can only be classified, however, as descriptive research. Causal research in the area of motor carrier pricing is extremely rare and causal research studies based on disaggregated data are rarer still. Only two studies using extensive disaggregated databases to study the impact of deregulation 
on motor carrier pricing behavior have been reported in the literature. Both of these studies, dicussed below, were excellent, but limited in scope. The databases used in the two studies have geographic, product; and motor carrier limitations which make the generalizabilty of the study results doubtful.

Blair, Kasserman, and McClave (1986) examined motor carrier rates within the state of Florida and restricted their study to six markets, three of which were large and three small. They also restricted their study to the pricing behavior of 10 motor carriers transporting five freight classes. Beilock and Freeman (1987) expanded the geographic area covered by including data from both Florida and Arizona in their study. They examined motor carrier pricing behavior in six large markets and seven small ones in Arizona. In Florida, they included eight large and nine small markets in their study. They examined the rates charged by four carriers in Florida and 19 in Arizona. Like Blair et al., Beilock and Freeman restricted their study to only a few of the 23 product classes.' In Florida they included five product classes in their study while in Arizona they only studied four classes.

\section{Research objectives}

The first general research objective of this paper is to make a contribution to the understanding of the pricing behavior of the motor carrier industry in a deregulated 
environment. Empirical studies which address the issue of deregulated motor carrier pricing are extremely limited. Therefore, any studies in this area will enrich our understanding of the subject.

A second general research objective is to overcome some of the limitations of the two previously discussed major postderegulation motor carrier rate studies which used disaggregated databases. This can be accomplished by using a database which is national in scope and broader in coverage than those previously used. The number of carriers involved and products transported need to be expanded significantly.

A third general research objective is to test the stability and suitability of a readily available, but seldom used, database which is accessible to researchers under the Freedom of Information Act. If this database can be used successfully, it could well be the initial step leading to the first national study of motor carrier pricing.

A final general research objective is to develop a motor carrier rate model which might be useful to individual firms and economic development agencies located in the Greater Oklahoma City area. The model could assist these organizations in the formulating corporate or public policy strategy .

The more specific research objective of this paper is to identify the statistically significant variables, in addition to weight and distance, which underlie pricing 
behavior in the unregulated motor carrier industry. It is widely reported in the transportation literature that shipment distance and weight are the two major variables considered when motor carriers establish the price for a transportation service. In some studies these two variables alone accounted for a significant amount of the variance in motor carrier pricing behavior.

Prior studies have found that the explanatory powers of the rate models were improved significantly by including additional factors which have geographic, product, service, and carrier attribute dimensions. To explore the idea that deregulated motor carriers consider factors other than distance and weight when setting rates, nine hypotheses are developed and empirically tested. Testing these hypotheses for statistical significance will support or refute the idea that deregulated motor carrier pricing behavior is influenced by more than shipment weight and the distance involved. The hypotheses and the dimensions they are associated with are listed below. These hypotheses and dimensions are fully defined and discussed in Chapter V. The nature of the data and the statistical tests to be used are also specified below and discussed fully in Chapter $V$.

\section{Product Attributes}

Hypothesis 1 . As the product class number increases the rate charged increases. The data used to test this hypothesis are continuous in nature; therefore, regression 
and correlation analysis are appropriate statistical techniques.

Hypothesis 2. Variation from the ideal product density increases the rate charged. The data used to test this hypothesis are also continuous in nature; therefore, regression and correlation analysis are appropriate statistical techniques as they are for testing Hypothesis 1.

Hypothesis 3 . As the value of the product increases the rate charged will increase. The data used to test this hypothesis are again continuous in nature; therefore, regression and correlation analysis also are appropriate statistical techniques as well.

Hypothesis 4. As the need for special product handling increases the rate charged will increase. The data used to test this hypothesis are binary in nature; therefore, t-tests of means are appropriate statistical techniques.

\section{Geographic Attributes}

Hypothesis 5 . As the region of shipment origin varies the rate charged will vary. The region of origin data are nominal in nature and the rate charged data are interval in nature; therefore, an ANOVA model is an appropriate statistical technique.

Hypothesis 6 . As the size of the origin area population increases the rate charged decreases. The data 
used to test this hypothesis are continuous in nature; regression and correlation analysis are, therefore, the appropriate statistical techniques to use.

\section{Carrier Attributes}

Hypothesis 7. If multiple carriers are involved in a shipment, the rate charged will increase beyond that charged by a single carrier. The data used to test this hypothesis are binary in nature; therefore, $t$-tests of means are appropriate statistical techniques.

Hypothesis 8 . As the size of the carrier increases the rate charged will decrease. The data used to test this hypothesis are continuous in nature; therefore, regression and correlation analysis are the appropriate primary statistical techniques to use in this case.

\section{Service Attributes}

Hypothesis 9. As the service level increases the rate increases. The data used to test this hypothesis are continuous in nature; therefore, regression and correlation analysis are also appropriate statistical techniques.

\section{DataBase}

The data that will be used in examining the hypotheses summarized above are secondary data based on the records of individual freight shipments, made from 46 of the 48 contiguous United States, to Tinker Air Force Base (TAFB), 
located just outside of Oklahoma City, Oklahoma. This data was obtained from the files of the Military Traffic Management Command (MTMC) which has its headquarters in Falls Church, Virginia. Researchers, under the provisions of the Freedom of Information Act, have access to this database.

The shipments chosen for study include those made from July 1, 1983 through June 30, 1984. This period was chosen for several reasons: First, it represents the first full year in which motor carriers had almost complete pricing freedom under the provisions of the Motor Carrier Act of 1980. Second, after July 1, 1983, motor carriers were no longer allowed to use product demand factors in assigning a product to a class. Third, after this date the volume of freight shipped could no longer be considered in the classification process. Finally, this period was chosen because it avoided much of the industry turbulence which resulted in numerous carrier failures during the middle 1980's. The basic bill of lading information contained in the MTMC database was supplemented by data from three other sources: the Rand McNally Commercial Atlas, the Massachusetts Institute of Technology's Disaggregated File of Commodity Attributes, and the National Motor Freight Classification Manual (NMFCM). 


\section{Contributions}

The findings of this research will have both practical and theoretical implications. From a practical point of view, a shipper can use the findings as a guide to actions which will reduce overall product distribution costs. Cost reduction is becoming more important in many industries as the limit is reached on production efficiencies. Controlling costs appears to be the key to maintaining or increasing profit margins in today's competitive environment. A reduction in shipping costs will also make it possible for a firm to expand its market area or to become more competitive in its present market area.

From a theoretical point of view, this study should enrich the understanding of unregulated motor carrier pricing behavior. Specific factors, thought to underlie motor carrier pricing behavior, are examined individually for statistical significance. The finding of this portion of the study alone should make the effort worthwhile. The study's theoretical contribution is constrained somewhat by the limits of the database. The study involves multiple shipment origin points with only a single destination. The findings will be valid for that single destination but it is unclear whether they will be valid for other destinations. The study will, however, be a first step in expanding the scope of postderegulation motor carrier pricing studies. 
Report Organization

This report is made up of seven chapters. Chapter I outlines briefly what will be studied and why. Chapters II, III, and IV examine the literature of the motor carrier industry in detail. Chapter II explores the development of the highway system in the United States, the motor carrier industry structure, and the history of the motor carrier industry. Chapter III reviews the literature in the areas of motor carrier pricing system development. It also examines the impact of regulation on motor carrier pricing behavior and outlines the arguments for and against the use of railroad type pricing in the motor carrier industry. The issue of regulatory cost is examined and the major motor carrier pricing studies are discussed. Chapter IV discusses the impact of deregulation on motor carrier pricing behavior. It also discusses motor carrier rate modeling and government freight shipments. Chapter $\mathrm{V}$ discusses in detail the nine hypotheses to be tested, measurement issues, and the tests to be used. The chapter also describes and discusses the development of the database used in the study. Chapter VI describes the empirical results of the study. Chapter VII, the final chapter, presents the conclusions reached and suggests areas for future research in the area. 
CHAPTER II

MOTOR CARRIER INDUSTRY STRUCTURE

AND HISTORY

The United States Transportation System

Over the last twenty-five years there has been a steady decline in the percentage contribution to Gross National Product (GNP) made by the industrial sector. As the industrial sector becomes less important, the percentage contribution of the freight industry to GNP declined. The percentage of GNP spent on passenger and freight transportation has remained stable at 18 to 20 percent, but a smaller percentage of GNP is spent each year on freight transportation. Although the percentage of the GNP spent on freight transportation declined, the total constant dollars spent on this vital industry more than doubled. This conflict in transportation statistics can be explained by the growth of the GNP. The GNP is three times larger today than it was 25 years ago. Freight transportation payments increased in constant 1969 dollars from \$62 billion to $\$ 141$ billion, while ton-miles increased from 2145 billion to 4100 billion, or from 1000 to 1600 ton-miles per capita. ${ }^{1}$ This 1.A ton-mile is a commonly accepted measure of output for freight transportation. It reflects the weight of a shipment and the distance it is moved. Multiplication of 
equals a 20 ton truckload of goods carried more than 800 miles for every person in the U.S. (Hazard, 1977). By the year 2000 the total ton-miles should reach 6300 billion (Altschiller, 1982).

The reasons for the increase in freight ton-miles per capita are varied. Some of the growth can undoubtedly be attributed to concentrated production and universal demand. When a product is produced in a single location to meet nationwide demand, this leads to an increase in ton-miles per capita. Also, many sellers now offer an extremely wide assortment of merchandise which would lead, in turn, to more transportation ton-miles.

\section{Roadway Development}

Transportation is not only a necessary factor in any organized economy, it is often the limiting factor (Sampson, Farris \& Shrock, 1985). Goods have no value unless they are available when and where they are needed. The United States has developed the most extensive roadway network in the world to meet its transportation needs (Fair \& Williams, $1981) \cdot 2$

The first major federal government roadway development project began in 1806 when Congress authorized a survey of a

the shipment weight in tons by the miles traveled gives the ton-miles involved in moving a particular shipment between two points. Speed of travel is not considered. This common measure of transportation output allows direct comparisons of the production of the various modes of transportation. 2. A way is the medium over which a transportation system travels such as a highway, railway, airway, etc. 
route from Cumberland, Maryland to Vandalia, Illinois. Construction began in 1811 , and by $1839, \$ 3,000,000$ had been spent. There were, however, questions about the constitutionality of the construction funding by the federal government. In 1830 President Jackson had vetoed the Maysville Road Bill because he thought that federal involvement in regional roadway construction was unconstitutional (Luna, 1971).

Centralized roadway development did not re-emerge until the late $1800^{\prime}$ s. Railroads wanted shippers to have easier access to rail terminals and farm groups wanted roadways to open markets (Luna, 1971). The development of the automobile industry made roadway development urgent (Becht, 1970). New Jersey, in 1891, began to repay local governments for one-third of the cost of highway construction and maintenance (Locklin, 1972) . By 1915, 45 states had enacted state aid to roadways statutes, 40 had established highway departments, and 24 had developed plans for highway systems (Sampson \& Farris, 1966). In 1916, Congress passed the Federal Aid Road Act which removed highway development responsibility from local governments and placed it in state hands.

In the early 1920's hard surfaced road miles exceeded the number of railroad miles for the first time (Lowe \& Morydas, 1975). During the next ten years the hard surfaced mileage doubled, then doubled again in the next twenty years. The depression of 1929 stimulated highway 
construction. One study reported that 651,000 miles of roadway and 100,000 bridges were built or improved. In addition, 135,000 miles of roadway drainage projects were completed (Owen, 1964). World War II interrupted highway development, but it became clear that a system of high speed super-highways was needed (Luna, 1971). In 1956, the 42,500 mile National System of Interstate and Defense Highways was authorized, and the funds to start construction were voted in 1962. The Interstate Highway System is now completed, but about half of it needs to be upgraded (Altschiller, 1982). Today the highway system in the U.S. includes about 3.9 million miles of roads, which vary a great deal in quality (Johnson \& Wood, 1986).

\section{The Motor Carrier Industry}

The highway system allows the motor carrier industry to provide transportation to any location in the country where an economic requirement exists. Before World War II the motor carrier industry expanded at a slow but steady rate, but after the war it grew rapidly. In 1939, motor carriers produced 53 billion ton-miles. By 1979, the number of tonmiles produced had increased to 628 billion before falling to 565 billion in the recession year of 1980 (Harper, 1982). By 1984, the number of ton-miles produced had increased to 602 billion (Coyle, Bardi \& Cavinato, 1986). As a percentage of all ton-miles carried by all modes these figures represented 9.7 percent in $1939,24.3$ percent in 
$1979,22.6$ percent in 1980 , and 24.1 percent in 1984 (Transportation Policy Associates, 1985).

\section{Industry Structure and Size}

The motor carrier industry is made up of groups of heterogeneous carriers having different legal, service and commodity characteristics (Coyle, Bardi \& Cavinato, 1986). A single motor carrier can be a member of several subindustries (Coyle \& Bardi, 1984). The legal structure of the motor carrier industry is depicted in Figure 1.

Private carriers are usually involved in the transportation of high value, high rated traffic and commodities that require personalized service (Coyle \& Bardi, 1984). The exact size of the private fleet is unknown, but the number of firms involved in private transportation activities during 1980 was estimated to be about 500,000 (Dun's Review, 1980).

An additional sub-industry is made up of firms involved in intrastate transportation. This sub-industry has two components, intracity and intercity. A for-hire motor carrier transporting a commodity locally or intracity might be regulated or completely unregulated. There is no reliable estimate about the size of this sub-industry.

The for-hire interstate sub-industry consists of two types of carriers. The first transports commodities that are exempt from regulation. In 1980, there were slightly more than 42,000 individual firms engaged in the 
transportation of exempt commodities (Taft, 1980). The privately owned and exempt carriers combined transport about 60 percent of the total motor carrier interstate ton-miles (Coyle \& Bardi, 1984).

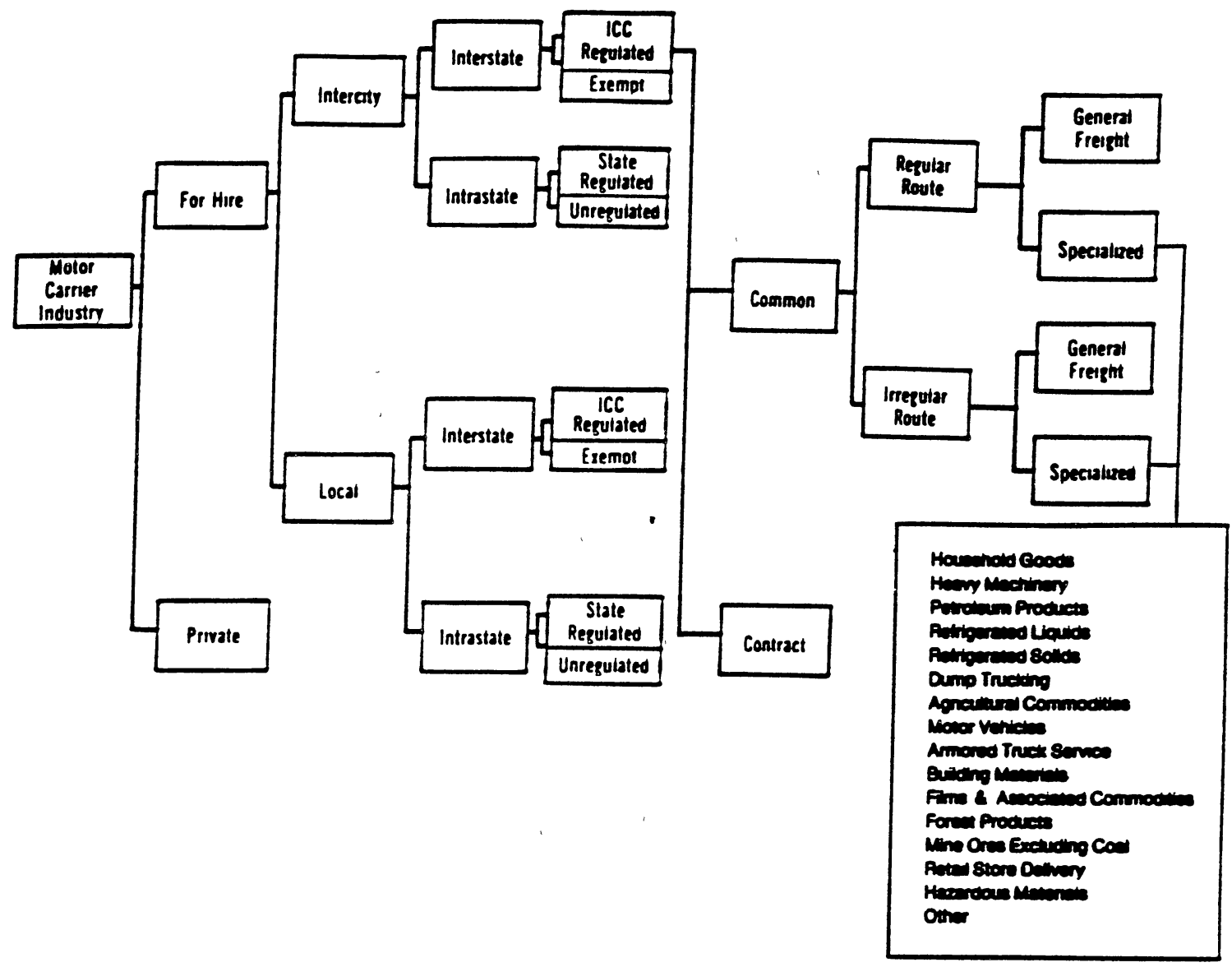

Figure 1. Motor Carrier Industry Legal Structure

Sources: The Economics of the Motor Carrier Industries ( $p$. $9)$ by Garland Chow, 1978, Bloomington, Indiana: Division of Research, School of Business, Indiana University and Transportation USA (p. 301) by Frederick J. Stephenson, Jr., 1987, Reading, Massachusetts: Addison-Wesley Publishing Company.

A second type of for-hire interstate carrier is the regulated contractual or common carrier. Contractual and 
common carriers differ in the extent of their commitment to the shipper (Bowersox, 1978).

The ICC maintains 17 different commodity

classifications for common carriers, with the largest number operating as general freight carriers (Lieb, 1981).

Interstate common carriers must report specific data to regulatory agencies, making them the only sub-industry about which exact statements can be made. In 1945, there were 20,872 interstate common carriers, but by 1974 , there were only 15,100. By 1979, this downward trend in the number of firms had been reversed when the number of interstate motor carrier firms exceeded 17,000 (American Trucking Association, 1979). By 1981, there were about 21,800 firms; and, by 1984 , the number had increased to 30,012 (Coyle \& Bardi, 1984; Johnson \& Wood, 1986). In 1987, the number of interstate common carriers stood at 37,627 (ICC Annual Report, 1987). The large increase in the number of common carriers is attributed to the easing of industry entry restrictions.

In 1980 , slightly more than 89 percent of the interstate common carriers had annual operating revenues of less than one million dollars. Six percent of the firms had annual operating revenues between one and five million dollars while five percent had annual operating revenues of more than five million dollars (Coyle, Bardi \& Cavinato, 1986). The largest common carrier had annual operating revenues approaching one billion dollars (Harper, 1982). 
Not depicted in Figure 1 is the owner-operator subindustry. Owner-operators are difficult to classify because they may lease their vehicles to a private company, haul exempt commodities, or sub-contract with a regulated carrier (Lieb, 1981). There may be as many as 100,000 owneroperators, and they transport between 25 and 40 percent of the total motor carrier intercity ton-miles (Wyckoff \& Maister, 1975).

\section{Motor Carrier Market Competition}

The markets of the motor carrier industry are often situation-specific. Many small carriers might compete vigorously for any available freight. This approaches pure competition. When only a few firms are authorized to transport a commodity, the market becomes semi-monopolistic. This is the case with very specialized carriers such as explosive or nuclear material transporters. A monopolistic situation occurs when a single motor carrier offers service over a route. With regard to shipment size, an oligopolistic situation exists in the small shipment area. Only a few large firms can afford the necessary investment in terminal facilities required to compete in this market. The motor carrier industry transports most of the small intercity shipments (Harper, 1982). Small shipments are important to the common carriers in that they generate more than 60 percent of the revenues and account for more than 45 percent of the tonnage (Bowersox, 1978). Sixty six percent 
of the small shipments weigh under 500 pounds and 99 percent weigh under 10,000 pounds (Johnson \& Wood, 1986). One study found that the average shipment size was 1600 pounds (Wyckoff, 1974). The motor carriers have captured most of the shipments made between firms involved in the distributive trades such as wholesaling and retailing. These shipments are usually made over shorter distances where intermodal competition is lacking (Bowersox, 1978).

\section{Motor Carrier Revenues}

Motor carriers clearly dominate the shipment of certain product groups. It is not possible to say specifically, however, how much each product group contributes to total motor carrier revenues. Only four to five percent of the firms must report revenue data to a central agency. Motor carriers are thought to receive about 73 percent of the total transportation dollars spent, although they handle less than 25 percent of the intercity freight tonnage (Coyle \& Bardi, 1984; Transportation Association of America, 1981). Average absolute revenues per ton-mile increased incrementally from 4.1 cents in 1945 to 8.5 cents in 1970 (Transportation Association of America, 1980) . This upward trend continued, with the 1980 figure reported as 18 cents per ton-mile (Transportation Association of America, 1981). One large motor carrier was reported to have an average revenue per ton-mile of 22.7 cents in 1985 (Johnson \& Wood, 1986). When the figures are adjusted for inflation, 
however, there has been very little change in ton-mile revenues.

\section{Motor Carrier Historical Development}

The history of the motor carrier industry can be divided into three periods. The first period spans the years from the turn of the century until the passage of the Motor Carrier Act of 1935. This Act placed for-hire motor carriers engaged in interstate and international transportation of freight and passengers under the jurisdiction of the ICC. The second motor carrier industry historical period covers the years between 1935 and 1980 . The Motor Carrier Act of 1980 marked the end of the second period of motor carrier history and the beginning of the third or current period.

To understand motor carrier behavior generally, and more specifically, motor carrier pricing behavior, it is necessary to examine the history of the industry. Before the passage of the Motor Carrier Act of 1935, the motor carrier industry suffered through a period of intense competition and often practiced survival pricing. This was brought on by the depression of 1929 which began about 10 years after the industry entered the growth phase of its lifecycle. Before this intensely competitive industry could adjust to the depressed economic environment, it was regulated by the federal government. Pricing, under regulation, was controlled by a centralized agency and not 
by the motor carriers themselves. Today, the responsibility for pricing has been returned to the motor carriers. How they react to this new pricing freedom will have a significant impact on all segments of the economy of the United States.

Motor Carrier Industry 1900-1935

The number of motor vehicles involved in freight transportation before 1900 was insignificant. Trucks appeared in 1896 and by 1898 , several manufacturers had "motor delivery wagons" for sale" (Karolevitz, 1966, p.39). By 1911, there were about 25,000, trucks in operation, but by 1920, the number had increased to 1.1 million. In 1925, more than 2.5 million trucks were in operation and 155,000 of them were involved in for-hire transportation (Wood \& Johnson, 1989). By 1930, there were 3.5 million trucks in operation in this country (Mertins, 1972). The demand for motor carrier services grew rapidly and the for-hire carriers became intercity as well as intracity carriers (Harper, 1982).

Many motor carriers were unable to provide the service expected by the public. They could not serve everyone and bankruptcy occurred frequently. The motor carriers charged rates that were often unreasonable, not because they were too high, but rather, because they were too low to allow the carriers to make a fair profit (Harper, 1982). The individual states tried to regulate the motor carrier 
industry, but major problems arose because state standards were not uniform (Lieb, 1981; Harper, 1982; Sampson, Farris \& Shrock, 1985). By 1925, 37 states had established some form of economic regulatory controls and several other states claimed the right to do so (Harper, 1959). By 1932, 39 states had regulated for-hire motor common carriers operating within the states (Moore, 1972). By 1933, this number had increased to 42 states and contract carriers were subject to economic regulation in 31 states (Harper, 1982). Initially the states tried to regulate all motor carriers as common carriers (Lieb, 1981). In 1923 Michigan enacted legislation that held that any person or company engaged in the for-hire transportation was a common carrier and could be regulated as such. Common carriers were expected to meet very specific service standards because the service they provided was considered to be a public necessity. Some carriers, however, were conducting operations under contracts. The Supreme Court declared this statute to be unconstitutional and ruled that a state could not transform a contract carrier into a common carrier simply by passing a law. ${ }^{3}$ Similar statutes in California 4 and Florida ${ }^{5}$ were also held to be unconstitutional. This problem was solved when the Court upheld a Texas law which treated common and contract carriers separately. 6 This 3.Michigan Public Utilities Commission v. Duke, 266 U.S. 570 (1923).

4.Frost v. Railroad Commission of California, 217 U.S. 507 (1926).

5. Smith V. Cahoon, Sheriff, 283 U.S. 553 (1931).

6. Stephenson V. Binford, 287 U.S. 251 (1932). 
decision established a precedent which allowed regulatory agencies to divide the motor carriers into several different classes, each with its own set of rules (Harper, 1982).

The states assumed that without federal legislation, they could regulate interstate as well as intrastate carriers. In 1925, however, the Supreme Court upheld the doctrine of federal supremacy in all areas of interstate transportation. ${ }^{7}$ In Washington ${ }^{8}$ and Maryland ${ }^{9}$ cases the Court held it unconstitutional for the states to require motor carriers to secure a state's operating authority before starting interstate operations (Harper, 1982).

During the late $1920^{\prime} \mathrm{s}$, political pressure to impose federal regulation on the motor carrier industry increased. The industry was overcrowded, which led to extreme intramodal and intermodal competition (Hudson \& Constantin, 1958). The demands for regulatory action came from the railroads, the motor carrier industry itself, some shippers, the states, and various government agencies (Harper, 1982). Much of the higher rated traffic was being taken from railroads by unregulated motor carriers. This "cream skimming" left the railroads with low valued commodities, able to support only a modest transportation rate. This threatened the railroad pricing structure which was based on charging high rates for high valued products (Owen \& Braeutigan, 1978). Therefore, the railroads demanded that 7.Wabash, St. Louis and Pacific Railroad v. Illinois, 118 U.S. $557(1886)$. 8. Buck V. Kuykendall, 267 U.S. 307 (1925). 9. Bush V. Maloy, 267 U.S. 317 (1925). 
their major competition be regulated (Sampson, Farris \& Shrock, 1985). The railroads also wanted motor carrier regulation to protect what remained of their declining market share (Mentzer \& Gomes, 1986). Railroad revenue had been severely reduced by economic conditions. The growing, highly competitive motor carrier industry was seen as a major threat (New York Times, 1934). The railroads argued that their taxes were being used to build highways which effectively subsidized their competition (Harper, 1982).

The existing motor carriers argued regulation was necessary to protect them from the less firmly established newcomers (Mentzer \& Gomes, 1986). They hoped federal regulation would bar new entrants, help them fix rates, and allow them to divide the market among themselves (Wright, 1983). The most important motor carrier lobbying group, the American Trucking Associations, switched from a strong antiregulatory orientation to one that strongly supported regulation.

Shippers pointed out that unregulated motor carriers often operated with sub-standard equipment and failed to pay damage claims. They also ignored contracts and other agreements, did not maintain schedules, stopped service without notification, and otherwise did not fulfill the duties required of for-hire common carriers (Harper, 1982).

The states, who supported regulation, were often motivated by the desire to protect railroads who were large taxpayers (Harper, 1982). In 1925 the National Association 
of Railroad and Public Utility Commissioners called for federal regulation of motor carriers. They were joined by the ICC in 1928 and by the Federal Coordinator of Transportation in 1934 (Sampson, Farris \& Shrock, 1985).

The public was indifferent about motor carrier regulation (Harper, 1981). The agricultural sector, however, did not want motor carrier regulation. Agricultural organizations and individual farmers used their political influence to insure that carriers of agricultural products were excluded from the provisions of any regulatory legislation (Sampson, Farris \& Shrock, 1985; Lieb, 1981). During the early 1930's it became obvious that something had to be done in the area of motor carrier regulation. Many railroads were bankrupt while many others were on the brink of failure. The gross operating revenues of the industry fell drastically. The railroad workforce was reduced by a third, and their return on investment declined steadily (Phillips, 1969). Cost cutting measures and freight rate increases did not improve the profitability of the railroads, and by 1933, 75 of the largest were in the hands of receivers (Harper, 1982). After ten years of trying, Congress passed the Motor Carrier Act of 1935. It was the thirty-seventh bill that had been introduced to impose federal economic regulation on the motor carrier industry in the previous ten years (Lieb, 1981). 
Motor Carrier Industry $1935-1980$

The Motor Carrier Act of 1935 extended the monopoly type of railroad regulation to the motor carrier industry (Sampson, Farris \& Shrock, 1985). The aim of railroad regulation was the prevention of monopoly abuses. The aim of motor carrier regulation was to control pervasive, intensive competition (Farmer, 1964). Competition has always been looked upon as a superior market regulator, but in the motor carrier industry in 1935, competition was not working well. Pro-regulatory advocates argued that competition was causing poor, unreliable services, contributing to unstable financial conditions, and causing duplication of effort (Sampson, Farris \& Shrock, 1985). Industry entry and exit had been easy and in the 1930's excessive capacity and survival price competition was common. Competition often resulted in below cost rates and the diversion of traffic from the distressed railroads. It was hoped that regulation would bring order to a troubled industry.

The Motor Carrier Act of 1935 contained a "grandfather" clause to protect the operating rights of existing common and contract carriers (Harper, 1982; Wood \& Johnson, 1989). Motor carriers eventually granted operating rights under the grandfather clause numbered slightly more than 20,000 (Snow, 1977). The certificates and permits issued to the grandfathered carriers at no cost became valuable commodities (Sampson, Farris \& Shrock, 1985). A certificate 
gave a firm the right to provide service over a specified route. The ICC was frequently accused of being too protective of existing carriers' operating rights at certificate and permit hearings. About 80 percent of the applications for extended operating rights for existing carriers were approved while less than 10 percent of the applications of new carriers were considered favorably (Lieb, 1985).

The Act made the regulated motor carriers subject to the same rate tests used in the rail industry. Rates had to be fair and reasonable and they could not offer unjust preference to any person, place or commodity. Rates had to be published and any deviations could not occur without opponents being given the opportunity to challenge them.

The Act required contract carriers to publish and file their minimum rates, but not their actual rates. If the ICC decided that a minimum rate was too low, it was empowered to prescribe the minimum rate, but it could not set the actual rate (Lieb, 1981). Competition from other contract and common carriers was relied on to provide control of the maximum contract rates. To assure that the common carrier restraint on contract rates remained intact the ICC did not allow dual operations until the late 1970's (Lieb, 1981). It was 1957 before contract carriers had to file and publish the actual rates charged for their service (Sampson, Farris \& Shrock, 1985). The number of contracts that any one 
contract carrier could have in force at one time was limited to eight (Wood \& Johnson, 1989).

The Act also dealt with the operating of private motor carriers. It included provisions to prevent the private carriers from expanding into for-hire operations (Lieb, 1981). Private motor carriage was viewed as a specialized operation designed to meet the needs of the division of a company that controlled it. That division was not allowed to transport goods owned by another division of the same parent company on a for-hire basis (Coyle, Bardi \& Cavinato, 1986). This provision of the Act was upheld by the courts when they ruled that a subsidiary used by a parent company for transportation services was not engaged in private motor carriage. 10 These restrictions often resulted in gross inefficiencies because many companies had freight moving in only one direction. 11

Private carriers with surplus capacity were allowed to lease equipment and drivers to common carriers, but the lease had to be for at least 30 days. This prevented the use of single trip leasing as a tool to reduce the number of empty backhaul miles (Show, 1977). It was estimated that as much as 40 percent of the private motor carrier miles involved the movement of empty trailers (Coyle, Bardi \&

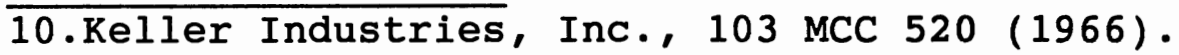
11. Empty backhauls have always been a problem for private motor carriers. In 1978 the ICC decided to allow private motor carrier to seek and obtain for-hire common carrier authority on the backhaul route (Toto Purchasing and Supply Company, Inc., 128 MCC873, March 24, 1978). In 1982 the private carriers were allowed to trip lease on a single trip basis to authorized common carriers. 
Cavinato, 1986). This figure was confirmed by a survey which found that 33.2 percent of all of the non-specialized, privately owned motor carriers were traveling empty (Federal Highway Administration, 1972).

A final segment of the industry recognized by the Act was the carriers exempt from economic regulation. Free entry into this segment was allowed and the rates charged depended on demand. Exempted vehicles were primarily used to move farm production to markets and supplies from the markets to farms (Lieb, 1981). The exemption given to agricultural commodities was eventually extended to marine and horticulture products and newspapers (Sampson, Farris \& Shrock, 1985). A common, private or contract carrier could become an exempt carrier if it was transporting an exempt product.

A second group of exempt carriers was defined by geography. Motor vehicles operated wholly within a city, between contiguous cities, or within a zone adjacent to and commercially contiguous to a city were exempt (Sampson, Farris \& Shrock, 1985). This provision of the Act recognized that most of these vehicles were operating as intrastate carriers, and state regulatory procedures were quite highly developed. The exemption of a large portion of the industry from regulation recognized that the industry was extremely complex. It was unlikely that one agency could regulate the entire industry efficiently. 
Under regulation, motor carriers knew what services they had to provide at what rates. The shippers knew what services were available at what costs. Rapid changes in rates and services were not possible due to the regulatory process. Among negative aspects of regulation was the expense involved. Shippers and carriers suffered the expense of keeping abreast of regulatory change. Decision making was slow, and even if a change were approved, the carrier relinquished income during the regulatory delay. Regulation led to operating inefficiencies, excessive energy consumption, and made it difficult for motor carriers to react to changes in the environment.

Between 1935 and 1958 the number of regulated motor carriers decreased steadily (Sampson, Farris \& Shrock, 1985). Most operating rights were controlled by carriers that had been grandfathered. The easiest way for them to expand was through merger. As existing certificates were combined, restrictions were placed on the surviving carrier. The motor carrier buying operating rights or acquiring them through merger gained the right to operate over certain desirable routes; however, the firm was also compelled to operate over some highly undesirable ones. Firms often found they could carry freight in only one direction and serve certain terminal points, but not intermediate points. They could only serve certain cities by following circuitous routes and could transport some goods, but not others. Some specialized carriers could not legally transport specialized 
freight on the backhaul, even if such freight were readily available (ICC, 1965).

The railroads, who had strongly supported the regulation of the motor carriers, were not satisfied with the results. They were concerned about the continued improvement of the highways which enhanced the motor carriers' ability to compete. The railroads argued that motor carriers were not required to pay fees in proportion to the benefits received. The agricultural exemption also caused much difficulty. Judicial interpretation led to a growing list of exempt commodities and by 1980 the number was more than 100 (Lieb, 1981; Lieb, 1985). Another question that proved difficult, to answer was when a motor carrier was involved in for-hire and private motor carrier operations (Sampson, Farris \& Shrock, 1985). Motor carriers would "buy" goods at their source, transport them to their destination, and "sell" them to the user for the purchase price plus transportation fees. The motor carriers contended they were transporting goods that they owned; therefore, they were exempt from regulation.

Many critics felt that the continued regulation of the motor carrier industry was a mistake. In 1961 and 1962 seven major studies of the transportation system and regulation were published (Sampson \& Farris, 1975). These studies supported the proposition that greater reliance should be placed on market forces (Lieb, 1985). In 1962 President Kennedy criticized the regulatory structure as 
being inconsistent and outdated. President Johnson contended that the nation's transportation system lacked coordination and this resulted in many system inefficiencies. He proposed that a Department of Transportation (DOT) be created to coordinate existing federal programs. The DOT, from its start, was a strong advocate of regulatory reform. The DOT's position on transportation regulation was contained in the following statement:
Carriers, shippers and passengers face a web of restrictive government regulations which stifle competition, discourage innovation, and foster inefficiency. The present regulatory structure is in many respects, outdated, inequitable, inefficient, uneconomical, and frequently irrational. It often misplaces incentive and disincentive, distorts competitive advantage, protects inefficient carriers from efficient competition, over restricts market entry, artificially inflates rates and misallocates our Nation's resources. The inflexibility of these outmoded regulations impedes the development of lower cost, more efficient national transportation (U.S. Department of Transportation, 1975).
In 1971, the DOT began to submit annually legislation to deregulate the motor carriers (Lieb, 1981). Agencies joining the DOT in its call for regulatory reform were the Department of Justice, the Federal Trade Commission, and the President's Council of Economic Advisers (Lieb, 1985). Consumer groups, who felt that motor carrier regulation was more for the protection of carriers than for the benefit of the public, joined the campaign (Snow, 1977). Academicians contending that the regulation of a competitive industry led 
to the misallocation of resources, supported regulatory reform (Sampson, Farris \& Shrock, 1985; Keyes, 1980).

One study of misallocation in the motor carrier industry estimated that the societal cost was $\$ 5$ billion per year (Moore, 1972). Moore's findings were supported by two earlier studies, one involving railroads and the other airlines. These studies found that the social costs of regulation were underestimated and concluded that it was unlikely that the benefits of regulation exceeded its cost (Friedlaender, 1969; Jordan, 1970).

The public was also becoming interested in conditions in the motor carrier industry. They were concerned about inflation in the 1970's and were angered when Teamsters Union members got large wage and benefit increases. Motor carriers simply raised rates to cover these new wage agreements (Johnson \& Wood, 1989). The fuel crisis of the early 1970's also increased public interest in regulation. As motorists waited in lines for gasoline they read about airlines and motor carriers operating empty because of regulatory restrictions.

The public was upset with regulation, but the shippers were not (Lieb, 1981). Research showed that the shippers were basically satisfied with existing services and rates (Jones, 1979). The motor carriers and the Teamsters were very much against deregulation. They argued that changes would promote market instability, undermine the financial position of existing carriers, promote predatory pricing, 
and reduce service quality. In addition, they argued that deregulation would reduce, or in some cases end, service to small communities, decrease fuel efficiency, and increase highway safety problems (American Trucking Associations, $1979)$.

The ICC acknowledged the criticism of regulation but did not respond, preferring that the legislative or executive branch act (Lieb, 1985). President Ford began to support deregulation in all areas including transportation; and, when President Carter also endorsed regulatory reform, the ICC acted (Harper, 1981). It released an internal report that contained 39 recommendations for regulatory change (ICC 91st Annual Report, 1977). President Carter responded by refusing to appoint commissioners to fill ICC vacancies unless the candidates were pledged to support deregulation (Sampson, Farris \& Shrock, 1985). The size of the ICC shrank from eleven to seven active members, and the deregulation forces became more powerful.

From 1977 to 1979 , the ICC took many actions that affected motor carrier regulation. Perhaps the most significant action it took was to relax industry entry requirements (Lieb, 1985). Under this new entry policy, there was a large increase in the number of carriers applying for certificates and permits. The high approval rate of the applications reversed the years long downward trend in the number of regulated motor carriers. In 1979 
the approval rate of new carrier applications reached 98 percent (Sampson, Farris \& Shrock, 1985).

The ICC also increased the number of customers a contract carrier could serve and allowed private carriers to enter the for-hire transportation market under certain circumstances. The ICC allowed regulated carriers to operate as both contract and common carriers, and removed route restrictions that forced some carriers to follow circuitous routes. In May, 1979 a second ICC internal report was released. It concluded that regulation should be limited to protecting the public from harm (Lieb, 1985). It recommended that rate and entry control be abolished for 12 specialized segments of the motor carrier industry, including those that hauled lumber, building metal, and household goods (ICC, 1979).

The ICC's administrative changes of long standing regulatory policies did not go unnoticed; it was called before various congressional committees to justify the actions taken. The matter came to a head when senator Cannon and Representative Johnson wrote to the ICC. They formally requested that the Commission cease setting national transportation policy through administrative actions until Congress acted on pending deregulation proposals (Wall street Journal, Oct.23, 1979). In June, 1979, President Carter submitted to Congress his proposal to 
deregulate the motor carrier industry. After extensive hearings the Motor Carrier Act of 1980 was approved. 12

Motor Carrier Industry 1980-Present

The 1980 Motor Carrier Act is a long and complex statute. Some people wondered if its passage was necessary because the industry was being deregulated administratively (Pustay, 1985). The Act amended the Declaration of National Transportation Policy to include a section related to the motor carriers only (Sampson, Farris \& Shrock, 1985). A goal of the new national transportation policy was to promote a competitive, efficient motor carrier industry. ${ }^{13}$

The Act liberalized industry entry standards and ended many operating restrictions imposed by regulation. Specifically, the ICC was directed to remove all gateway and circuitous route limitations, to broaden groups of commodities a carrier could transport, to authorize service to intermediate points on existing routes, and to authorize round trip authority where only one way authority existed. The ICC was also directed to drop any other restrictions that were wasteful of fuel, inefficient, or contrary to the public's interest (Sampson; Farris \& Shrock, 1985).

The Motor Carrier Act of 1980 also paid extensive attention to the ratemaking process. For the first two years after the Act's passage, carriers could raise or lower rates ten percent per year over or under the previous year's 12.Motor Carrier Act, Public Law 96-296 (1980). 13.Title 49 U.S. Code, Sec.4 Section $1010(a)$. 
rates. After two years, the upper rate limit could increase or decrease by the percentage change in the Producer Price Index, compiled during the proceeding 12 months. There was no restriction on minimum rates (Lieb, 1985). The Act directed the ICC to authorize rates which were adequate to permit a well-managed carrier to cover operating costs and to earn a fair rate of return. The Act also reduced the power of the rate bureaus (Wood \& Johnson, 1989).

Under the provisions of the Act, motor carriers with dual authority were allowed to transport mixed loads, and private motor carriers could engage in compensated intercorporate hauling. The number of exempt commodities was expanded and the transportation of regulated and exempt commodities was allowed in the same vehicle. The Act acknowledged the legitimacy of many of the ICC's previous administrative actions and allowed for greater reliance on market forces.

\section{Effects of Deregulation}

The ICC was directed to hold annual hearings to determine whether the law was working as intended. These hearings have produced conflicting testimony. Some say that deregulation is working very well. Others say that deregulation has been a disaster (Davis, 1987).

Since deregulation, there have been major changes in the structure of the industry, the rates charged, and the services offered. One startling development has been the 
increase in the number of for-hire motor carriers. In the first year alone 2452 new for-hire carriers received certificates or permits (Sampson, Farris \& Shrock, 1985).

Deregulation has not been accomplished without trauma. Between 1980 and 1983, 305 intercity, for-hire motor carriers failed. These firms represented $\$ 3.2$ billion in sales and employed 64,000 workers (Traffic World, Dec.26, 1983). In 1984 alone the number of failures was 550 (Traffic Management, Aug.,1985). In 1985 another 714 carriers failed (Traffic World, Mar.17, 1986). Not all the firms which failed were small, new entrants into the industry. In December, 1985 one of the largest carriers in the western United States, System 99, failed (Traffic Management, Dec.,1985). It was quickly followed by the collapse of McLean Trucking Company which had annual sales of $\$ 550$ million (Monroe, 1986). The American Trucking Associations estimated that, in late 1985, 20 percent of the interstate, for-hire general freight motor carriers, representing about $\$ 3.1$ bilition in sales, were being threatened with failure (Wood \& Johnson, 1989).

The number of firms in the motor carrier industry has increased, but many of the new motor industry members were small firms seeking specialized niches in the contract truckload market. The number of LTL carriers remained stable, but their environment became more competitive as they expanded their service areas (Wood \& Johnson, 1989). Overnight Transportation, one of the few large non-union LTL 
carriers, had restricted their service area to the southeastern states. Now its service area includes the surrounding states plus California, Utah and Colorado. Yellow Freight, the largest of the LTL carriers, opened 135 new terminals during the 1983-1984 period (Johnson \& Wood, $1986)$

From 1980 to 1984 , the three largest LTL carriers expanded their share of revenues from 13.5 to 22.5 percent. By 1986 , the ten largest LTL carriers had captured about 60 percent of the total LTL revenues (Enis \& Morash, 1987). Many motor carrier industry analysts feel that five to ten large motor carriers will eventually dominate the LTL portion of the industry (Schneider, 1985; Morehouse, 1983; Walters, 1987).

Motor carrier industry changes have not been limited to the contract TL and general freight LTL common carriers. Before deregulation the ICC had limited the number of explosives carriers to four, but they granted 17 additional nationwide operating authorities after 1980 (Wood \& Johnson, 1989). Private carriers also experienced significant changes in their operations. In 1981, 719 corporations with more than 7,700 subsidiaries told the ICC that they intended to engage in compensated intercorporate freight transportation (Sampson, Farris \& Shrock, 1985).

One of the major concerns of Congress was the impact of deregulation on service to small shippers and rural communities. Many argued there would be a decline in the 
quality and availability of service to these shippers (American Trucking Associations, 1979). Congress directed the ICC to conduct a study of service to small communities and to report no later than september 1, 1982 (Lieb, 1985). Most of the more than 1,500 small community shippers surveyed reported that service levels had increased (Taylor, 1982). An independent study found that nationwide, small community service levels were the same or higher (Beilock \& Freeman, 1984). A study of small community shippers in Minnesota also found that service levels had increased (Harper, 1982). The issue of motor carrier service to small shippers was also studied and the findings were similar to those for small communities (Wood \& Johnson, 1989; Harper, 1982; Williamson, Singer \& Peterson, 1983).

The Motor Carrier Act of 1980 also had a major impact on the industry's rate structure. The rates charged to perform a transportation service today are significantly different from those rates charged to perform the same service before July 1, 1980. To understand fully what has happened to motor carrier rates, the prederegulation motor carrier rate structure must be examined. This will be accomplished in the following chapter. 
CHAPTER III

MOTOR CARRIER INDUSTTRY PRICING, REGULATION, AND RATE RESEARCH

Regulated Motor Carrier Pricing

Transportation rates are prices charged for transportation services; price is the mechanism by which products and services in limited supply are rationed among buyers (Harper, 1966). All major pricing systems are complex, but none is more complex than the pricing of transportation. The number of variables involved becomes overwhelming when an individual item pricing approach is taken. Supply and demand, regulation, legal obligations, competition, system capacity, and historical precedents are a few of the general factors that must be considered in transportation pricing. More specific factors are the type of carrier, the route over which the service is performed, and the item transported (Harper, 1981; Lieb, 1985). Transportation is also a service, and Lovelock (1984) feels that services, due to their intangible nature, are more difficult to price than products.

In the past motor carrier pricing has been controlled by the carriers (1900-1935) and by the government (19351989). Now an era is at hand (1980-present) in which the 
price will again be controlled by the carriers themselves. An examination of the factors that entered into pre-1980 pricing will provide the background and insight necessary to understand today's free-market motor carrier pricing. It is essential to determine how motor carrier prices are now set in order to understand fully the impact of deregulation on our economy.

\section{Transportation Pricing Problems}

There are more than 2 million different commodities in commerce in the United States. Every one of them is subject to transportation between any two of the 50,000 cities and towns which are normally origins and destinations for freight shipments (Sampson, Farris \& Shrock, 1985; Harper, 1982). Transportation pricing is made more complex by the existence of multiple routes. There are more than 4.7 million possible rail routes between just one origindestination pair, Dallas, Texas and Detroit, Michigan (Sampson, Farris \& Shrock, 1985). A single motor carrier serving all origins and destinations and transporting all commodities over all routes might have to compute and publish more than 40 trillion individual rates (Morse, $1980)$

The pricing policy of the transportation industries cannot be one which calls for the setting of individual product rates. Pricing has been simplified by establishing a few classes and grouping all commodities into these 
classes (Locklin, 1972). The railroads used this

classification concept in their pricing and also took steps to reduce the number of origin and destination points. The country was divided into sectors, and the most important shipping point within each sector served as the rate basis point for other points in the sector (Coyle \& Bardi, 1984). Some writers contend that this rate basis point system led to discrimination and placed some firms at a competitive disadvantage (Snow, 1977; Corsi \& Roberts, 1982).

When the motor carrier industry was regulated, the carriers had to file their rates with the ICC. Rather than developing their own freight classification and rate basis point system they chose to adopt, with some changes, the system used by the rail carriers (Lieb, 1981). A National Motor Freight Classification Board was organized to assure standardized product descriptions, class assignments, and uniformity in packaging requirements. Actual rates were set either by ten regional motor carrier rate bureaus or by individual carriers.

\section{Freight Classification Factors and Freight Classes}

Not all products move under class rates, but all products are assigned to a class. The class rating is often used to determine other rates. Before 1983, the ICC allowed 15 factors to be considered in assigning a product to a class. One author divided the 15 factors into two groups: the first, based on cost and, the second, on demand (Harper, 
1981). The cost factors were divided into two subgroups, those associated with the commodity and those associated with the route. Commodity cost factors were loading characteristics, susceptibility to loss and damage, the volume of traffic moved, regularity of the movement, and whether any, special equipment was required. Route cost factors included distance, operating conditions and traffic density.

Demand factors were divided into the same two subgroupings. Under commodity demand factors the value of the commodity, the economic conditions in the shipper's industry, and the rates charged to transport competing commodities were listed. Under route demand factors, competition with other carriers, production point competition, market competition and traffic density were identified.

In 1983, the factors which classification agencies could consider were limited to four (Sampson, Farris \& Shrock, 1985; Wood \& Johnson, 1989). These factors were density of the product or weight per cubic foot; stowability of the product which considers unusual lengths, widths, and shapes; ease or difficulty in handling the product; and the potential liability of the carrier for handling the product caused by theft, perishability, or damage to other goods. Cost to the carrier was the underlying concern in these factors. 
A distinction was made between freight tendered in TL and LTL quantities. A shipment in LTL quantities might be a class 100 shipment while a shipment of the same product in TL quantities might be a class 85 shipment. The difference in the class number assigned was justified on the basis of lower shipping cost per unit for the larger TL quantities. If this volume discount had been consistently applied, it would be possible to defend the policy. However, two different products, assigned to the same class, often had different volume discounts. There were also inconsistencies in how much weight it took to make a truckload. One shipment of 20,000 pounds might qualify for a TL rating while a second shipment of the same class (which could be expected to be assigned a similar TL weight) might have to be tendered in a quantity of 30,000 pounds or more. The extent of these TL weight inconsistencies is wide spread. Within each of the 23 recognized LTL classifications there are about 10 different TL weight breaks. 1

Deviations from class rates are common in current motor carrier pricing. The two major deviations from class rates are the exception and commodity rates. An exception rate is a modified class rate (Wood \& Johnson, 1989). The class rate formula is used to calculate the freight charge, but an exception to the calculated charge is granted. Exception rates were established to recognize the differences in 
competitive conditions between modes or individual carriers and unusual local or regional operating conditions.

A commodity rate applies only to the movement of a single commodity or group of related commodities between two specific points over well defined routes. This type of rate is usually established for commodities moved regularly in large quantities (Coyle \& Bardi, 1984). Goods moving under commodity rates are described as those in which the transportation charges represent a significant portion of the selling price (Corsi \& Roberts, 1982).

Rate basis and classification systems were developed to simplify the ratemaking process. Exception and commodity rates, however, made the ratemaking process more complicated. Inconsistencies in the application of the classification system were criticized. Snow (1976) argued that motor carriers charged rates that were too high, the rating system was too rigid and too complex, and rates were often irrational and discriminatory. Corsi and Roberts (1982) felt that the classification system and the rate structure were flawed and their misapplication led to widespread abuses.

\section{Railroad Industry Pricing}

To understand motor carrier pricing an understanding of railroad pricing is necessary. This relationship exists because motor carrier pricing was derived directly from the railroad pricing model. The railroads took a coordinated 
approach to pricing, forming rate bureaus which set

territorial rates for freight classes. Railroad pricing had always been based on the value of the service to the shipper (Fruin, 1981). They brought this pricing approach with them when they were placed under the control of the ICC.

Initially the ICC had to depend on the industry it was regulating for pricing guidance. The regulation of an entire industry by a quasi-judicial commission was an undertaking with which the nation had no experience. This represented a retreat from the laissez faire approach to capitalism. The newly formed ICC had to proceed in a slow and systematic fashion, laying the basis for regulation and pricing as it progressed (Sampson, Farris \& Shrock, 1985).

The 1887 Act to Regulate Commerce was aimed mainly at the prevention of monopoly abuses and the control of discrimination (Sampson, Farris \& Shrock, 1985). The first six sections of the Act addressed these issues in broad general terms. The Act lacked detail as to exactly what it was that Congress was trying to regulate. It also lacked details on how the ICC was to go about accomplishing this task. Section 1 addressed the issue of rates. This section required all rates charged by the railroads to be "just and reasonable." Rates that were found to be "unjust and unreasonable" were to be considered to be unlawful. Congress did not tell the ICC what was meant by the words "just and reasonable." Congress also did not tell the ICC 
how it was to go about determining "justness and reasonableness."

Sections 2, 3, and 4 of the Act dealt with the subject of discrimination, again in broad terms. Discrimination in the railroad industry often took the form of some type of rate discrimination. Section 5 made it illegal for railroads to pool freight and share revenues. Section 6 required that the railroads publish their rates in a timely manner and make them available to the public. This section also stipulated that rates could not be changed without prior public notice.

Adoption of Railroad Pricing by Motor Carriers

Before 1935, rates in the motor carrier industry were set under conditions approaching pure competition. Under regulation market pricing forces were replaced by a quasigovernmental agency. The regulation of competition was something new and the regulators looked to the railroads for pricing guidance. For this reason motor carrier and railroad rates were often the same (Lieb, 1985). The motor carriers also adopted the railroad's use of the rate bureau as a centralized method of rate determination. By adopting the railroad's freight classification and rate basis point schemes along with many of the railroad's rates, the regulated motor carriers adopted, indirectly, value-ofservice pricing. 
Value-of-Service Pricing

Value-of-service pricing, also called differential pricing, demand pricing, or charging what the traffic will bear, is the practice of setting rates according to the value of the service to the shipper (Friedlaender, 1969). Value-of-service pricing is based on third-degree price discrimination (Corsi \& Roberts, 1982; Davis \& Combs, 1975). This practice entails charging transportation rates for expensive or high value goods which greatly exceed the cost of providing the service while charging rates for inexpensive or low value goods which equals or only slightly exceeds the costs of providing the service.

Before a firm can sucessfully practice third-degree price discrimination or value-of-service pricing three factors must be present. First, the firm attempting to practice this type of pricing must be able to exercise some degree of monopoly power. Second, the firm attempting to practice value-of-service pricing must be able to identify the varying elasticities of demand for the products being shipped. Some buyers will not continue to purchase a product if the transportation rate goes up a very slight amount. Their demand for the product in question would be price elastic. Other buyers would continue to buy a product even if the transportation rate doubled. Their demand for the product would be inelastic. Third, the various submarkets for the product must be segregated in some manner to 
prevent the reselling of the product between the submarkets .

There was no question that the unregulated rail carriers met all of the criteria necessary to practice value-of-service pricing. The railroads were monopolies in areas where there was no competition from other railroads or other modes of transportation. While they were not able to examine all of the varying product elasticities of demand, they assumed that the demand for expensive products was inelastic while the demand for inexpensive products was elastic. The rail carriers were able to segregate the various markets to prevent reselling through the use of a comprehensive classification system for freight. The newly regulated motor carriers failed, however, to meet the first of the three conditions necessary to practice value-ofservice pricing.

The Act to Regulate Commerce prohibited rate or service discrimination between persons, organizations, places or types of traffic (Sampson, Farris \& Shrock, 1985). The Act did not, however, make it illegal to discriminate between products, and product discrimination is the key to value-ofservice pricing. Price differentiation is not evidence of discrimination if the price is based on costs; however, when different rates exist and they cannot be justified by costs, discrimination exists.

There is considerable evidence that freight rates are positively related to the value of the commodity transported 
(McMullen \& Schary, 1986; Olsen, 1972). However, it is obvious that the market value of the product alone does not determine completely the transportation rate charged to move a particular product. Discrimination can frequently be practiced even when a product has a relative low market value. The lack of competition on one transportation lane might allow a transportation company to practice value-ofservice pricing while it is unable to do so with the same product on a second transportation lane because of competition. Competition is the lack of transportation supplier control over price and this lack of control is reflected in the price elasticity of demand for freight service faced by particular transportation firms. DeVany and Saving (1977) speculated that carriers charge higher rates for higher value products because higher valued products cost more to transport. Price differences between products in this situation would not be discrimination, but simply a reflection of cost.

If higher rates were offset by higher costs, one could expect profits of the motor carrier to remain the same. It was discovered, however, that carriage of higher valued commodities was positively associated with increases in average profits (McMullen \& Schary, 1986). If the rate for a product was higher than the rate for a similar product, and costs did not account for this difference, it would be plausible to assume that the value of the service to the shipper was greater. If the value of the service was high, 
the shipper would be willing to pay a higher rate (Friedlaender \& Spady, 1981; McMullen \& Schary, 1986). The previous statement is only true, however, if the elasticity of demand for the product is low.

In summary, it is safe to say that if rates were set too high, a product would not move unless the market demand curve was completely price inelastic. If, on the other hand, rates were set too low, the carriers would not recover their costs. Most authors contend that demand considerations set the upper limit on freight rates, and that cost considerations set the transportation rate floor (Harper, 1982; Lieb, 1985; Sampson, Farris \& Shrock, 1985).

\section{Value-of-Service Pricing studies}

Most economists believed that the railroads had always considered the value-of-service to the user when establishing rates. Some of these economists also believed that motor carriers used costs as a pricing basis (Levin, 1978). Other economists, however, felt that value-ofservice pricing might have been used more by regulated motor carriers than by rail carriers (Boyer, 1978).

Opposition to the use of value-of-service pricing by the regulated motor carriers was based on the cost structure of the industry and economies of scale. The proponents of value-of-service pricing argued that the value of the service was the primary factor to be used in setting rates for all modes of transportation. Demand for the product 
itself was to be considered a strong secondary pricing factor. This position was supported by writers dealing with non-transportation pricing. They also felt that demand was more important than cost in setting price (Lockley, 1949). opponents agreed this would be an acceptable approach to pricing, but pointed out that rate bureaus rather than market forces set rates. The rate bureaus could only guess about the level of actual market demand for a product and the value of the service to the shipper. Rate bureaus could not determine the demand for every product. They were forced to use the estimated value of the product as a proxy for actual demand. Value-of-service pricing opponents felt that each transportation situation was unique. Demand, competition, market, and product characteristics varied for every shipment. The classification system, used to apply the value-of-service pricing concept, led to unjust rate discrimination between products (Boyer, 1978; Corsi \& Roberts, 1982).

All firms interested in maximizing their profits would practice third degree price discrimination if they could. However, all firms cannot meet the three requirements necessary to practice such discrimination. Those firms which successfully practiced value-of-service pricing generally have the common characteristics of high fixed cost and unused capacity (Harper, 1981). Proponents of value-ofservice pricing argued that if fixed costs were high and the carrier had excess capacity, it was profitable in the short 
run for the carrier to charge a rate that would not cover the fully distributed costs. Value-of-service pricing was justified if the rate was high enough to cover variable costs and make a contribution to fixed costs. Value-ofservice pricing was also justified when necessary to attract certain freight if there was unused capacity in the system.

Opponents of value-of-service pricing argued that carriers had to charge rates high enough to cover all costs and to make a suitable profit. If some commodities were transported at rates below fully distributed costs, the rates charged would have to be higher than normal for other commodities. Opponents of value-of-service pricing in the motor carrier industry pointed out that the railroads had high fixed costs and considerable excess capacity. In the motor carrier industry, fixed costs were low and excess capacity could be quickly adjusted. ${ }^{2}$

Legal and Legislative Actions Affecting Pricing

Shortly after the passage of the Act to Regulate Commerce, its weaknesses became apparent. Problems were noted in the areas of testimony, enforcement of orders,

2.The controversy between the use of value-of-service pricing and pricing based on fully distributed costs is covered completely in summary articles by Clamus, 1969 and Davis and Combs, 1975. For readers who are interested in more detailed coverage of arguments in favor of value-ofservice pricing in transportation see Barrett, 1972; Coyle, 1965; Coyle, 1966; Edwards, 1969; and Roberts, 1965. For readers who are interested in more detailed coverage of arguments against value-of-service pricing in transportation see Doyle, 1969; Meyer et al., 1959; Nelson, 1971; Sampson, 1966; and Wilson, 1962 . 
power of the commission to set rates, and discrimination interpretations (Sampson, Farris \& Shrock, 1985). In two cases involving rates the Supreme Court held that the ICC did not have the power to set actual rates ${ }^{3}$ or to set maximum rates. ${ }^{4}$ These two decisions effectively removed the ICC from the ratemaking area.

The ICC had assumed it had been granted the power to set maximum rates or actual rates once it had found a rate to be unjust and unreasonable (Sampson, Farris \& Shrock, 1985). Now the ICC had to identify an unjust and unreasonable rate and try to get the courts to agree. If the courts sided with the ICC, the guilty party could change the rate slightly and the entire process would start over. ICC authority was further eroded when a supreme Court decision effectively gutted the provisions of section 4 . The Court held that it was up to the railroad to determine whether or not competitive conditions were dissimilar. Dissimilar competitive conditions at end points of a transportation move, and not at intermediate points, were reasons to justify a departure from the provisions of Section 4.5 In a dissenting opinion, Justice Harlin summed up the status of the ICC at this point:

Taken in connection with other decisions defining the powers of the Interstate Commerce Commission, the present decision.......goes far to

3.Cincinnati, New Orleans and Texas Pacific Railway Company V. ICC, 162 U.S. 116 (1896). 4.ICC V. Cincinnati, New Orleans and Texas Pacific Railway Company, 167 U.S. 479 (1897). 5.ICC v. Alabama Midland Railway Company, 168 U.S. 144 (1897). 
make that Commission a useless body, for all practical purposes, and to defeat many of the important objectives designated to be accomplished by the various enactments of Congress relating to interstate commerce. The Commission was established to protect the public against the improper practice of transportation companies involved in commerce among the several states. It has been left, it is true, with the power to make reports and to issue protests. But it has been shorn, by judicial interpretation, of authority to do anything of an effective character. It is denied many of the powers which, in my ${ }_{6}$ judgment, were intended to be conferred upon it. 6

Congress acted to remedy the situation by passing a series of statutes designed to strengthen the ICC. To overcome the long delay that occurred when the ICC went to court to get rate and discrimination findings enforced, the Expediting Act of 1903 was passed. It gave ICC cases priority over other cases on the court docket. In the same year Congress passed the Elkins or the Antirebate Act. Any departure from a published rate was considered to be prima facie evidence of discrimination. Adherence to the published tariffs became enforceable by court injunction.

In 1906 Congress passed the Hepburn Act which required a 30 days notice of any rate changes. This gave the ICC, shippers, and other carriers time to study the proposal. The ICC was also given the power to prescribe the maximum rate where it had investigated a rate and found it to be unjust and unreasonable. They were not given the power, however, to prescribe either actual or minimum rates. The last major effort to strengthen ICC ratemaking power

6.ICC V. Alabama Midland Railway Company, 168 U.S. 144, p. 176 (1897). 
occurred in 1910 when Congress passed the Mann-Elkins Act. A proposed rate could be delayed for 120 days while the ICC investigated the reasonableness of the rate.

Congress was trying to force the railroads to compete vigorously where competition was possible. Where it was not possible, control by the ICC was substituted for competition (Wilcox, 1966). The major concern was for the shipper, with little attention being given to the revenue needs of the railroads (Lieb, 1981). The ICC, between 1911 and 1920, proceeded to suspend, then to deny, most rail rate increases (Farris \& Williams, 1975). The railroads faced increasing costs, but their ability to increase revenues was restrained. This resulted in delayed or reduced maintenance of equipment and roadbeds, reduced service levels, and many bankruptcies (Moore, 1972).

By the end of World War $I$, the country was facing a transportation crisis. The result was the passage of the Esch-Cummins Act, also known as the Transportation Act of 1920. The legislation added section $15(a)$ to the Act to Regulate Commerce and directed the ICC to consider the railroad's revenue needs during rate hearings. The railroads were to receive a "fair return" on the "fair value" of their investments. The wording of this section was consistent with the wording in a previous Supreme Court case that prescribed the general level of compensation for regulated industries. 7

7.Smyth V. Ames, 169 U.S. 466 (1898). 
Congress gave the ICC the power to set minimum rates for rail services in a competitive situation. The Commission had been actively seeking this power since the late 1800's (Moore, 1972). The ICC was also given the power to prescribe actual rates once a rate was found to be unjust or unreasonable (Lieb, 1981). At this point the ICC control over rail carrier rates was complete.

One Congressional action during this period had a significant impact on the rate structure of the railroads and later on that of the regulated motor carrier industry. The Hoch-Smith Resolution 8 of 1925 addressed" economic problems of the agricultural sector. It directed the ICC to consider conditions in various industries when determining the minimum rates. It specifically directed the ICC to establish the lowest possible lawful rates for agricultural products and livestock: The lowest lawful rate had been defined as a rate that allowed the carrier to recover the costs incurred. Exactly which costs were to be recovered was not clear. What was clear, however, was that all profit would come from non-agricultural freight. This resolution was important because Congress effectively gave official approval to value-of-service pricing (Lieb, 1985).

\section{Collective Ratemaking}

The ICC assumed that all freight transportation firms sold the same product, ton-miles. This output could be

8.stat. $801(1925)$. 
differentiated by quality of service, in the short run, but it was difficult for a firm to maintain this differentiation (Farmer, 1964). Given this homogeneous product, the ICC decided that railroad regulatory procedures could be applied to the motor carrier industry. Motor carriers were allowed to set up rate bureaus and practice collective ratemaking as the railroads had been allowed to do.

Representatives of the motor carriers met to set rates within a rate bureau's boundaries. Shippers could attend ratemaking sessions and testify but they could not vote. Protection from pricing abuses lay in the requirements that rates had to be published and sent to the ICC for approval. Anyone could protest a rate and a protested a rate could not become effective until public hearings were held (Taft, 1961). The chance of a protest was very small, with less than one percent of the proposed rates drawing opposition (Harper, 1981).

Rate bureau pricing has always had a questionable legal basis. In 1890 , the Sherman Act $^{9}$ had made collective ratemaking illegal. The Justice Department, however, declined to prosecute those firms engaging in collective ratemaking while the ICC retained the power of final rate approval. The individual railroads and motor carriers retained the right to take independent rate action, and this was also thought to prevent collective ratemaking abuses (Pegrum, 1973).

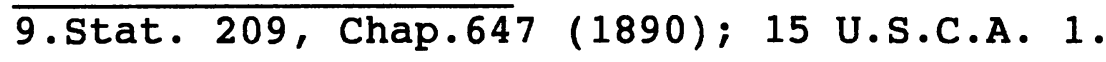


In 1944, the Department of Justice finally challenged the legality of collective ratemaking ${ }^{10}$ and, in 1945, a previously filed collective ratemaking case was decided by the supreme Court. 11 The Court ruled that railroads were subject to the Sherman Act, and that Congress had not exempted collective ratemaking from the provisions of the law. Congress held extensive hearings and discovered that both shippers and carriers strongly supported collective pricing (Chow, 1980b). They then passed the Reed-Bulwinkle Act $^{12}$ which specifically exempted collective ratemaking from the provisions of the Sherman Act.

Collective ratemaking continued until 1976 when railroad rate bureau members were no longer permitted, as a group, to vote on single line rates. Only those carriers that could actually participate in a joint line movement were allowed to vote (Association of American Railroads, 1976). Motor carrier ratemaking was also undergoing a reevaluation. In 1975 the ICC issued an order that kept rate bureaus from opposing independent rate filings (Lieb, 1985). When the Motor Carrier Act of 1980 was passed, it stipulated that only motor carriers with a specific route operating authority could vote on a rate bureau pricing proposal. This provision of the Act applied to both single and joint line rates. The Act also stipulated that in 1984 ,

10.U.S. V. Association of American Railroads, U.S. District Court, Lincoln, Neb. 4 F.R.D. 510 (1944).

11. State of Georgia v. Pennsylvania Railroad Company, 342 U.S. 439 (1945). 12. Stat. 472 (1948). 
the discussion by rate bureau members of single line rates would no longer be allowed.

The Motor Carrier Act of 1980 established a Motor Carrier Ratemaking Study Commission. This group was responsible for investigating the collective ratemaking exemption from the provisions of the sherman Act. It reported that collective ratemaking conflicted with the goals of the National Transportation Policy Statement because it effectively reduced competition (U.S. Motor Carrier Ratemaking Study Commission, 1983). It also reported collective ratemaking resulted in shipper's paying higher prices, inefficient motor carriers were protected, and efficient ones over rewarded (Lieb, 1985). The Commission recommended that motor carrier collective ratemaking activities be removed from the antitrust immunity .

The findings of the Commission were strongly opposed by the American Trucking Associations and Congress was slow to act on the recommendations. The ICC held hearings on a proposal to end antitrust collective ratemaking exemptions on shipments weighing less than 1000 pounds. It also announced it was considering doing away with all collective ratemaking (American Trucking Associations, 1983a). The regulated motor carriers strongly opposed these actions. The Department of Transportation and Senators Packwood and Kennedy, however, continued to urge the ICC to withdraw 
antitrust immunity from collective motor carrier ratemaking (American Trucking Associations, 1983b).

\section{Impact of Motor Carrier Regulation}

The basic goal of regulation was to provide the public with adequate transportation services at reasonable costs (Harper, 1982). The regulation of monopolies could be justified because, without regulation, they would enrich themselves at the expense of society. Most critics of motor carrier regulation made the point that the industry was made up of many small firms and it exhibited none of the characteristics of natural monopolies. It was not an acceptable course of action, they argued, to apply monopoly type regulation to the motor carrier industry (Harper, 1981). Major objections came from academics associated with the field of economics. One of the earliest critics was James C. Nelson. Nelson (1936, p. 489) noted that:

there are sound economic grounds for questioning the usefulness in the public interest of attempting to control by direct means either the supply of motor carrier service, particularly truck service, or the rates at which it is offered to the public.

Nelson pointed out that the public had benefited from the pre-regulatory growth of motor carriers. He speculated that under regulation, overall services would decline due to entry control and that the motor carriers would lose one of their greatest advantages, their flexibility. Nelson predicted that the motor carrier industry would lose its "little man" characteristics as the size of firms increased 
and that motor carrier earnings would increase. He refused to speculate about what would happen to motor carrier rates. 13

Studies of the effects of regulation on motor carrier rates and services did not begin to appear in the literature until the mid-1950's. Some of the anti-regulatory forces had expected regulation to end when the country emerged from the economic crisis of the 1930's. When deregulation did not occur, a series of studies that supported the earlier doubts begin to appear.

The issue of regulatory misallocation of traffic between modes and between individual carriers was addressed by Meyer et al. (1959), who felt that the ICC policy of keeping the rates high enough to protect the market share of the higher cost mode or carrier led to a misallocation of traffic. They contended it was incorrect to allow any situation to exist where freight was carried by a carrier or mode which had higher costs for similar services than others.

\footnotetext{
13.During the late 1930's and throughout the 1940's and 1950 's Nelson continued to study the impact of regulation on the motor carrier industry and he produced, during this period, a series of reports that were highly critical of the motor carrier regulatory process (Nelson, 1942; Nelson, 1945; Nelson, 1959). Over the years he was joined in his criticism by other economist such as Clark (1940), Pegrum (1952), Williams (1958), Nupp (1963), Cort (1970), and Moore (1972) among others.
} 


\section{Transportation Cost Studies}

The cost structure of the railroad and motor carrier industries generated a significant amount of research. Four basic types of costs are recognized (Harper, 1981; Lieb, 1985; Sampson, Farris \& Shrock, 1985).- They are fixed, variable, joint and common costs. Fixed costs are those which remain the same regardless of the volume of traffic moved. Variable costs are those, that have a direct relationship to the volume of traffic. Joint costs are those incurred as a result of producing another service. Common costs are those which cannot logically be traced to the production of any one service.

The fixed costs of railroads were significantly higher than they are for motor carriers, and they account for a much larger percentage of total cost. The railroads have a larger investment in fixed assets, such as rights-of-way. In 1954, the ICC conducted a detailed analysis and concluded that the fixed costs of an average regulated motor carrier only accounted for ten percent of total costs (Wood \& Johnson, 1989). In 1969, an independent study reported that fixed costs for the regulated motor carriers was 25 percent of total costs (Shirley, 1969). These estimates were computed before the large fuel cost increases of the 1970's. Higher fuel costs undoubtedly caused fixed costs to decrease as a percentage of total costs.

Estimates of recent railroad fixed costs range from 40 to 65 percent of total cost (Sampson \& Farris, 1979; Wood \& 
Johnson, 1989). Perhaps one reason that estimates vary widely is that, in the long run, all costs are variable (Locklin, 1972). This difference in motor carrier and railroad fixed costs made it hard to justify the use of a common pricing policy for the two modes. If the cost of providing a service is to have any bearing on the price, then carriers with different cost structures should have different rate structures.

If, in the short run; the fixed costs for rail carriers are more than they are for motor carriers, as the volume of traffic increases, the average cost per unit will decrease for the railroads. This relationship between increasing volume and decreasing costs would remain true until a system reaches full capacity (Harper, 1981). This would be a classic example of an industry that enjoys economies of density, not economies of scale. The general consensus is that economies of density do exist in the railroad industry (Borts, 1954; Due \& Clower, 1966; Healy, 1961).

Throughout the literature on transportation pricing the term economies of scale is used when the correct term should be economies of density. In the long run, all costs for all firms are variable in nature. The costs cannot be divided into fixed and variable components. In the long run if costs per unit produced declines as the size of a firm increases, this would be solid evidence that the firm enjoys economies of scale. In the short run cost can be divided into fixed and variable components. Average unit cost 
declines caused by spreading fixed costs over more units of production would be economies of density.

The issue of economies of scale in the motor carrier industry has also been studied, but the findings have been mixed (Lieb, 1985). Variations in the approach used, methodology, and coverage of the various studies make it difficult to reconcile the conflicting conclusions. If there is a general consensus about this question, it is that economies of scale in the motor carrier industry do not exist in all instances. When they do exist, the size of the scale economies is less for motor carriers than it is for railroads. Chow (1978) reports that some economies of scale exist in the LTL general freight segment of the industry, but all other segments exhibit the characteristic of constant return to scale. A later study found that apparent economies of scale in the motor carrier industry were due to regulatory influence rather than economic factors (Friedlaender \& Spady, 1981).

Effects of Motor Carrier Regulation on Pricing

Opponents of motor carrier regulation argued that entry restrictions and the use of railroad classification and rate setting techniques resulted in higher transportation rates. They produce a series of studies to support their contention that the factors affecting motor carrier rate making under regulation differed from those under deregulation. 


\section{Exempt Carrier Studies}

The Motor Carrier Act of 1935 exempted all motor carriers from regulation when they were transporting certain agricultural commodities. The Act did not specify the agricultural commodities to which this exemption applied. The ICC felt that the provisions of the Act were not to be interpreted literally. The existence of the agricultural exemption provided the opponents of motor carrier regulation with several opportunities to quantify the costs of regulation.

The agricultural exemption did not apply to products that had been "processed" or "manufactured" from exempt commodities (Harper, 1981). The ICC limited the scope of the agricultural exemption by narrowly defining the words manufactured and processed. This narrow definition was overturned by the Supreme court. In two cases, one involving fresh dressed and frozen poultry and the other involving frozen fruits and vegetables, the court ruled an exempt commodity did not become a regulated commodity if it largely maintained its identity after the processing or manufacturing had occurred. 14

The Department of Agriculture saw this as an opportunity to measure the effects of motor carrier regulation on rates. Before these decisions fresh dressed poultry, frozen poultry, frozen fruits, and frozen 14.East Texas Motor Freight Lines v. Frozen Food Express, 351 U.S. 49 (1956), and Home Transfer and Storage Company v. U.S., 141 Fed. Supp. 599 (1956). 
vegetables were products subject to regulation. The rates charged before the Supreme Court decision were compared with those charged after the decision. The rates for fresh dressed poultry declined 33 percent while the rate for frozen poultry declined 36 percent (Snitzler \& Byrne, 1958). The rate decline for frozen fruits and vegetables was a significant 19 percent (Snitzler \& Byrne, 1959). The stop off charges of $\$ 5$ to $\$ 15$ per stop, commonly charged before the exemption of these commodities, were either dropped or significantly reduced by deregulation (Miklius, 1969).

\section{Cross Sectional studies}

Another study, trying to measure the impact of regulation on motor carrier rates, took a cross-sectional, rather than a longitudinal approach (Farmer, 1964). This study did not look at rates charged but rather at revenues per intercity ton-mile, costs per intercity ton-mile, and net revenue per intercity ton-mile of 25 exempt agricultural motor carriers and 171 regulated common and contract motor carriers. The costs and revenues of the regulated motor carriers exceeded the costs and revenues of the exempt motor carriers by 60 percent or more on average. No reasons were offered as to why the revenues of the unregulated carrier were so much lower than those of the regulated carriers; but, when costs were subtracted from gross revenues, the unregulated motor carriers had the highest net profit per ton mile. 
One reason for this difference was that the average number of tons per load for the exempt carrier was significantly higher (14.8 tons) than the regulated carriers (9.6 tons). Meyer et al. (1959) reported the terminal cost for a shipment of 149 pounds or less was $\$ 54.32$ per ton. A shipment of 20,000 pounds had a terminal cost of $\$ 1.70$ per ton. The small, high terminal cost shipment was one that a regulated carrier might have had to accept regardless of its costs. The large, low terminal cost shipment was typical of the shipments transported by unregulated motor carrier. It is difficult to conclude, however, that the entire difference in costs was due to the lighter average load and terminal costs.

\section{Canadian Studies}

To support the proposition that regulation increased rates, the proponents of deregulation have examined motor carriage in countries which had a more relaxed or different approach to the regulation. In Canada, there was no economic regulation of the motor carrier industry at the national level except for grain movements. The differences in the regulatory approaches taken by the provinces provided researchers with a real-world laboratory in which to study motor carrier regulation. Sloss concluded that regulation added 6.73 percent to the rates charged (Sloss, 1970).

This study is widely quoted as an authoritative source on the cost of economic regulation, but it is also widely 
criticized (Chow, 1981; Maister, 1978; Maister, 1979; McRae \& Prescott, 1979). It was reported that rates in the strictly regulated provinces of Saskatchewan and Manitoba were actually lower than rates in unregulated Alberta (McRae \& Prescott, 1979). The same study found, however, that motor carriers rates in unregulated Alberta were lower than those in the partially regulated provinces of Ontario, British Columbia and Quebec. In these three provinces motor carrier industry entry was strictly, controlled but rates were only nominally regulated. Chow concluded that both industry entry and rates would have to be strictly controlled to achieve maximum regulatory benefits (Chow, $1980)$

Felton (1978), another critic of the sloss study, reached a completely different conclusion. He felt two of the variables, average length of haul and average net weight per loaded vehicle, included in the sloss regression equation may have been adversely affected by regulation. Felton believed this relationship caused the sloss study to understate significantly the impact of regulation on motor carrier rates.

\section{European and Australian Studies}

Europe and Australia also received their share of attention from researchers. Moore (1976) reported that the charges per ton-mile in West Germany and the U.S. were about the same. He concluded that this was reasonable because the 
countries had a similar approach to regulation. The regulatory stringency of the two systems were also about the same. Klaus (1981) reported, however, that a gradual relaxation of regulation had been underway in West Germany since the early 1970's. He estimated that this easing of regulation had resulted in a 20 percent reduction in rates by 1978 .

Moore also examined motor carrier rates in Great Britain, Belgium, the Netherlands, and Sweden where economic regulation was less strict than it was in the United States. He concluded that rates in these countries were about 43 percent lower than they were in the United States. Felton (1978) speculated that higher labor costs in the United States contributed to some of this rate difference. He pointed out, however, that higher fuel costs in Europe would offset some of the higher United States labor costs. Nelson (1978) reported on the impact of transportation deregulation in Australia. Deregulation occurred suddenly when the Australian High Court invalidated a regulatory system very similar to the one in the United States. A survey of shippers showed that freight rates were significantly lower than they had been when transportation was regulated. Tausz (1985) reported that as a result of Australian deregulation, competition increased, rates were reduced, and the level of motor carrier service was either maintained or improved. 


\section{New Jersey $\underline{\text { Study }}$}

A study of the impact of regulation on rates was also conducted in New Jersey. New Jersey was selected because it had never imposed economic regulation on the intrastate motor carrier industry. The study found rates charged by unregulated intrastate motor carriers to be $9.88 \%$ below those charged by the regulated interstate motor carriers (Allen, Lonergan \& Plane, 1978). Intrastate shippers reported they were also receiving service that was equal to or better than the service they received on regulated interstate shipments (Wright, 1983).

The New Jersey study was criticized by Chow (1980; 1981), who pointed out that the regression model only explained $51.8 \%$ of the variance in the interstate rates and $54.5 \%$ of the variance in the intrastate rates. He noted that a study by Manalytics (1978) of interstate and intrastate rates in seven states produced mixed results. The study found intrastate rates to be lower than interstate rates in Texas and Georgia. Only California had intrastate rates that were consistently higher than the interstate rates. In the remainder of the states mixed results were produced. Chow (1981, p.30) pointed out that although unregulated New Jersey intrastate rates were lower than the regulated interstate rates, this was "not proof" that regulation causes higher rates. 
Weaknesses in Rate Level Research

The effects of regulation on motor carrier rates has been the subject of much debate; however, most of the evidence comes from surveys, aggregated data studies, or studies based on micro-economic theory. Each of these approaches had significant drawbacks.

Survey based studies might only reflect the respondents' feelings and depend on the ability of the respondent to recall information (Dillon, Madden \& Fertle, 1987). Aggregated data smooths out many types of variation and the sensitivity produced by disaggregated data studies is lost. Aggregated data can also hide discrimination in the rate structure (Corsi \& Roberts, 1982; Samuelson \& Lerman, 1977). Rate studies based on micro-economic theory have to recognize product heterogeneity to determine rates, and this requires the individual matching of supply and demand (Hoover, 1985; Harper, 1982; Hunt, Muncy \& Ray, 1981). Existing data sources are unable to provide the information necessary to conduct micro-economic rate studies on a large scale (Bernstein \& Darjani, 1979). Regulatory impact studies, based on actual motor carrier rates or the factors underlying these rates, are rare. The ones that have been conducted are often limited in scope (Beilock \& Freeman, 1987).

A reader unfamiliar with the ICC regulated motor carrier rate structure would assume that its study would be simple because all rates must be published. However, the 
tariffs are difficult to use and poorly catalogued. Commodity descriptions are not standardized and there are no logical groupings of origins and destinations. A person desiring to discover the lowest rate for a product would have to consult many documents, work with complex formulas, and interpret footnotes and exceptions to rules (Samuelson \& Lerman, 1977). A 1962 study reported that the ICC had 205,275 active tariffs on file. A tariff might consist of a single page, hundreds of pages, or in some cases thousands of pages of rates (Sampson \& Farris, 1971): Stern (1972) reported there were 43 billion freight rates on file with the ICC. He also noted that 336 million commodity and rating numbers existed, and there were 288 trillion possible commodity rates.

The study of the motor carrier rate structure and its underlying factors would be a complex research problem. No industry wide motor carrier rate study has ever been attempted for this reason. In theory such a study could be done, but the computer time and manpower necessary for such a project makes it impractical. A suitable database would also have to be created for the study because such a database does not exist. Unlike the railroad industry, where a one percent sample of the freight waybills is regularly taken from less than 100 carriers, the creation of a database for the study of motor carrier pricing would involve the sampling of waybills from thousands of individual carriers. Without such studies, however, it is 
not possible to say who is correct about the impact of regulation on motor carrier rates and pricing behavior.

Advocates of regulation argue that it allows motor carriers to charge lower rates. They point out that from January 1967 through the first quarter of 1979 the rates charged by regulated motor carriers rose 79 percent while the Producers' Price Index rose 123.7 percent. During the same period the Consumers' Price Index rose 107 percent (McCormick, 1980).

This argument was examined by Paxson (1981) who looked at the changes in intercity trucking costs between 1950 and 1980. He concluded that it was not surprising that motor carrier rates increased at a slower rate than the Producers' and Consumers' Price Indexes. Paxson argued that motor carrier rate increases were lower because the cost per tonmile in constant 1980 dollars had decreased by 21 percent during the period. In 1980, the cost of a standard heavy duty tractor was only 74 percent of what it was in 1950 . The wages for intercity drivers had been rather stable, increasing only about nine percent. Although fuel costs increased about 37 percent, this was largely offset by a 28.5 percent increase in fuel efficiency. Overall, Paxson estimated that the costs per ton-mile increased by two cents. Offsetting this minimal increase was the 43 percent reduction in transit times made possible by the interstate highway system. 
Advocates of deregulation also claimed that rates would go down if the motor carrier industry were deregulated. As evidence, they cited the various studies which estimated the costs of regulation. They also argued that deregulation would allow new firms to enter the industry freely, thereby increasing competition and lowering rates. They felt that rates were already high because of collective ratemaking, limited entry, and an over restrictive freight classification system. Both sides argued their approach to regulation would lead to the more efficient use of fuel (Rakowski, 1981).

\section{Rate Adequacy Measures}

With both sides making claims and counter-claims, deregulation of the motor carrier industry was in doubt. One piece of evidence, the profitability of the regulated motor carrier industry, probably tipped the scales for deregulation. One of the major reasons motor carriers were regulated was to assure that a suitable profit level was made by members of the industry. Before regulation, competition was intense and very few firms made a profit large enough to assure their long-term survival. During the period when motor carriers were regulated, their profits exceeded all expectations. They were not only making a profit, they were making excess profit. 


\section{Return on Investment}

The return on investment (ROI) of the regulated motor carriers was much higher than that of other modes and industry in general. The ICC had established a target ROI of eight percent as appropriate for the rather low risk motor carrier industry (Miklius \& Casavant, 1975; American Enterprise Institute, 1980). The ROI for industry in general ranged from nine to fourteen percent from 1960 through 1983 (Lieb, 1981; Lieb, 1985). Also troubling was the fact that the operating rights which many of the motor carriers recieved at no cost in 1935 were carried on the company books as investments worth millions of dollars.

The ROI for the largest regulated motor carriers was 11.53 percent in 1960 , but it had increased to 22.56 percent by 1965. During the ten year period, 1970 through 1979, it only fell slightly below 14 percent twice. In the other eight years the ROI ranged from 15.14 to 25.76 percent. During 1980, the ROI was 19.32 percent and in 1981, the first full year of motor carrier deregulation, it dropped slightly to 18.97 percent. In 1982 , it dropped drastically to 1.81 percent, but by 1983 it recovered to 8.91 percent.

The suggested reasons for the drop in ROI in 1982 included rapidly rising fuel cost, rapidly raising labor cost, economic recession, and deregulation (Sampson, Farris \& Shrock, 1985). Rising fuel cost, however, had been a factor in motor carrier costs since 1973. The same argument can be made about labor costs. As far as economic 
conditions accounting for the drop, the economic recession began in 1978; still, the motor carrier industry average ROI remained well above the national average for three years. If rising operating costs and economic recession can be discounted as causes for the decrease in motor carrier industry average ROI, deregulation remains as the most likely cause.

In the past, rate bureaus could apply for a general rate increase for all of their members (Harper, 1981). The Motor Carrier Act of 1980 restricted this power and the ICC was reluctant to continue to approve blanket rate increases. Without this authority, the rate structure could not be adjusted rapidly enough to keep pace with inflation. The ROI of the regulated motor carriers was, therefore, adversely affected.

The Motor Carrier Act of 1980 gave the individual motor carriers considerable pricing freedom. The limit on yearly percentage of rate change, however, kept the full impact of the new pricing freedom from becoming apparent until the end of the second year of deregulation. This could be a possible reason why the ROI for the formerly regulated motor carriers did not show a significant decline until 1982 .

Evidence of the intent of Congress for ROI to be the measure of transportation rate reasonableness is contained in the Transportation Act of 1920. The use of ROI to judge rate reasonableness was in accord with Smyth v. Ames, which held that well managed, regulated companies were entitled to 
a fair return on investment. The use of an absolute measurement of rate reasonableness, such as ROI, led to problems. What was a well managed company? Should the ROI be computed using all assets of a firm, or should the differences in individual firms' ratios of debt to equity be recognized? Should the investment in productive assets be calculated at original costs less depreciation or should they be based on replacement costs? Should the motor carrier be rewarded because a purchased asset, like operating rights, had gone up in value?

The American Trucking Associations felt the ICC did not give sufficient weight to the cost of acquiring operating rights and their increased value when considering the revenue needs of regulated motor carriers (American Trucking Associations, 1974). Snow (1977) argued that operating rights only had value because the ICC was suppressing competition. He pointed out that any rate increase based on increased operating right value would reward motor carriers for doing nothing.

Economists were critical of the use of an absolute ROI figure to test the reasonableness of motor carrier rates. In 1944, the supreme Court recognized the validity of their arguments and, in the Hope Natural Gas case, held that the ROI was not the most crucial rate reasonableness test. 15 Economists contended that rates had to be high enough to permit the firm to maintain financial integrity, but not so 15. Federal Power Commission v. Hope Natural Gas Company, 320 U.S. 591, 1944 . 
high as to permit the firm to earn excess profits. This decision left many questions unanswered in the area of motor carrier rates. It did, however, move the issue of rate reasonableness from a narrow legalistic path into the area of economics (Sampson, Farris \& Shrock, 1985).

\section{Operating Ratio}

With the loss of ROI as the primary rate evaluation tool the ICC turned to the operating ratio (Harper, 1981). The operating ratio is defined as the ratio of operating expenses, not to include income tax and interest expenses, to operating revenues (Wood \& Johnson, 1989). The ICC contended that the major risk faced by the motor carriers lay not in their investment but rather in the large amount of expenses they incurred (Harper, 1981). In 1979, the 872 Class I regulated interstate motor carriers had operating revenues of about $\$ 30$ billion and operating investments of more than $\$ 6.7$ billion. 16 This meant that $\$ 1$ invested in operating assets produced $\$ 4.5$ in operating revenues (ICC, 1980). This confirmed an earlier study which found that the investment required for motor carriers to produce $\$ 1$ of revenue was only $\$ 0.22$ (Association of American Railroads, 1973)

\footnotetext{
16. The definition of a class I motor carrier has changed several times during the course of motor carrier industry history but at this time a class I motor carrier was defined as a motor carrier, subject to the jurisdiction of the ICC, which had annual operating revenues of over $\$ 3$ million.
} 
If the average operating ratio was above 93 percent, this was considered to be strong evidence that rates were too low. Using an average operating ratio concealed, however, the fact that some of the carriers were highly profitable at the current rate levels (Harper, 1981). The regulated carriers contended that an operating ratio of 95 percent or more would impair their stability (Lieb, 1985). This argument is not supported by the evidence. Operating ratio data, published at five year intervals between 1945 and 1980, show all Class I and Class II motor carriers (all those regulated motor carriers having annual operating revenues of more than $\$ 500,000$ ) had an average operating ratio below 95 percent only once (American Trucking Associations, 1981). An average operating ratio of 95 percent produces satisfactory rates of return for most carriers. The small investment required to generate the revenue necessary to produce a satisfactory rate of return is the reason this condition exists (Wood \& Johnson, 1989).

\section{Return on Equity}

The ICC, aware of the shortcomings of previous measures of revenue needs, began to require regulated carriers to supply the data necessary to compute a return on equity (ROE). The ICC had to get this information directly from motor carriers. Only 23 of the thousands of regulated motor carriers were publicly held corporations, required to publish equity data (American Trucking Associations, 1980). 
The ICC continued to use the operating ratio to measure revenue needs, but it used the ROE as a secondary evaluation tool (Levine, 1973). By 1978, ROE was the primary evidence used in general rate increase hearings. 17

The ICC set 14 percent as a desirable ROE for regulated motor carriers; but in 1978, the average ROE for the eight largest regulated motor carriers was 28 percent (The Economist, 1980). The ROE for the 15 largest regulated motor carriers averaged 18.8 percent for the six year period from 1973 through 1978 (Burck, 1978). Gatty (1983) reported the average ROE to be 15 percent for the entire regulated motor carrier industry. The ICC staff, noting that in 1977 the 100 largest regulated motor carriers had an ROE of just under 20 percent, acknowledged "excessive profits are being earned by these firms" (American Enterprise Institute, 1980, p. 20)

The general consensus among motor carrier deregulation advocates was that regardless of the method used to measure the revenue needs of the motor carriers, the collective system of ratemaking, the rate structure, and the freight classification systems protected marginal, poorly managed companies and over rewarded well managed ones (Farmer, 1964; Burck, 1978; Felton, 1978; Wright, 1983; Nelson, 1987).

17.ICC, Investigation and Suspension Docket no. M-28772, General Increase-Southern Motor Carriers Rate Conference (April, 1978). 
CHAPTER IV

\section{DEREGULATION AND MOTOR CARRIER PRICING BEHAVIOR}

Rate Studies and the Deregulated Motor Carrier Industry

Deregulation of the motor carrier industry was an emotional issue, but in the end, the deregulation coalition proved to be too strong for the regulated carriers and the Teamsters Union. The regulation forces claimed that continued regulation would result in lower overall rates, saved fuel, and continued service to small communities at reasonable rates (Rakowski, 1981). The deregulation forces claimed that the same benefits would occur under deregulation (Ferguson, 1982). Now that the emotion of the deregulation debate is past, research is needed to study pricing behavior in the deregulated motor carrier industry.

Deregulation of the motor carrier industry has caused shippers to become increasingly concerned about rates (Paden, 1982). Before deregulation, they had limited influence over freight rates and they accepted these rates as a given and known cost factor (Coyle \& Bardi, 1984). Deregulation effectively did away with a rate structure that was known and stable and replaced it with one that was unknown and volatile. Under regulation changing a rate was 
a long and expensive process (Ballou, 1987). Today carriers can change rates almost at will. Tariffs are often simple price lists or the results of shipper-carrier bargaining (Wright, 1983). The ICC has accepted most of the rates filed (Schneider, 1985).

\section{Surveys, Case Studies, and Empirical Investigations}

There are three sources of information available to a researcher studying the current rates of the motor carrier industry. First, there are case studies which take the form of testimony describing what has happened to freight rates paid, services received, and competition for business. The second source of rate information comes from the professional transportation journals, government documents, and government funded studies. This source consists of the published reports of shipper/carrier surveys. The third source of information comes from the limited number of empirical studies done in the field.

\section{Case studies}

In one case study Richard Warren of Lever Brothers, Incorporated, reported that more than 96 percent of the company's LTL shipments were being shipped at negotiated rates rather than class rates (Traffic World, 1986). From 1980 through 1985, Warren stated that transportation costs had declined six percent while the consumer price index had increased 28 percent. The Vice President for Materials of 
Sherman-Williams Company stated that, under deregulation, his company was receiving better services and was paying a rate that was 15 percent lower than the rate previously paid (Handling and Shipping Management, 1982). One large midwestern meat packer reported that as a result of large rate decreases the firm ended its private fleet operation (Duncan, 1984).

A general estimate of the total savings from lower rates during 1981 to 1985 was $\$ 25$ billion (Machalaba, 1985). Since 1980, one writer reports, discounts from published class rates have averaged from 18 to 20 percent with the largest shippers occasionally receiving discounts of up to 40 percent (Labich, 1985). The same writer found "the big shippers get the big discounts, but even the smallest ones pay less than before deregulation" (Labich, 1985, p.138). Case studies are interesting but they relate only what the impact of deregulation has been on the rates and services received by one particular shipper. This shipper is usually involved in the distribution of a single or limited line of products over fixed transportation routes at regular intervals.

A second shortcoming of the case study approach to transportation rate research is that the results cannot be verified. Most shippers are reluctant to share the databases used to reach the conclusions reported. They contend that such records are proprietary and that their release would harm the company's competitive position. The 
lack of verifications lends credence to the argument that these results could not be generalized to apply to all shippers .

\section{Surveys}

Surveys are the second source of postderegulation motor carrier rate information for researchers.' One survey reported more rate flexibility and competition in the motor carrier industry as a result of deregulation (Griffith, Daniel, Shrock \& Farris, 1983). The same study found that discounting from published tariffs was rampant. Harper and Johnson (1987) report there has been a large increase in the number of interstate carriers and many of the established carriers reacted to the increased competition by practicing aggressive pricing.

Harper (1982; 1983) surveyed interstate motor carriers and shippers in Minnesota in an effort to measure the impact of deregulation on small quantity and rural shippers. He found that carriers had increased sales and marketing activities directed at these shippers. Most of the carriers surveyed also reported that they had decreased some or all of their rates between 1977 and 1982. Rate discounting occurred in the small shipper area, but it was less prevalent than it was for larger shippers.

Harper did not investigate rural shippers' rates, but two later studies did (Beilock \& Freeman, 1984; Glaskowsky, 1986). These studies reported that rural shippers were 
paying lower rates, but they were not receiving rate reductions as large as those received by similar shippers located in urban areas.

A survey conducted to measure the change in interstate motor carrier rates between 1977 and 1982 showed that for 35 $\mathrm{TL}^{1}$ shippers, the average rate paid had declined 25 percent in constant dollars (Moore, 1983). The same study surveyed 30 LTL shippers and found that their rates had declined by an average of 16 percent. A General Accounting office study concluded there had been downward pressure on motor carrier rates since 1980 and the size of the decreases had been between 12 and 15 percent (Traffic World, 1984).

A survey of presidents of class I and class II regulated route general commodity common carriers was conducted in 1983. A large majority of those surveyed reported they were offering one or more types of discounts (Hoover, 1985). Williamson et al. found motor carriers were offering a much greater variety of services and were willing to negotiate rate-service packages (Williamson, Singer \& Peterson, 1983).

In a survey of 320 interstate carriers, 54 percent reported their general rate levels had declined an average of 13.5 percent since 1980 . Forty six percent reported that their general rate level had increased an average of 14.9 percent (Williamson, Singer \& Bloomberg, 1985). The rate of

1.The ICC defines truckload shipments as those shipments greater than 10,000 pounds and less-than-truckload shipments as those of 10,000 pounds or less. 
increase for those reporting higher rates was less than the 20 percent increase in the Consumer Price Index. The contention that rates which increased by less than the inflation rate were effectively rate reductions was supported by a study which found that interstate rates had not kept pace with inflation by a wide margin (Bowers, 1986).

In one survey, more than 90 percent of the respondents reported that at least half of their LTL traffic was shipped at rates discounted from the regular rate bureau tariffs (Traffic Management, 1985). The average discount was in the 25 to 40 percent range, but a few respondents, about 15 percent, reported that they had received discounts of up to 50 percent.

Like case studies, surveys have produced interesting results but also have serious limitations. The sampling frames used in most carrier/shipper surveys have been limited in their coverage. Hoover (1985), for example, surveyed only class I and Class II regulated route common carriers of general commodities. This survey produced significant results, but only addressed the pricing behavior of the 732 specific motor carriers and ignored thousands of others. Harper $(1982 ; 1983)$ limited his sampling frame to those motor carriers and shippers domiciled in the state of Minnesota.

A second major limitation of survey research is that it reports on the perceptions and the memory of respondents 
about what has happened to rates and services. The survey done by Beilock and Freeman (1982) of shippers and motor carriers in Florida reported their findings about what motor carriers and shippers felt to be the impact of deregulation on rates. This study was interesting but the results cannot be applied universally. Motor carriers and shippers in other areas of the country might have a different feeling about what has happened to rates. Questions remain whether these feelings are significantly different and just how strongly they are felt.

\section{Empirical Investigations}

There have been many general rate studies, but empirical studies continue to be hampered by the lack of a large, disaggregated database (Samuelson \& Lerman, 1977; Bernstein \& Darjani, 1979; Boyer, 1978; Morton, 1971; Chiang, Roberts \& Ben-Akiva, 1981). Case studies and surveys have produced interesting results, but, as discussed, both have significant limitations. Both research approaches tell us that motor carrier rates have declined under deregulation, but they do not identify the factors which underlie this general decline.

The number of freight rate studies based on actual shipment data gathered in a deregulated environment are limited. An extensive search of the literature revealed only two such studies conducted since the passage of the 
Motor Carrier Act of 1980 (Blair, Kasserman \& McClave, 1986; Beilock \& Freeman, 1987).

These studies tried to measure the impact of deregulation by comparing freight rates before and after deregulation. The basic hypothesis was that any changes in freight rates could be attributed to deregulation. In both studies, actual shipment data consisting of commodity classes, origin-destination pairs, distances, and weights were used to develop rate models. Both studies recognized the linkage between costs and rates and tried to control for this by including a cost variable in the rate model. Inflation effects were controlled by using constant dollars. They were also interested in measuring the impact of deregulation on rates charged to serve large and small communities; therefore, variables for both those markets were included in the models. The databases employed by both research teams were impressive in size.

The Blair, Kasserman, and McClave Study. The study by Blair et al. involved motor carriers operating within Florida. Florida was chosen because it offered the unique opportunity to examine freight rates in both a regulated and a deregulated environment. Florida had a regulatory system in 1980 which closely paralleled the federal system. The regulatory system was abolished suddenly, however, when the state legislature unexpectedly failed to extend the authority of the Public Service Commission. Overnight, intrastate motor carrier regulation ended. 
The Commission had used its power to limit the number of motor carriers authorized to serve specific routes or areas. In return for protection from competition the carriers agreed to submit to rate regulation. Intrastate freight rates were set collectively and approved by the Commission. The carriers were also restricted in the commodities hauled, types of vehicles used, and backhaul authority. The Florida carriers incurred the common carrier obligation, which required them to offer services to all customers at approved rates. This service had to be offered even if it resulted in the motor carriers' serving unprofitable small markets. 2

Blair et al. gathered data on 27,000 individual freight shipments from ten motor carriers for their study. The shipments originated in Jacksonville, Tampa, and Miami with destinations throughout Florida. Observations were taken for June, 1980, the month before deregulation occurred, to establish a baseline to measure change over time. Postderegulation observations were taken in February, 1981, February, 1982, and September, 1982, respectively.

Five different classes of freight were represented in the data, classes $77.5,100,150,200$, and 250. Data were also collected on the weight of each shipment, the distance, and whether the shipments were destined for a large or a small market. Blair et al. had three research goals. regulated intrastate motor carriers in Florida prior to July 1, 1980 see Ranson and Sheldon, 1980. 
First, they wanted to test the hypothesis that the removal of regulatory constraints would reduce the rates charged. They hoped to add empirical support to the perceptual and case studies which reported that deregulation had lowered motor carrier rates. Second, they hoped to test the hypothesis that the price differentials between product classes would persist, even if regulation were not a factor. Third, they wanted to test the hypothesis that with deregulation the price decreases in large markets would exceed those in the small markets.

Blair et al. assumed that the supply of motor carrier services would be infinitely price elastic at the market rate. Based on this assumption, they developed a model of the determinants of the motor carrier supply price which included the product and cost related characteristics of the shipments. This approach was consistent with previous studies done in the period before deregulation occurred (Sloss, 1970; Spady \& Friedlaender, 1978).

Blair et al. expected to find motor carrier rates to be less after deregulation. They reasoned that the removal of regulatory constraints would lead to increased competition between existing carriers, that new carriers would enter the market, and that overall operating efficiency would improve. They reported that deregulation resulted in an average decrease of 14.62 percent in rates.

They also examined the pricing behavior of the ten individual motor carriers and found that their reaction to 
new pricing freedom varied widely. In the first year three firms opted to reduce their rates significantly, four firms left rates about the same, and three firms raised rates. By the end of the third period only one of the firms that had chosen to raise rates had sustained the increase. The rates charged by the four firms which chose to maintain their prederegulatory rates were lower at the end of the study period.

Based on the average rate decrease of 14.62 percent and the pricing behavior of nine of the ten study subjects Blair et al. claimed that their first hypothesis was supported. This finding added empirical support to the case studies and surveys that had previously reported that freight rates had declined as a result of deregulation.

Blair et al. also found that the rate differentials between product classes had narrowed somewhat, but they had not completely disappeared. Higher classified freight continued to pay a premium for transportation services. This finding supported their second hypothesis, that the differences in rates for different product classes would persist under deregulation. The finding does not, however, identify which of the product classification factors are responsible for the continued class rate differentials. Unless it can be shown that different freight classes involve different costs, the study findings appear to show that price discrimination between higher classified freight 
and lower classified freight continues to exist under deregualtion.

Under regulation rate differentials between large and small market destinations were found to be insignificant. After deregulation, the rate differentials were found to be about three percent, with the smaller destination markets paying the higher freight rates.

Blair et al. reported that shippers in small markets benefited from rate reductions under deregulation, but the size of the reductions was less than it was for shippers in large markets. This finding partially supported Posner (1971), who feels that one of the principal functions of regulation was for larger markets to cross-subsidize service to smaller markets. Blair et al. pointed out they could not be sure cross-subsidization across markets existed before deregulation. They lacked information on the volume of shipments made to the smaller markets at subsidized rates, and without such data, it was not possible to be certain cross-subsidization took place. It had been pointed out a cross-market subsidy does not exist unless service is actually provided to the smaller markets at the reduced rates (Breen \& Allen, 1980; Allen, 1981).

The Blair et al. rate model produced results which were quite robust. Using a simple natural logarithm model to explain motor carrier freight rates, they produced an $\mathrm{R}^{2}$ value of 0.79 . When interaction terms were included, the 
more complex specification added significantly to the explanatory power of the model with an $R^{2}$ value of 0.895 .

The Beilock and Freeman study. Beilock and Freeman also examined the impact of deregulation on the motor carrier industry at the state level. They gathered prederegulation and postderegulation data from Florida, but expanded their study to include data from Arizona. The regulatory system in Arizona was similar to that which had existed in Florida and at the federal level before 1980. Rate differentials were sanctioned based on the product's handling and transportation characteristics. Large shipments subsidized small ones, urban shippers subsidized those located in rural areas, and high valued products subsidized the movement of lower valued products (Allen, 1981).

There were significant differences in the two states, however. Deregulation in Florida occurred suddenly, but in Arizona it was preceded by an extensive debate. Deregulation in Arizona was approved by the voters in November of 1980, but did not become effective until July 1, 1982. Arizona is largely a rural state with its population concentrated in the Tucson and Phoenix areas. Florida has several large population centers and the population density is much greater. The geography of the two states also differs significantly. Florida is long and narrow with very few points located far from an interstate highway or the Florida Turnpike. Motor carriers serving the most remote 
locations in Florida can make use of a highly developed highway system for at least part of the trip. Arizona has a limited interstate highway system and the motor carriers operating there are unable to use the interstate highway system as extensively as it is used in Florida.

To measure the impact of deregulation on freight rates, Beilock and Freeman gathered data on 49,967 shipments in Arizona and 105,500 shipments in Florida. Monthly data were collected in Arizona for the period from January, 1980 through October, 1984. The Florida monthly data covered the period from January, 1979 through October, 1984. In Florida, the LTL industry was highly concentrated, and data were collected only from the four largest motor carriers. These carriers accounted for about 75 percent of the Florida intrastate shipments. In Arizona data were collected from 19 large and mid-sized motor carriers, which accounted for more than 90 percent of the intrastate shipments.

In Arizona, data involved twelve traffic lanes. Seven of the lanes were classified as urban-rural, and five lanes were classified as urban-urban. In Florida, data were collected for twenty traffic lanes, nine urban-rural and eleven urban-urban. The data collected consisted of the rate charged to move a specific commodity class shipment of a certain weight between two points. In Arizona the subject commodity classes were $60,70,85$, and 100 . In Florida, they were $65,70,77.5,100$, and 125. Where they existed, Beilock and Freeman also collected the corresponding 
interstate rates over all routes, including 16,704

interstate rate observations for Arizona and 35,000

interstate rate observations for Florida.

In their study of the effect of deregulation, Beilock and Freeman tested six hypotheses. First, they felt the overall rates would fall because of increased competition. Second, they felt the overall rates per mile would fall because of improved load factors. Third, they felt the class-based rate differentials would be less. Fourth, they felt the rate differentials based on shipment size would increase. Fifth, they felt the rate differentials between urban and rural shipments would increase. Finally, they felt the rates charged would become more variable.

To test hypotheses two through five, Beilock and Freeman used a reduced form regression model of motor carrier freight rates. As precedents for their choice they cited the previous works of Binkley and Harrar (1981) as well as that of Ferguson and Glorfeld (1981). Their model held that the freight rate for a particular shipment would be a function of economic conditions, time, carrier, costs, freight class, weight, distance, remoteness, and regulation or deregulation.

Demand is affected by economic conditions, and they chose to use the monthly state unemployment rate as a demand measure. The cost of fuel was selected as a proxy for all other operating costs. Other costs were those associated 
with the transportation of products of varying size and density with different handling and shipping characteristics. These costs are captured by the weight and classification variables. Beilock and Freeman also believed that the remoteness of pickup or delivery points would have an effect on rates because backhauls from remote locations might be empty or only partially loaded. They quantified this variable by determining the proportion of total distance traveled off a four lane highway.

The Beilock and Freeman freight rate regression model also produced results that were robust. In Arizona, the model produced an $\mathrm{R}^{2}=0.75$ and in Florida the $\mathrm{R}^{2}=0.77$. The support provided for the individual hypotheses was less impressive. In hypothesis two they contended that as the result of deregulation, overall freight charges per mile traveled would fall. In Arizona prederegulation freight charges were 1.932 cents per mile traveled, while after deregulation they were 1.226 cents. This was a significant difference. In Florida, however, the prederegulation freight charges were 1.005 cents per mile traveled, while after deregulation they were 0.9983 cents. This difference was insignificant. Beilock and Freeman felt that hypothesis two was supported by the Arizona data. The failure of the Florida data to support the hypothesis, however, led them to report the model produced inconclusive results.

Hypothesis three tested the proposition that classbased rate differentials would be less in a deregulated 
environment. As expected, the data from both states showed there was a considerable regulatory period class differential. After deregulation there was a slight decrease in the size of these class differentials, but none of the changes were significant. Hypothesis three was, therefore, disproved in both states. Beilock and Freeman noted that, although this finding was contrary to expectations, it gave support to other studies. These studies contend that value-of-service pricing structures might exist, not because of collective ratemaking, but because there are unmeasured elements of service quality associated with cargo value (DeVany \& Saving, 1977; Salop \& Stiglitz, 1979).

This finding is also consistent with a previous study, which found strong evidence of value-of-service pricing in a never regulated, competitively structured, motor carrier market (Beilock, 1985). Beilock and Freeman also speculated that shippers of high valued commodities make a less extensive search for transportation alternatives; therefore, they operate with imperfect information.

The model also produced results which were contrary to hypothesis four. This hypothesis was based on the assumption that the regulated motor carrier rate structure contained a large shipment-small shipment cross subsidy. There is considerable debate in the literature on the subject of cross subidies. Some of the situations where this condition is thought to exist are high value-low value 
products, high class-low class products, urban-rural shipments, large shipper-small shipper, etc. It can be argued that in each of these different situations different price-cost margins might exist. However, when cross subsidy is measured as the percentage of traffic that is losing money and must be subidized by traffic which is making money, most motor carriers agree that cross subsidies exist (Hoover, 1985).

This rate bias for small shipments was thought to be necessary to protect small shippers from the power of the large specialized LTL motor carriers. Under deregulation Beilock and Freeman assumed that the small shipment subsidy would disappear and the rate differential between large and small shipments would increase. Contrary to expectations, it was found in both states after deregulation, the premium charged for small shipments actually decreased five to six percent. The authors pointed out that although their hypothesis was not supported, the results did support researchers who argued there were no economies of scale for motor carriers specializing in small shipments (Spady \& Friedlaender, 1978; Sugrue, Ledford \& Glaskowsky, 1982).

The test of hypothesis five also produced results that were contrary to expectations. Opponents of deregulation argued that service to small communities would decrease and rates would rise. Beilock and Freeman did not address the service issue, but they did examine the effect of deregulation on rates paid by rural shippers. It had been 
assumed that urban shippers had been charged higher rates to keep rates down for rural shippers. The study results show that before deregulation rural shippers in Arizona were paying a large rate premium, and after deregulation it was sharply reduced. Before deregulation in Florida, shippers in rural areas were paying less than shippers in urban areas. After deregulation, the rate differential continued to exist and the size of the differential was unchanged. One can only speculate on the cause of the urban-rural rate differential under both regulation and deregulation. In any case, the concern about deregulation increasing the motor carrier rates to rural areas was unfounded.

To test hypotheses one and six Beilock and Freeman used interstate freight rates as controls. They pointed out that interstate and intrastate freight rates were influenced by the same economic conditions but interstate rates were still subject to some regulation and collective ratemaking. Beilock and Freeman reported that their model produced inconclusive results on the effect of deregulation on motor carrier freight rates. In Arizona the model found the effect to be positive and significant. In Florida the model found the effect to be negative and insignificant.

Faced with these inconclusive results Beilock and Freeman developed ratios of intrastate to interstate rates. In Arizona, they found that the ratio of intrastate to interstate rates had declined during the study period. In Florida the ratio between these rates also declined. Based 
on the assumption that interstate rates were still regulated and collectively set, Beilock and Freeman cited these declining ratios as strong evidence in support of hypothesis one. Their conclusion was that under deregulation overall rate levels declined.

Beilock and Freeman also used ratios of intrastate rates to interstate rates to test hypothesis six. They reported that the size of the difference between rate changes in interstate and intrastate rates was less after deregulation in both states. In Arizona the frequency of rate changes had declined while in Florida, they had increased. Based on these findings, Beilock and Freeman concluded that hypothesis six was not supported in Arizona and that the results were inconclusive or mixed in Florida. They reported, however, that the fears that deregulation would lead to instability in the freight rate structure were not supported.

Conclusions. The studies by Blair et al. and Beilock and Freeman are extremely important initial steps in developing an understanding of the impact of motor carrier deregulation on freight rates. They are, however, limited. These studies measure the impact of deregulation on intrastate freight rates in only two states. They also produce results which appear inconsistent.

For example, Beilock and Freeman reported a postderegulation increase of 40.8 percent in the mean intrastate motor carrier freight rates in Arizona for class 
100 commodity shipments weighing under 1000 pounds. For Florida, they reported that the mean motor carrier freight rate for intrastate shipments of class 125 commodities weighing less than 500 pounds only increased by 12.5 percent.

Though there is some difference in the class of the commodities and the weight of the shipments, there is a significant difference in the rate of increase of freight rates. The results are even more puzzling, considering only four motor carriers in Florida were subjects while 19 subjects from Arizona were involved. Based on the reported results, it is possible to conclude that in an LTL motor carrier market, concentrated, unregulated motor carriers provide more rate control benefit to shippers than the rate control provided by many competitors. It would also appear there are economies of scale associated with the less-thantruckload motor carrier industry. This conclusion would be directly opposite that reached by researchers who studied the problem of concentration extensively, and reported there are no economies of scale associated with the LTL motor carrier industry (Spady \& Friedlaender, 1978; Friedlaender \& Spady, 1981; Sugrue, Ledford \& Glaskowsky, 1982).

Need for More Empirical Studies

More empirically based studies are needed to determine the impact of deregulation on motor carrier freight rates and pricing behavior if this research stream is to progress 
beyond the anecdotal stage. This point has been made repeatedly in the literature (Kriebel \& Baumel, 1979; Kriebel \& Baumel, 1983; Sargious \& Tam, 1985; Hoover, 1985; Beilock \& Freeman, 1987). It is unlikely that studies based on aggregated data will contribute anything new to the understanding of this problem. In the past, many researchers have been forced to use aggregated data because a suitable disaggregated public use database was not available. This has been identified repeatedly as one of the major factors hindering motor carrier rate and pricing behavior research (Morton, 1971; Samuelson \& Lerman, 1977; Boyer, 1978; Friedlaender \& Simpson, 1978; Casavant, 1979; Chiang, Roberts \& Ben-Akiva, 1981; Beilock \& Shonkwiler, 1982; Sargious \& Tam, 1985).

It is unlikely that traditional governmental information sources will be changed to provide the detailed data needed. The United States Census of Transportation is the best source of transportation data available; however, it is too aggregated in shipment origin, destination, and commodity coding to be used in developing a general model of motor carrier freight rates (Chiang, Roberts \& Ben-Akiva, 1981).

In the past two rate bureaus made disaggregated data available to selected researchers. These databases have been used to produce some very important prederegulation rate studies (Morton, 1971; Samuelson \& Lerman, 1977; Boyer, 1978; Bernstein \& Darjani, 1979). The Boyer study used a 
computer tape containing information from "several hundred thousand" individual motor carrier freight bills for 1972 . This tape was provided by the Rocky Mountain Freight Bureau. The Morton, Samuelson and Lerman, and Bernstein and Darjani studies used an individual shipment database for the year 1967, gathered from 29 regulated motor carriers belonging to the Middle Atlantic Rate Conference. This type of data has not been made available to study the deregulated motor carrier industry rate structure. If such a database were available, it would undoubtedly have attracted the attention of at least a few researchers interested in measuring empirically the impact of deregulation on motor carrier freight rates.

\section{Government Freight Transportation}

Transportation researchers may feel that they are hampered by the lack of a proper database, but there is just such a database available. This database contains detailed information on the thousands of Department of Defense (DOD) shipments made annually. Before deregulation, the rates charged to transport government freight were not considered to be typical of those charged to move comparable commercial traffic. Samuelson and Lerman (1977, p.390) specifically stated they removed the government waybills from their database. They justified this action by noting "government freight is subject to special government rates" and these 
rates "would probably not conform to a model of more ordinary regulated freight rates."

Before July 1, 1980 this attitude could be justified because government freight rates had always been set by negotiations while ordinary freight rates were set by motor carrier rate bureaus. The government agency had been free to accept or reject the rates tendered. The carrier had been free to withhold the offer of a rate tender. Today, every shipper can negotiate with the motor carriers; therefore, the distinction between the two types of shipments should be less pronounced. A study using disaggregated military freight shipment data is very likely to produce results which could be generalized, at least in some degree, to the commercial shipment of freight.

\section{History of Government Freight Transportation}

The federal government is the largest user of transportation services in the United States. In fiscal year 1983 it was reported that the DOD spent $\$ 2.58$ billion to transport freight, personal property, and passengers within the U.S. (Hillen, 1984). The transportation bill for freight alone was $\$ 526.3 \mathrm{million}$.

The federal government has always maintained a special relationship with the transportation industries. In the decade between 1850-1860, Congress approved the first of many land grants to the railroads. Each of these grants contained a provision in the enabling legislation which 
required the railroads to provide free transportation service to the federal government. By 1871 , the federal government had given the railroads more than 132 million acres of free land along the railroads rights-of-way. These grants or gifts of land were not absolutely free. They were justified on the grounds of being a prepayment for future transportation services (Jones, 1940).

In 1879, free transportation was interpreted by the courts to mean that the federal government should pay at least 50 percent of the commercial rates for traffic moved over the land grant portion of the railroads (Jones, 1940). In this decision the courts reasoned that the "free use" provision of the land grant legislation only applied to the use of a railroad's roadbed and permanent equipment. These two items accounted for only 50 percent of the total assets of the railroads.

\section{Section 22 Rates}

Section 22 of the Act to Regulate Commerce stated that railroads "may transport property of the U.S. Government, a State, or a municipal government without charge or at reduced rates." 3 section 22 was included to give legal

3. This statement was contained in section 22 of the original Act to Regulate Commerce (Also referred to as the Interstate Commerce Act) therefore special government rates are often called Section 22 rates. When the Interstate Commerce Act was revised and codified as Title 49 , Subtitle IV, U.S. Code in October of 1978 the relevant portions of section 22 were redesignated as Section 10721, Government Traffic. More specifically this wording can be found in 49 USC $10721(\mathrm{~b})(1)$. Many authors in the transportation literature use the terms interchangeably (Section 22 rates and section 
sanction to the existing agreements between the government and the land grant railroads that would have otherwise been inconsistent with Section 2 of the Act. Section 2 made it illegal for a railroad to charge one shipper more than another for like service under similar circumstances and conditions (Lieb, 1985). With the growth of government traffic, most non-land grant railroads agreed to charge the government the same net rates they received from the land grant lines. From 1898 to 1902 some 100 railroads entered into these rate equalization agreements and, from 1901 to 1946, these agreements were in force on most important railroads (Department of Defense, 1955).

When the Motor Carrier Act of 1935 was passed, section 217 (b) made the provisions of Section 22 of the Act to Regulate Commerce applicable to the regulated motor carrier industry. It is unclear from the legislative history of the Motor Carrier Act why this provision was included. One source speculated that it was most probably done to put motor carriers on an equal competitive footing with railroads (ICC, 1979). One could also argue that the motor carriers received free use of the highway system developed and maintained by government agencies; therefore, governmental agencies were entitled to reduced transportation rates.

10721 rates) which causes some confusion to the reader who is not familiar with the history of this segment of transportation literature. The term Section 22 rates will be used throughout the remainder of this paper in the interest of consistency. 
The importance of federal government traffic was rather minor until the mid-1930's, when several major economic recovery programs increased the government's use of the transportation system significantly. During 1938 and 1939, the steps taken to increase military preparedness also increased the amount of government material and personnel moved. By 1940 it became obvious that the obligation of the land-grant railroads to move government traffic at 50 percent of the normal rate was counter-productive. The railroads, partly because of this obligation, found themselves in greater financial difficulty. They were moving an increasing volume of government freight at rates that were often not compensatory. As indirect financial aid to the railroads, the Transportation Act of 1940 relieved the land-grant railroads of the obligation of transporting non-military government materials, mail, and personnel at reduced rates; however, the obligation to transport military related shipments at reduced rates remained in effect until October, 1946 (Locklin, 1966).

During World War II the motor carrier industry entered into a series of rate equalization agreements with the federal government.' They agreed to set their rates for military shipments at a level equal to the lowest rates charged by non-land grant railroads. These agreements also remained in effect until 1946. From this point onward each carrier was free to charge the government a rate based 
entirely on negotiations between the two parties (Lieb, 1981).

During the 35 years between 1946 and 1980 Congress repeatedly declined to repeal or modify the provisions of Sections 22. In 1955, the second Hoover Commission had recommended its repeal (ICC, 1979). In 1959, the Doyle report also recommended repeal (U.S. Congress, 1961). In 1972, the Department of Transportation joined the call of many others for repeal of Section 22 (Department of Transportation, 1972). Others supporting repeal were the motor carriers, some shippers, and the ICC itself (ICC, 1979). The ICC argued that section 22 rates were often noncompensatory. This resulted in an additional burden being imposed on commercial freight traffic.

Those favoring the retention of section 22 rates included many government agencies and the railroads (ICC, 1979). The DOD was particularly strong in its support of the retention of section 22. It pointed out that:

The location of many military installations does not coincide with commercial traffic patterns and this often precludes the use of commodity rates available to commercial shippers. Often the only legal rates available are based on unreasonably high classification ratings which, for the most part, are merely paper rates with little or no traffic moving under them (Department of Defense, 1955, p.3).

Supporters of Section 22 rates maintained that it provided large savings to the government directly and to the taxpayers indirectly. Section 22, supporters argued, 
allowed the government to make shipments under what were, in effect, commodity rates.

The only legislative action taken on section 22 rates occurred in 1957. Congress passed legislation requiring that all subsequent section 22 rate agreements be filed with the ICC. The only exception involved shipments affecting national security. This action was believed necessary because secrecy had surrounded many of the section 22 rates. Many carriers, because of the secrecy, lacked the knowledge to determine where they stood in the competition for government traffic (Cover \& Cutler, 1959). This legislation required that a file of government freight rate tenders be maintained in the Public Tariff Room of the ICC. This tariff file has been very active. Some 25,000 rate bureau and individual carrier tenders were on file at any one time. From the above discussion it is possible to conclude that under section 22 government freight rates have been set in a deregulated environment (Chagnon, 1980). The total repeal of the land-grant obligation in 1946 released rail carriers from the duty to transport government freight at rates that might not have been compensatory, and it is extremely doubtful that any carrier would be willing to continue to provide the government free or below cost transportation services. It is assumed, therefore, that carriers which transport government freight are paid at a rate the carrier chooses to accept. The carriers have the option of not transporting government freight if they think 
the rates are non-compensatory (Hillen, 1984). It is clear that government traffic pricing was to be decided largely by market forces (Lucas, 1979).

The Comptroller General reported that the government would have to pay significantly more to ship its goods if Section 22 rates had not been available (Chagnon, 1980). The same report stated that section 22 rates more than covered the cost to the carriers involved.

The transportation of government freight is undeniably an attractive proposition for motor carriers even if the rates are set by negotiations. The average rates paid per hundred-weight to transport DOD freight are significantly higher than the rates paid to transport civilian traffic (Chagnon, 1980). In 1978, roughly 1500 motor carriers had ICC approved route authority, and also had approved tenders on file for the transportation of government freight (ICC, 1978). In 1984, this number had increased to 3881 (Hillen, 1984). This 160 percent increase in the number of carriers is undeniable proof that the rates negotiated by the DOD are compensatory.

DOD Freight Shipments versus Commercial Freight Shipments

A freight rate model developed using government shipment data between 1946 and 1980 would produce significantly different results than a model for nongovernment regulated shipments. If the government were involved in the transportation of exempt commodities, the 
freight rates paid by the government and the exempt shipper would be similar. The government is not, however, a shipper of exempt commodities; rather, it is a shipper of processed or finished goods.

The profile of products shipped by government agencies more closely resembles the profile of those which, before 1980, were subject to rate regulation. Some products shipped by an agency like the DOD are unique; however, most products shipped are the same as those shipped in regular commerce. If, before 1980 , there was a significant difference between the transportation charges paid by the DOD and a commercial shipper to transport the same products, it is logical to assume that some of the difference was due to regulation.

A database does not exist which would enable a researcher to examine the relationship between freight rates for identical unregúlated government shipments and regulated commercial shipments. It would be possible, however, to compare a generalized government freight rate model to prederegulatory commercial rate models. Any differences in rates could be attributed to regulation in the civil transportation sector. The government freight rate model could be compared to the prederegulation models developed by Samuelson and Lerman (1977), Bernstein and Darjani (1979), Morton (1971), Boyer (1978), or Ferguson and Glorfeld (1981). This comparison could, depending on the findings, add support to either side of the argument that has raged 
for years concerning costs (or lack of cost) of regulation in the transportation industry. It would also give us additional empirical evidence about the impact of deregulation on the transportation rate structure.

If the comparison of postderegulatory military and commercial rate models produces similar results, an entire new field of transportation rate research will be opened. One of the major limitations of transportation pricing research, the lack of a large disaggregated database, will have been overcome. If, on the other hand, the results produced by the military shipment rate model are significantly different from those produced by a commercial shipment rate model, then an additional field of transportation research is opened. The research question becomes: "Why are rates for similar products shipped under similar circumstances different?"

\section{A Disaggregated Military Traffic Database}

The Military Traffic Management Command (MTMC) is a unified command with headquarters located in Falls Church, Virginia. It acts as a single transportation manager for all of the uniformed services as well as the Defense Logistics Agency. The MTMC also acts as the depository for data extracted from every DOD domestic government bill of lading. It is estimated that 85 percent of all DOD domestic traffic moves under a government bill of lading or under a converted commercial bill of lading (Chagnon, 1980). In 
1979, MTMC processed and stored in a public use database, the information contained in 1.2 million bills of lading for domestic military freight movements (Fisher, 1980). By 1984 the number of bills processed and stored had increased to 1.4 million annually.

For 75 percent of these bills of lading, the transportation charges were less than $\$ 200$. These small shipments, however, represented only 25 percent of the transportation dollars paid out by the DOD. There is no breakdown on the percentage of these small shipments moved under section 22, commodity, or class rates. It is known, however, that 81 percent of the carload and truckload tonnage moves under section 22 rates. An additional 13 percent of the carload and truckload tonnage moves under commodity rates (Chagnon, 1980).

The MTMC database captures most of the information on a large percentage of DOD shipments, and at least in the full load transportation segment, section 22 rates are extremely important. If Section 22 rates and commodity rates, often described as wholesale rates, are considered together, it becomes obvious that only a small portion of DOD full load traffic moves at regular commercial rates. From the above discussion, it is clear most DOD freight traffic moves under a negotiated rate: 


\section{The Freight Information System}

The government bill of lading information is entered into a Freight Information System (FINS) at MTMC. FINS is an automated management information system used by MTMC and other DOD agencies to generate reports, to study transportation rates, and to support rate negotiations. 4 The information entered in the FINS database is gathered from the services and the Defense Logistics Agency finance centers. The finance centers were selected as data collection points because all government bills of lading are submitted to them for payment. The bill of lading is the only document that contains the freight data of interest. The finance centers submit information on each shipment's origin, destination, government bill of lading organization office code, and the Uniform Freight Classification or the National Motor Freight Classification of the product being shipped. Data are also submitted on any type of special equipment used, the pick-up carrier, the delivering carrier, and the weight of the shipment. In addition, information is included on the actual charges paid, the shipment pickup date, the delivery date, the government bill of lading number, and the voucher number used to make payment. From the above discussion, it can be

4.Anyone with a need for traffic management data can request information from the FINS database. All requests originating outside of the Department of Defense, however, must be submitted in writing to the Commander, MTMC, Attn: MT-INFQ, 5611 Colombia Pike, Falls Church, Virginia, 220415050. The telephone number to call for further information is (202) $-756-1173$. 
seen that the FINS database would be extremely useful to transportation research if the information it contains also represents commercial shipments. This database would overcome many of the limitations of transportation rate research imposed by the aggregated data which is now available to transportation researchers.

\section{Motor Carrier Rate Modeling}

Someone unfamiliar with transportation pricing would quickly realize that, of all the factors which have been used to study pricing, none are more important than distance traveled and weight. These two primary rate determinants appear in almost all transportation pricing studies. This has been as true in pricing studies done when the transportation industry was highly regulated or largely unregulated as it is today. There is universal agreement that weight and distance would have to be included in any research which tried to develop a descriptive or explanatory transportation pricing model, but beyond these two variables, there is a lack of consensus as to which others to include. This lack of consensus concerning which of the many additional variables to include in transportation pricing behavior studies is one of the major weaknesses of transportation pricing research. 
Distance, Weight and Cost Relationships

The probable reason that weight and distance have endured as variables in transportation pricing studies is that they are both directly related to cost. A regulated or unregulated industry must recover its costs if the industry is to survive. Distance of the shipment is an especially important pricing factor in the motor carrier industry.

About 90 percent of a motor carrier's costs are variable in nature. If the owner of a truck chooses to let it sit idle, his expenses drop immediately to near zero. on the other hand, if the motor carrier chooses to expand services, the distance traveled will increase. Expenses for fuel and operating supplies will increase almost directly in relation to the increase in services. Distance is also directly related to time; the greater the amount of time involved, the higher the amount of driver wages. Fuel and labor costs have often been identified as the primary costs of the motor carrier industry, and they are both variable costs. If motor carrier costs increase in relation to distance, it is logical to assume that the greater the shipment distance, the greater the price for the transportation service involved.

The weight of the shipment and its relationship to the costs incurred by motor carriers is not as clearly defined as the relationship between distance and costs (Hall, 1985). Some motor carriers, especially those moving freight under contract, might charge a certain price per mile regardless 
of the shipment weight. These contract movements usually use the entire capacity of the vehicle, so the weight of the shipment is unimportant. If a shipment is less than a truckload and moves by common rather than contract carrier, the weight of the shipment becomes very important in determining the charge for the shipment. Less-thantruckload and minimum charge shipments usually share the vehicle with other shipments. The portion of the total vehicle capacity used by an LTL shipment can usually be estimated, directly or indirectly, by the weight of the shipment.

Without other factors, the weight of an LTL shipment and the distance involved could be used to determine the portion of the vehicle total costs each shipment would pay. However, as important as weight and distance are in determining the charges levied by motor carriers, there is a sizable amount of variation in their pricing behavior beyond that which is explained by these two factors alone. Morton (1971) found for shipments of equal weight and length of haul, one-third paid a rate which was more than 30 percent above or below the mean rate.

\section{Motor Carrier Rate Models}

Many motor carrier rate models have tried to replicate the actual motor carrier rate structure. This type of research has also been undertaken to identify factors which might help explain motor carrier pricing behavior. Beyond 
the almost universal use of shipment weight and distance, there is very little agreement about what other variables to include to increase the explanatory power of the models. Additional variables such as product value (Samuelson \& Lerman, 1977; Beilock \& Shonkwiler, 1982; Sargious \& Tam, 1985), cube of the shipment (Ferguson \& Glorfeld, 1981), product density (Samuelson \& Lerman, 1977), fuel cost (Beilock \& Shonkwiler, 1982; Blair, Kasserman \& McClave, 1986), direction of shipment (Sargious \& Tam, 1985), shipment origin and destination (Blair, Kasserman \& McClave, 1986; Beilock \& Freeman, 1987), and product class (Blair, Kasserman \& McClave, 1986; Beilock \& Freeman, 1987), among others, have been used to develop more complex rate models than those that only use weight and distance as variables. This lack of consistency in the choice of what could be called independent variables has led to gaps in our understanding of motor carrier pricing behavior. If the same variables had been used in every model, our understanding of motor carrier pricing behavior would be more complete. Differences between studies could be attributed to situations rather than to the variables chosen for the models.

There has also been considerable variation in the form the dependent variable has taken in the various motor carrier rate model studies. Ferguson and Glorfeld (1981) and Beilock and Shonkwiler (1982) used the total charge paid by the shipper, while McMullen and Schary (1986) and Morton 
(1971) used average revenue per ton-mile. Fuller, Makus and Lamkin (1983) used the linear form of cents per ton-mile while Blair, Kasserman and McClave (1986) used the logarithmic form of this variable. Sargious and Tam (1985) and Samuelson and Lerman (1977) used the logarithmic form of cents per kilogram and cents per hundred-weight respectively. Beilock and Freeman (1986) used the linear form of cents per hundred-weight as the dependent variable. This inconsistency in the choice of dependent variables, like the inconsistency in the choice of independent variables, has made it difficult to assimilate the various study findings into a stream of research leading to a general theory of motor carrier pricing behavior.

Problems Caused by Inconsistent Variable selection

The choice of independent and dependent variables by researchers involved in the study of transportation pricing behavior has undoubtedly been influenced by the objectives of these studies. The choice of variables has also been influenced by data availability. It is extremely difficult to get transportation data from individual firms because they usually treat it as proprietary information. Data from most government sources has been aggregated to the degree that significant differences between situations are hidden within the data. Difficulty in getting appropriate data forces researchers to design their models to fit the data rather than using data to test a model. 
The lack of standardization in variable selection makes it extremely hard to transform individual study findings into a general theory of transportation pricing behavior. For example, it is not known with a high degree of certainty what factors, other than weight and distance, underlie the motor carrier rate structure. Only two postderegulation motor carrier rate studies based on disaggregated data have been reported in the literature to date and the variables, both independent and dependent, vary between the studies.

\section{Deregulation and Motor Carrier Rates}

The construction of motor carrier freight rate models and the measurement of the significance of the factors which underlie these models has become more difficult to accomplish. Deregulation of the motor carrier industry has fragmented the pricing process. While the motor carrier industry was regulated, pricing was centralized. The various rate bureaus assigned rates to particular transportation moves for certain classes of products. The rate bureaus did not have to reveal the specific factors they considered in assigning a rate to a product, but if a shipper disagreed with the rate assigned, the rate could be challenged. The rate bureau would have to defend its decision at a public hearing before a regulatory body, and the factors underlying the pricing decision would become public knowledge. 
Under deregulation centralized pricing has diminished and more often the pricing decisions are made by individual motor carriers. The rate bureaus continue to function, but individual motor carriers can and frequently do choose not to accept the rate set by the rate bureau. In this case pricing becomes an individual motor carrier function, and the factors underlying these pricing decisions become even more obscure.

Under regulation motor carrier freight rates were stable. Common carriers collectively fixed rates through rate bureaus and federal regulators limited competition by restricting industry entry. This meant that the collectively set rates dominated motor carrier pricing. A shipper, if he knew his product's class rating, could determine exactly how much it would cost to move a product weighing a certain amount between two geographic points. The shipper had no concern about the factors used by rate bureaus to set the rate or the factors used by the classification committee when assigning a product to a particular class. Everyone shipping exactly the same product paid exactly the same rate to transport that product between the two same points. With deregulation, however, uncertainty prevails about what factors are considered when freight rates are set. Almost all transportation researchers feel that deregulated motor carrier will set rates that are more closely associated with their costs. 
The uncertainty about rates is, therefore, directly associated with an uncertainty about motor carrier costs. 


\section{CHAPTER V}

\section{METHODOLOGY}

\section{Research Hypotheses}

In studies of the regulated motor carrier industry, two factors accounted for more than 50 percent of the variation in motor carrier rates. These factors are the distance a shipment travels and its weight. In the current deregulated motor carrier industry environment, it is thought that a myriad of other factors have become increasingly important as determinants of motor carrier pricing behavior. These factors reflect, among others, the motor carrier's orientation to service, geographic positioning, sensitivity to competition, and opportunities for sharing cost between shipments. This chapter addresses the methodological foundation for a study to examine these competitive environmental issues.

In addition to weight and distance, variation in the price charged by deregulated motor carriers is thought to be related to the attributes of the product, geographic factors, motor carrier-specific factors, and service factors. Four research propositions associated with product attributes, two with geographic factors, two with carrierspecific attributes, and one with service levels provided by 
the carrier are formulated and discussed. The database containing the primary information for analysis is described, the measures employed are discussed, and the empirical tests for statistical significance are specified.

\section{Product Attributes}

When interstate motor carriers operated under the regulatory control of the ICC, product attributes were of little concern to the individual shipper or motor carrier. Organizations such as the National Freight Classification Committee, regional rate bureaus, and the ICC considered product attributes when classifying products, establishing specific rates, or during classification and rate appeals. The shipper and motor carrier were more concerned with the class to which a product was assigned, and not the product attributes used to determine the class.

Product class has frequently been used as a predictor variable in both pre-deregulation and post-deregulation motor carrier pricing studies. Product class is, however, a composite or gross measure of all product attributes considered in assigning a product to a class. If one could determine the product attributes used by the classification agencies, it would be better to use those attributes as predictor variables rather than product class. Unfortunately, no data exists which specifically identifies the product attributes considered by classification bodies in product classification cases. Some of the product 
classification attributes in individual shipment situations can, however, be determined. Using these attributes as predictor variables in motor carrier pricing studies should produce more sensitive motor carrier rate models. These models could lead, in turn, to a deeper understanding of motor carrier pricing behavior.

When products are assigned to classes, a ranking system among the groups of products is established. This ranking system has, at the minimum, the properties of an ordinal scale. For example, a product placed in Class 75 would always pay less per ton-mile than a comparable shipment of a product placed in Class 100 . This rate differential would be for basically the same transportation services performed under similar circumstances. Although there are variations in the difference paid between product classes, a Class 75 product does not always pay three-quarters of what a Class 100 product pays. This characteristic of product class numbers keeps the class values assigned to individual products from being ratio scaled data.

The relationships discussed above lead to two transportation pricing research questions: First, how much of the variation in pricing behavior of a diverse group of motor carriers can be explained by the class of the product being shipped? Second, how much of this product class variation can be explained by individual product attributes used to assign a product to a specific class? The measures and tests used to operationalize the above research 
questions are discussed fully in a later section of this dissertation, but the basic research questions, as contained in the following hypotheses, are stated in the alternative forms :

Hypothesis 1. As the class of a product increases, the rate per ton-mile charged by the motor carrier increases.

Product class had a significant impact on the pricing behavior of the motor carriers in a regulated environment. Product class is also thought to have a major impact on the pricing behavior of motor carriers in the present unregulated environment. The probable reason for the product class/price relationship is that individual, unregulated motor carriers have not developed the expertise necessary to set prices on their own. If the null hypothesis is accepted, it supports the argument that product class is no longer considered when motor carrier rates are established.

Hypothesis 2. As the density of the product deviates from the ideal product density, the rate per ton-mile charged by the motor carrier increases.

The variation from the ideal density will have a direct relationship to the rate charged. The probable reason for this relationship is that the shipment of non-ideal density products led to the under-utilization of vehicle capacity. Vehicles used in the motor carrier industry to transport 
shipments have two capacity constraints, weight and volume. Every transportation vehicle has characteristics which make products with a certain density ideal for that particular vehicle. The trailer can only load a certain weight or volume before it reaches one of the two capacity constraints. Ideally, a shipment or combination of shipments should reach both vehicle constraints at the exact same time during the loading process. Under utilization of the vehicle capacity, either weight or volume, leads to higher costs, hence higher prices.

The density of a product, expressed as product weight per cubic foot, is one of the attributes used to assign a product to a class. Product density, therefore, can be thought of as a finer measure of a specific product attribute than that provided by the product class designation alone. If the null hypothesis is accepted it will indicate that product density is no longer a valid motor carrier pricing variable.

Hypothesis 3 . As the dollar value per ton of the product increases, the rate per ton-mile charged by the motor carrier increases.

The probable reason for this relationship is that a product with a high value increases the risk motor carriers incur when the product is accepted for shipment. Without a specific agreement indicating otherwise, the motor carrier, under common law, is responsible for damage that occurs 
during a shipment. For this reason the transportation rate paid for higher valued products prices will be higher then the rates paid for products of lower value. Like density, the value of a product is a product attribute used to assign a class rating to a particular product. Also like product density, product value is a more refined pricing variable then product class.

If the alternative hypothesis is accepted, it could be considered as support for the argument that motor carriers practice value-of-service pricing. If the null hypothesis is accepted, it will support the argument that greater perceived risks are no longer associated with the movement of high value products.

Hypothesis 4. As the need for special handling of a product increases, the rate per ton-mile charged by the motor carrier increases.

The probable reason for this relationship is that it is more expensive for the motor carrier to provide special handling services. The need for special handling is one of the factors considered in assigning a class rating to a product. Therefore, it would be more appropriate to use this product attribute as a predictor variable in a motor carrier pricing study than to use product class. If the null hypothesis is accepted, it is likely that special handling is no longer a factor to be considered in motor carrier pricing. 
Geographic Factors

If freight shipment origins are studied, differences in motor carrier pricing behavior might be discovered which are not accounted for by the distance and weight involved, or the product transported. A shipment origination point is associated with a specific city, state, and region. Each of these individual shipment locations is, in turn, associated with a certain population size, level of economic activity, and many other geographic factors. Hundreds of differences in individual motor carrier pricing behavior can logically be associated with geographic factors. It is unlikely, however, that a suitable database can be identified which would allow the study of each of these differences individually. It is possible, however, to identify instances where regional differences exist and to measure the extent of the differences in terms of motor carrier pricing behavior. It is also possible to measure the extent of the differences in motor carrier pricing behavior associated with shipment origin population density. The following hypotheses, based on shipment geographic factors, will be tested:

Hypothesis $\underline{5}$. As the region of product shipment origin varies, the rate per ton-mile charged by motor carriers will vary

One reason for regional motor carrier pricing differences is that the levels of economic activity within 
each of the regions is different. Economic activity in some regions might be depressed while in others it might be robust. Some regions might export raw materials and import manufactured and consumer goods while other regions might import raw materials and export manufactured and consumer goods. This type of economic activity imbalance leads to an imbalance in freight value and tonnage between regions. This in turn leads to less than optimum usage of the motor carrier capability between the regions.

There could any number of reasons for regional differences in motor carrier pricing behavior other than an imbalance in economic activity. The intent of this hypothesis is, however, to determine whether differences exist between regions, not to determine which specific geographic descriptors underlie these differences. Distance from the origin to the destination is a geographic factor and would clearly affect the total transportation charges paid for a shipment. The use of rate per ton-mile as the independent variable, however, offsets the difficulties encountered because of regional distance differences. If the null hypothesis is accepted, it will support the view that geographical aspects of the shipment do not affect motor carrier pricing behavior.

Hypothesis 6. As the size of the origin city increases, the rate per ton-mile charged by the motor carrier decreases. 
The most probable reason for this inverse relationship is that different city sizes affect the opportunity for the motor carrier to combine partial loads. This practice allows the spreading of fixed costs associated with vehicle operation over several shipments. Combining shipments is also practiced because the operational costs of motor carriers do not increase at a linear rate. It is reasonable to assume that the larger the origin city, the greater the opportunity for the motor carrier to combine shipments. Many have argued that under regulation, the rates charged per ton-mile for shipments to or from metropolitan areas subsidized shipments made to or from small towns and rural areas.

If the null hypothesis is accepted, it will support the argument that a large city and small city cross-subsidy does not presently exist. It would also support the contention of some researchers that it did not exist under regulation.

\section{Carrier Attributes}

Before deregulation, the number of firms operating in the industry declined steadily and the size of the firms increased. The period following deregulation of the motor carrier industry has been characterized by bankruptcies and mergers. The total number of motor carriers in the industry has, however, increased significantly. Most of these new firms entering the industry would be classified as small when the number of vehicles operated and the areas served 
are examined. The size of the firm becomes an important research variable if it affects the pricing behavior of the deregulated motor carrier.

Under regulation, a very small carrier with limited operating rights charged the same price per ton-mile for its service as that charged by a large carrier with nationwide operating rights. If there were economies of scale present in the regulated motor carrier industry, they were obscured by collective ratemaking. Under deregulation, it is possible to examine the issue of the relationship between motor carrier size and motor carrier pricing behavior. Size can be defined many ways, but to determine whether it has an impact on motor carrier pricing behavior, variables involving interline shipments and motor carrier sales are used.

Hypothesis 7. If multiple carriers are involved in a shipment, the rate per ton-mile charged will be higher than the rate per ton-mile charged by a single carrier.

If the shipment involves more than one motor carrier, it is known as an interline shipment. It is assumed in this hypothesis that the total freight charges per ton-mile for an interline shipment will be greater than the freight charges per ton-mile for a single carrier. The probable reason for this relationship is that the handling and administrative expenses for two motor carriers would be greater than those of a single motor carrier. These greater 
expenses would have to be reflected in the pricing behavior of motor carriers involved in interline shipments. If the null hypothesis is accepted it supports the argument that interline costs do not affect motor carrier pricing behavior.

Hypothesis 8 . As the size of the individual motor carrier increases, the rate per ton-mile charged for transportation services decreases.

The probable reason for this relationship is that economies of scale are involved in the motor carrier industry, as they are in many other industries. Larger motor carriers enjoy economies of scale while the smaller motor carriers do not. If the null hypothesis is accepted it will support the many transportation scholars who argue that economies of scale are not reflected in motor carrier industry pricing.

\section{Service Factors}

In a regulated motor carrier environment most of the pricing activities, as well as other competitive actions a motor carrier might engage in, were controlled centrally. This power to control pricing was invested in a regulatory body or a trade association. Regulated motor carriers could only compete in the area of service. If a motor carrier offered superior service, it was rarely allowed to recoup the additional costs incurred. The motor carrier might 
attract more traffic by offering better service but the increased cost per shipment of providing the better service might offset any revenue gains made. Under these conditions it can be argued that there was no incentive for a regulated motor carrier to offer customers superior service. The question of interest is to determine whether the unregulated motor carriers continue to provide superior service at no charge. Alternatively, do they now set their rate per tonmile at a higher level to recover the extra costs associated with providing superior service?

Hypothesis 9. As the level of customer service increases, the rate per ton-mile charged by the motor carrier increases.

The most probable reason for this relationship is that the costs involved in providing superior service are greater than the costs of providing a lesser level of service and are reflected in the price charged. If the null hypothesis is accepted, it will support the argument that the service provided by the motor carrier has no influence on the pricing behavior.

\section{Research Database}

An ideal database for the study of motor carrier industry, in either a regulated or deregulated environment, would be one that utilized the individual shipment as its basic unit of observation. Transportation researchers, 
without exception, would agree that such a database could advance the level of transportation research. The same transportation researchers might disagree, however, on exactly what information should be included in each database record. The desired database record content would be influenced by each individual researcher's objectives. Generally, each record or observation in the database should give the researcher information on the product shipped, the weight of the shipment, and the distance the shipment travels. The database should contain information on the shipment origin and destination, the individual motor carrier involved, and the service level. The database should cover a wide variety of products, origins, destinations, shippers, and carriers.

No known database meets the needs of all transportation researchers. There is, however, an under-utilized public use database that would be useful in advancing most areas of transportation research in today's deregulated transportation environment. This public use database, supplemented by other public use information, will be used to test the hypotheses described previously.

\section{Database Selection Criteria}

The basic data for this study comes from a database maintained by the MTMC located at Falls Church, Virginia. The active portion of the database contains information on approximately six million individual military shipments 
which have taken place during the preceding five years. The portion of the database selected for this research contains information on 15,059 motor carrier shipments to Tinker Air Force Base (TAFB), located just outside Oklahoma City, Oklahoma. The selected shipments were made during the one year period between July 1, 1983 and June 31, 1984 .

The period covered by this database was selected after careful consideration. It was desirable to have a database that was stable over time, with regard to pricing strategy, because the study covers a one year period. The period selected was judged to offer more stability than those preceding and following it. The double digit inflation rates, which characterized the late 1970's and the early 1980's had moderated. The country was emerging from the recession of the early 1980's, and increases in defense spending had declined from the high levels attained during the first years of the Reagan Administration. The study period was also chosen because it represented the first full year of motor carrier pricing freedom under the provisions of the Motor Carrier Act of 1980. It is also the first full year in which the ICC cost-based, freight classification criteria were in effect. The period immediately following the selected study period was characterized by extensive turbulence in the motor carrier industry with many well established firms failing.

This period was also selected because it is similar to the last year of the Blair, Kasserman and McClave (1986) and 
the Beilock and Freeman (1987) motor carrier pricing studies. These studies were discussed in detail in Chapter IV. As noted, they are the definitive studies of postderegulation motor carrier pricing behavior. It is possible that the validity of the two studies and the current research effort can be cross-checked because they cover the same time period.

It might be argued that the pricing decision process captured in the database under consideration would be different than that process captured in the data studied by Blair, Kasserman and McClave and Beilock and Freeman, since it involves military shipments. Prior to deregulation, this might have been true. However, following the passage of the Motor Carrier Act of 1980, both military and nonmilitary transportation rates have been set though negotiation. For this reason the decision processes involved in setting prices are thought to be similar.

Any of the thousands of military installations in the country or any combination of them could have been selected for study. However, the specific shipment destination, TAFB, was selected because of its location in the central part of the United States. A single destination was judged to be necessary to control for service differences between destinations. TAFB was also selected because of the economic implications this study might have for firms located in the Oklahoma City area. The Air Logistics Center at TAFB is the largest employer in the central oklahoma 
area. It spends millions of dollars each year for a diverse mixture of goods and services. As one of the six Air Logistics Centers in the country, what TAFB purchases and from whom it purchases has a significant impact on the local economy. A much larger sample of randomly selected shipments with multiple destinations could have been chosen for this study. However, the funding and manpower required to conduct a national study was not available.

\section{Database Content}

The database contains individual shipment information on the city and state of origin, the product involved, and the type of vehicle used. In addition, the identity of the motor carrier making the shipment pickup and delivery to TAFB is specified. The database also contains information on the actual weight of the shipment, charges paid, shipment pick-up date, and shipment delivery date. The original 15,059 records in the database contained numerous records in which one or more data elements were missing. The database also contained records which were judged to be beyond the scope of this study. All incomplete records were removed from the database. All records of shipments delivered by Federal Express, United Parcel Service, and freight forwarders were also removed. Shipments delivered by the latter three carriers involved very small weights. It is assumed, therefore, that the pricing behavior of these 
carriers would differ significantly from the behavior of conventional motor carriers.

Using the above described decision rules, the original records in the database were reduced to 5745. An additional 83 records were judged to contain incorrectly recorded information and were removed from the database. These records were identified through outlier analysis. The revised database contained a total of 5662 usable shipment records.

Supplemental Database Information

The information contained in the 5662 usable shipment records was supplemented by data from the Rand McNally Commercial Atlas, ${ }^{1}$ the Disaggregated File of Commodity Attributes (DFCA) developed by the Massachusetts Institute of Technology's Center for Transportation Studies, 2 and the National Motor Freight Classification Manual (NMFCM) developed by the American Trucking Associations. 3

1.The Rand McNally \& Company offices are located in Chicago, Illinois, 60680. The company publishes, on a regular basis, the Rand McNally Commercial Atlas which is available in most university and larger public libraries.

2.A Disaggregate File of Commodity Attributes was prepared for the United States Department of Transportation, office of the Secretary of Transportation under contract DOT-OS70006. The preparing organization was the Massachusetts Institute of Technology (MIT), Center for Transportation Studies. The MIT report number is CTS 79-12, dated August, 1979. The author is William $\mathrm{S}$. Kuttner. The report is based on previous work done in this area by Professors Ralph D. Samuelson and Paul O. Roberts also of MIT. 3. The National Motor Freight Classification Manual (ICC NMF 100-N), is issued on an as needed basis by the National Motor Freight Traffic Association, Inc., 2200 Mill Road, Alexandria, VA 22314. This organization acts as an agent for the American Trucking Associations, Inc. The edition 
Each product commonly involved in commerce in the United States has an assigned code number. An attempt was made to locate the product code for individual shipments in the NMFCM. When a shipment product code was located in the NMFCM, the LTL class number, TL class number, and weight break points between LTL and TL shipments were extracted. This information was added to the basic TAFB shipment information obtained from the MTMC. Using this search strategy the LTL class numbers, TL class numbers and the weight break points were determined for 2474 of the records in the database. Of the remaining 2988 database records, 2944 of them had a product code listed as 999912.0. This product code indicated that they were freight-of-all-kinds (FAK) shipments. The specific LTL class numbers, TL class numbers, and weight break points could not be determined for these shipments. An FAK shipment is one in which two or more products are mixed. With this mixing, it is not possible to identify a single product code for the shipment. The product code for 44 of the records in the MTMC database could not be matched with those listed in the NMFCM. The lack of total correspondence between the product codes in the MTMC database and those in the NMFCM could be due to product code entry errors. Thirty-one of the 44 individual shipments with unmatched product codes involved only one shipment. This strongly supports the assumption

used to develop information for this database was issued April 3, 1987. 
that unmatched product codes in the MTMC database were due to initial data entry errors.

The Rand McNally Commercial Atlas was used to gather information necessary to make two data inputs into the database. First, it was used to determine the distance from the point of shipment origin to Oklahoma City. Individual shipments originated in 46 of the 48 contiguous states and from 479 different points, mostly cities, within those states.

In determining individual shipment mileage, the Rand McNally United States Mileage Chart was used when possible. This chart, however, only gives the interstate highway mileage information between major cities. For this reason it could not be used in every case. When a particular shipment origin point was not located on the mileage chart, that point was identified on the Rand McNally state map. If the shipment origin point was located on the interstate highway system, the most direct interstate highway distance between the origin point and Oklahoma City was computed. If the origin point was not located on the interstate highway system, the most logical route to the interstate system was determined with no backtracking allowed. The direction of travel to intercept the interstate system had to be in the same general direction the shipment would travel en route to Oklahoma City. The shipment distance was computed by adding the distance to interstate intercept and the most direct 
interstate route distance from the point of intercept to Oklahoma City.

The second data element extracted from the Rand McNally Commercial Atlas was information on population size of the shipment origin point area. This information was added to the database to examine the impact of the size of the origin point on freight rates. The distance from origin to destination and the size of the origin point were determined for all of the 479 unique origin points in the database.

The DFCA was used to determine, where possible, the weight of the product in pounds per cubic foot and its value per pound. The DFCA uses the Standard Transport Commodity Code (STCC) for its primary product identifier and the National Motor Freight Classification Code (NMFC) as a secondary product identifier.

The DFCA is not a complete file containing information on all possible products, but rather a limited one containing information on the most commonly shipped products. The file contains data on only 1,200 of the more than 15,000 products identified in the STCC. For this reason, the product density and product value information on all shipments in the database could not be determined. It was possible, however, to determine the product value and product density information for approximately 1,200 of the individual shipments contained in the database. 
Measures

Nine different measures used to test the nine hypotheses previously discussed were taken either directly from the database or derived from information in the database. The development of these measures is discussed in detail in the following pages.

\section{Commodity Attribute Measures}

The NMFCM assigns all products to one of 23 classes ranging in value from class 35 to class 500. These class numbers represent a relationship between the 23 classes of freight with class 100 serving as the base class. The rate for products in freight class 35, for example, would be approximately 35 percent of the rate for products in freight class 100. The rate for products in freight class 200 would be approximately twice those of products in freight class 100 .

In assigning an individual product to a freight class, numerous factors are considered. Therefore, an individual product's classification number, used extensively to determine line haul rates for LTL and TL shipments, is a gross measure of a product's attributes rather than a specific measure. Before 1983, a product was assigned to a classification using both cost and demand oriented attributes associated with the product. From 1983 onward only cost oriented commodity attributes were considered. These attributes included the density of the product, its 
stowability, its handling characteristics, and the liability incurred by the motor carrier in accepting the product for shipment. The demand oriented commodity attributes, no longer considered in product classification actions, were trade conditions, value of the service, and commodity competition. A complete listing of these attributes appear in Table 1.

TABLE 1

PRODUCT CLASSIFICATION CRITERIA

Product Attribute

Cost-Oriented

1. Density

2. Stowability

3. Handling

a. Excessive length and width

b. Excessive weight

c. Special care

4. Liability

a. Value per pound

b. Susceptibility to damage

c. Susceptibility to damage other freight

d. Susceptibility to theft

e. Susceptibility to explosion of combustion

f. Perishability

Demand-Oriented

5. Trade conditions ${ }^{a}$

6. Value of the Servicea

7. Commodity competition ${ }^{a}$

a Indicates product attributes removed from the commodity classification process in 1983 by the ICC. 
If exact measures of all currently used commodity attributes could be obtained, it would be highly desirable to use them as independent variables in this study. Although product class captures the cost attributes as a group, it is not possible to determine their impact individually on motor carrier pricing behavior. It has been possible to determine exact measures for value of the product and density of the product, two of the eleven commodity cost attributes, for a significant number of individual shipments in the database. By matching shipment NMFC codes with NMFC codes contained in the Commodity Attribute File, it was possible to determine the product value per pound and density per cubic foot. In situations where these exact measures are available, it is possible to explore more precisely deregulated motor carrier pricing behavior. Product value and density information was developed for approximately 1200 of the 5662 individual shipment observations contained in the database. This represents about 21 percent of the total usable database.

For each of the 1200 identified shipments, product value is measured as dollars and cents per product pound. Product density was measured by the weight of the product per cubic foot of space occupied.

If a motor carrier must furnish special equipment for a particular shipment, it follows logically that this requirement would have an impact on the rate charged. For LTL shipments, the motor carrier would have less opportunity 
to enhance his total revenue by combining shipments to utilize the capacity of the vehicle. Only certain commodities, for example, are suitable for transportation on a flat-bed trailer, unprotected from the elements and the possibility of theft. If a shipment does not utilize the capacity of a flat-bed trailer, the motor carrier is limited in its choice of other shipments to complete the load.

There is also the probability that specialized equipment, used for either LTL or TL shipments, would be delayed at the destination point for an extended period awaiting suitable traffic for the backhaul. Data within the database are available to determine if a specific shipment required the use of specialized equipment. This data was transformed into a $0-1$ variable. The value 0 represents shipments made in ordinary closed vans which are suitable for the movement of most freight. The value 1 represents shipments made with special equipment.

\section{Geographic Measures}

Each shipment in the database was assigned a numeric code which identified the region, state, and city of shipment origin. The states were assigned to regions and given a code number to reflect their region of assignment. These regional code numbers ranged from one to nine. The states assigned to each region are listed in Table 2.

The regional classification scheme for this study conforms exactly to that used by the ICC to assign motor 
carriers to regions. This regional classification scheme will be used to determine the impact of region of origin on motor carrier pricing behavior.

TABLE 2

STATE REGIONAL ASSIGNMENTS

Region 1: New England: Connecticut

Maine

Massachusetts

New Hampshire

Rhode Island

Vermont

Region 2: Mid-Atlantic:

Delaware

District of Columbia

Maryland

New Jersey

New York

Pennsylvania

West Virginia

Region 3: Southern:

Alabama

Florida

Georgia

Kentucky

Mississippi

North Carolina

South Carolina

Tennessee

Region 4: Central:

Illinois

Indiana

Michigan(Lower Peninsula)

Ohio
Region 5: Northwestern:

Michigan(Upper Peninsula)

Minnesota

North Dakota

South Dakota

Wisconsin

Region 6: Midwestern:

Iowa

Kansas

Missouri

Nebraska

Region 7: Southwestern:

Arkansas

Louisiana

Oklahoma

Texas

Region 8: Rocky Mountain:

Colorado

Idaho

Montana

New Mexico

Utah

Wyoming

Region 9: Pacific Coast: Arizona

California

Nevada

Oregon

Washington 
Each state and each shipment origin city within a state were also assigned a unique numeric code number. For example, a shipment which originated at Dover; Delaware was coded 07 for the state and 01 for the city. Delaware was the seventh state alphabetically and Dover was the first origin point within the state.

This code number could be used to identify all shipments that originated from a particular location. Coding enables researchers to study the motor carrier rate structure from a particular city, state, or region to oklahoma city to see if it differs significantly from other freight rate structures.

Each of the 479 shipment origin points was also assigned a scale value from 1 to 6 . This value measured the approximate economic importance of the origin point area. A scale value of 1 indicated a high level of economic activity at the shipment origin. A scale value of 6 indicated that an origin point had a low level of economic activity.

In assigning economic activity scale values to origin points, it was assumed that areas with large populations had high levels of economic activity. It was also assumed that areas with less population had lesser levels of economic activity. Using this rationale, each of the shipment origin points was assigned a scale value which represented one of six economic activity levels. The population in an area, and not the population of a particular city, was used to assign economic activity scale values. If a shipment originated in a small city, located close to a much larger 
city, the population of the smaller city would not be a true indicator of the level of economic activity in the area.

Ranally Metro Areas (RMA) were used to define shipment origin areas. The size of the largest city within the RMA was used to assign an economic activity scale value to the shipment origin point. The RMA is Rand MCNally's definition of the developed areas around each important city with at least 50,000 population. The RMA's include one or more central cities, satellite communities, and suburbs. Their boundaries do not follow county lines as the more familiar Metropolitan Statistical Areas (MSA's) do. For this reason it is believed that RMA's provide a better portrayal of the extent of urban and suburban development than that provided by MSA's.

The MSA around Atlanta, for example, follows county lines and includes more than 2000 square miles. Some of this area is quite sparsely populated but is included in the MSA because of political factors only. The level of economic activity in the outlying areas is probably quite low. The RMA around Atlanta, on the other hand, only includes about 750 square miles. The parameters which define the RMA's are based on population density and employment patterns rather than on political divisions. If a shipment originated within an RMA and the largest city in the RMA had a population of over one million, the shipment was assigned a scale value of 1 . If a shipment originated in a rural area, it was assigned a scale value of 
6. The complete coding schema for assigning economic activity code values to all shipment origin points is contained in Table 3 .

TABLE 3

SIZE OF SHIPMENT ORIGIN POINT

RMA Central City Size:

Value Assigned

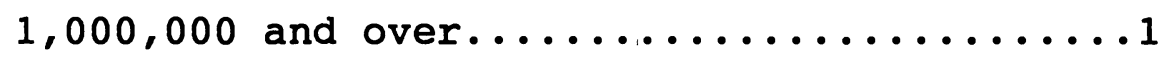

$250,000-999,999 \ldots \ldots \ldots \ldots \ldots \ldots \ldots \ldots \ldots \ldots \ldots \ldots . \ldots \ldots$

$100,000-249,999 \ldots \ldots \ldots \ldots \ldots \ldots \ldots \ldots \ldots \ldots \ldots \ldots$

$25,000-99,999 \ldots \ldots \ldots \ldots \ldots \ldots \ldots \ldots \ldots$

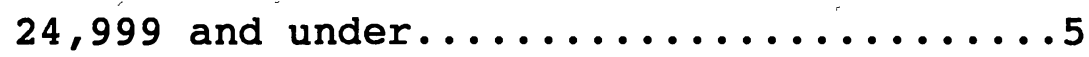

Rural. .......................6

Motor Carrier Attribute Measures

Some motor carriers represented in the database have operational area spans less than the entire United States. In this instance, the motor carrier which picks up freight turns the shipment over to a second motor carrier for final delivery. This is known as an interline shipment. It would be reasonable to assume that an interchange of freight would involve additional cost to the motor carriers taking part in 
an interline shipment. This increased expense would be due, in part, to additional freight handling and administrative expenses. To cover these additional costs the motor carriers involved have to charge a higher rate for the shipment.

From available data it was possible to determine whether motor carrier who picked up a particular shipment was the same carrier who delivered the shipment. Using this information, a 0 - 1 variable was created to measure the impact of shipment interlining on motor carrier freight rates. For all shipments with the same pickup and delivery motor carrier a scale value of 0 was assigned. For all shipments involving more than a single motor carrier a scale value of 1 was assigned.

As discussed in the literature review there has been considerable debate on the issue of the existence of economies of scale in the motor carrier industry. The general consensus has been that economies of scale are not present when shipments are made in truckload quantities. This is because shipments are picked up at the origin and delivered to the destination without using the services of the motor carrier's freight terminals. The size of the motor carrier would have no impact on freight rates. For shipments involving LTL quantities there is a higher likelihood that economies of scale exist, with larger carriers enjoying significant advantages over smaller ones. 
Shipments involving LTL quantities almost always use terminal facilities to combine shipments. This is done to reduce the line haul costs for the motor carrier. Maintaining these terminal facilities undoubtedly increases motor carriers' fixed costs, but the larger carriers have more of an opportunity to spread these fixed costs over more shipments. The spreading of fixed costs over more shipments reduces the terminal costs per individual shipment.

To measure the impact of motor carrier size on pricing behavior, the individual motor carriers in the database were assigned a scale value of 1 through 4 based on their 1984 sales. The break points selected were chosen because the 1984 motor carrier sales data shows a clear division between sales classes at these points. The specific carriers assigned to sales size classes 2,3 , and 4 are shown in Table 4. All other non-listed carriers are assigned to size class 1 by default.

\section{Service Measures}

The number of days shipments are en route between origin and destination is believed to be an indicator of the level of service provided by motor carriers. The distance shipments travel would have a direct impact on en route times, but shipment times can be adjusted to account for these distance differences. If all en route times were adjusted for distance, long en route times could be associated with low levels of service. Short en route times 
could be associated with a higher level of service. If the motor carrier expends additional resources to achieve a high level of service, it is likely that the price asked by the motor carrier would be higher. If this high level of service has any value to the shipper, it is likely that the shipper will pay the higher price asked by the carrier.

TABLE 4

MOTOR CARRIER SIZE BY SALES (1984)

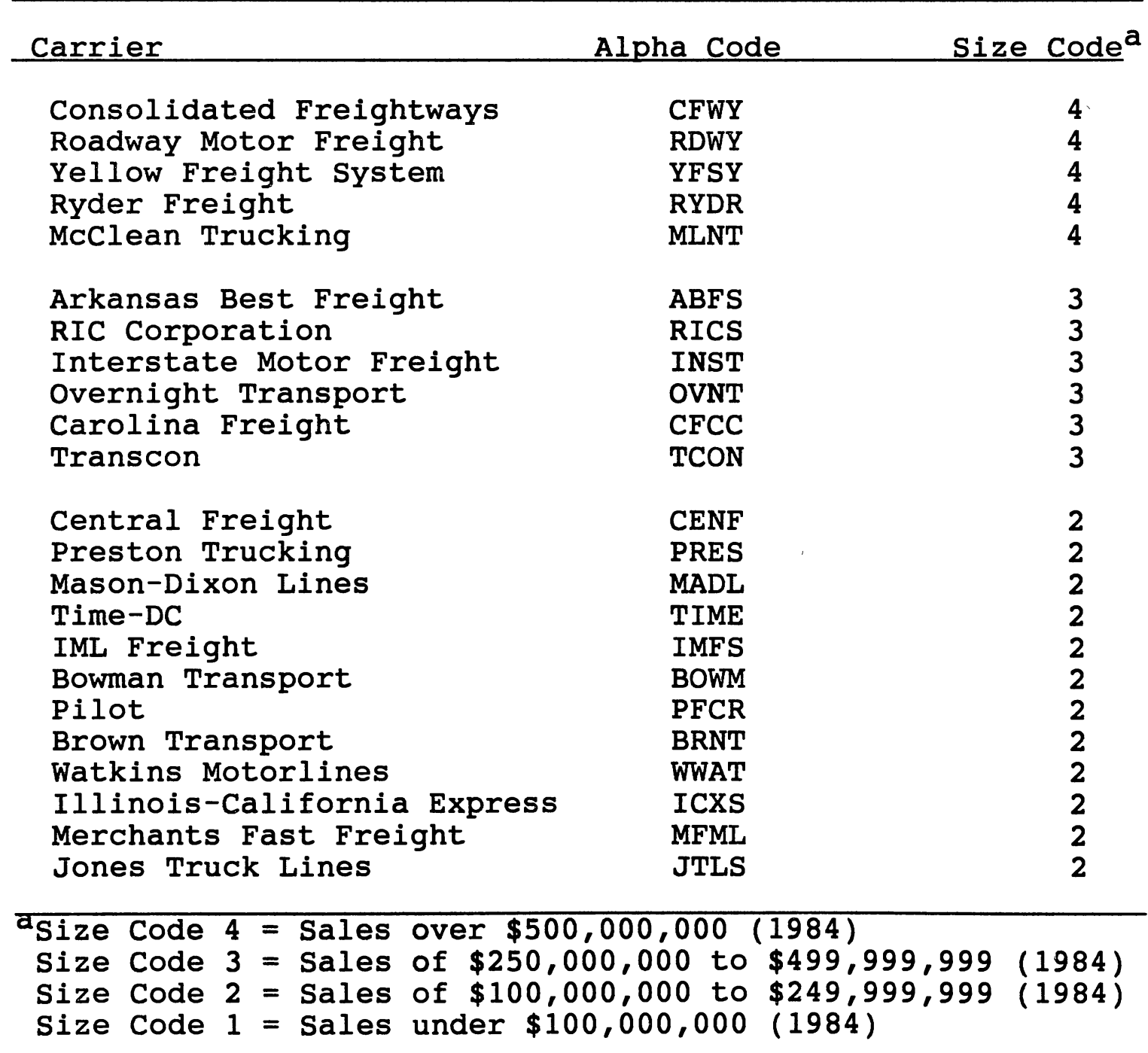


The number of days between the pick-up and delivery of each shipment in the database is known. The distance involved is also known. The actual number of days a shipment is en route, adjusted for the distance the shipment travels, can be compared to a motor carrier industry service standard. The result can be used as a measure of the level of motor carrier service. The motor carrier industry does not count the day of shipment pick-up as a service day. The day of delivery is included, however, when the number of service days is calculated.

A motor carrier service standard was developed using known physical and safety limitations. A shipment cannot, for example, travel 2000 miles in one day via motor carrier, because drivers of interstate motor carriers are restricted to 12 hours of total duty per day. This duty period includes time spent in rest stops and eating. The speed of travel, as shown in the driver's log book, cannot exceed 5052 miles per hour during the period he is on duty. Based on this information, it was determined that one driver could travel 500 miles during one duty period. The driver is required, by safety regulations, to stop for an extended period of rest after 12 hours of duty. Using the above information a set of service measures were developed for both LTL and TL shipments. A complete list of these standards is contained in Table 5 .

A three point scale was used to measure service levels provided by the motor carriers. If an individual shipment 
met the delivery time standard listed in Table 5, service for that shipment was assigned a scale value of 2 , which indicated average service. If an individual shipment was delivered in less than the time standard listed in Table 5, it was assigned a scale value of 1 to indicate superior service. If an individual shipment exceeded the time standard listed in Table 5, it was assigned a scale value of 3 to indicate less than standard service.

TABLE 5

SERVICE STANDARDS IN DAYS

\begin{tabular}{|c|c|c|c|c|c|c|c|}
\hline \multirow[b]{2}{*}{ Distance } & \multicolumn{3}{|c|}{ Truck Load } & \multicolumn{4}{|c|}{ Less-Than-Truckload } \\
\hline & $\mathrm{P} / \mathrm{U}^{\mathrm{a}}$ & $E / D^{b}$ & $\mathrm{STD}^{\mathrm{C}}$ & $\mathrm{P} / \mathrm{U}^{\mathrm{a}}$ & $\operatorname{com}^{d}$ & $E / D^{b}$ & $\mathrm{STD}^{\mathrm{C}}$ \\
\hline $0-500$ miles & 1 & +1 & $=2$ & 1 & +1 & +1 & $=3$ \\
\hline $501-1000$ miles & 1 & +2 & $=3$ & 1 & +1 & +2 & $=4$ \\
\hline $1001-1500$ miles & 51 & +3 & $=4$ & 1 & +1 & +3 & $=5$ \\
\hline $1501-2000 \mathrm{miles}$ & $5 \quad 1$ & +4 & $=5$ & 1 & +1 & +4 & $=6$ \\
\hline $2001-2500$ miles & $5 \quad 1$ & +5 & $=6$ & 1 & +1 & +5 & $=7$ \\
\hline
\end{tabular}

$\mathrm{a}_{\mathrm{P} / \mathrm{U}}=$ Pickup day

$\mathrm{b}_{\mathrm{E} / \mathrm{D}}=\mathrm{En}$ route and delivery day $(\mathrm{s})$

${ }_{\text {CTD }}=$ service standard for distance block

$\mathrm{d}_{\mathrm{COM}}=$ Combining with other LTL Shipments 
The service days for an LTL shipment were computed by allowing one day for pickup and one day for combining the shipment with other LTL freight. The distance the shipment travels was divided by 500 to arrive at an en route time in days. Fractional results from the division were rounded up to full days. The resulting sum of these three values, pick-up, combining, and en route days, represented the service standard against which actual shipment times were judged. The same general approach was used for TL shipments, but no extra day was allowed to combine freight with other shipments.

\section{Distance, Weight and Charge Measures}

The measures which represent these variables are straightforward, as discussed in the database description section of this paper. Distance, defined as the road miles from each shipment origin point to TAFB, was determined for each shipment and entered into the database. The distance variable represents mileage via the interstate highway system between the shipment origin and destination, but the exact route followed by a shipment was unknown. The mileage of the actual route taken by an individual shipment was judged not to be significantly different from the shipment distance measure used. The difference, if any, should have very little impact on a motor carrier's pricing. Shipment size was defined as the total pounds of freight involved in each shipment. The charge for a shipment was the actual 
amount paid by the Air Force for the services involved in moving a shipment to TAFB from one of the 479 shipment origin points.

Most previous motor carrier pricing research involved rate modeling. The rate charged, in one of several forms, served as the dependent variable in many models. The distance and size of the shipment, along with some combination of numerous other factors, served as the independent variables in the models. If the primary research objective of this paper were to develop a motor carrier rate model, this convention would be followed. However, the primary objective of this paper is to examine the impact of selected variables other than weight and distance on motor carrier pricing in a deregulated environment. With this objective in mind the actual shipment charge, distance, and weight are combined into a single dependent variable, rate per ton-mile (RTM). The created dependent variable, RTM, is used to test the nine research propositions of this paper. RTM is computed as follows: RTM $=$ charge $/(($ weight $/ 2000) *$ distance $)$.

\section{Hypothesis Tests}

This section specifies the statistical tests used to determine whether the nine hypotheses previously listed and discussed are supported by the data. Each hypothesis is subjected to at least one statistical test and in some cases, more than one test is performed. The statistical 
procedures associated with the t-test, one-way analysis of variance, correlation, and linear regression will be used.

Hypothesis 1 Test.

Hypothesis 1 examines the effect of freight class on the RTM charged by motor carriers making deliveries to TAFB during the study period. The database section of this chapter pointed out that the product freight class could be determined for about $40 \%$ of the individual shipments. For the other $60 \%$ of the individual shipments, the FAK product code assigned could not be associated with any single freight class.

For FAK shipments, the products, and therefore the product classes, are unimportant in determining the rate for the shipment. Products from multiple freight classes might be mixed and moved under a single FAK rate. When this is done, the product class numbers of the individual shipments become meaningless. The single FAK rate charged to move multiple class products is usually associated with the weight of the shipment. To test hypothesis 1 the FAK shipments in the database are ignored.

Regression analysis will be used to specify the relationship between the two variables, RTM (the dependent variable) and shipment product class (the independent variable). Only shipments for which the product class numbers are known have been analyzed. 
Hypothesis $\underline{2}$ Test

Hypothesis 2 examines the concept that there is an ideal shipping density for products. As the density of the product under study varys from that ideal density, the RTM will increase. An ideal product would utilize both the weight carrying capability of a vehicle and the total cubic area available.

If a product is lighter than the ideal density of 16.67 pounds per cubic foot, the RTM will increase, because the vehicle is filled before its weight limit is reached. If a product is heavier than this ideal density, the RTM also increases; in this case the van reaches its weight limit before its cubic capacity is filled. Due to the above relationships, it is possible to argue that the more a product varies from this ideal density, the higher the RTM will be. If the under-utilization of vehicle space is as costly as the under-utilization of vehicle weight carrying capacity, a line fitted to a plot of RTM and Density data points would be shaped like the letter $\mathrm{V}$ or $\mathrm{U}$. The global optimum, or ideal product density point, would be at the lowest point of this $\mathrm{V}$ or $\mathrm{U}$ shaped line. The most dense and the least dense products would be located at the two highest points of the $\mathrm{V}$ of $\mathrm{U}$ shaped line.

To examine hypothesis 2 , regression analysis will be used to fit a line to the data points of the more than 1200 shipments for which product RTM and Density data are available. These shipments will have to be examined as two 
different databases. One database should contain the shipments with a density of less than 16.67 pounds per cubic foot, while the other contains those with a density greater than 16.67 pounds per cubic foot. If this procedure is not followed, the variation in one side of the distribution is likely to cancel out the variation in the other side of the distribution. This cancellation of variation would give meaningless results.

If the regression model, $R T M=f$ (product weight per cubic foot), produces a significantly high $\mathrm{R}^{2}$ in both analyses, this supports the alternative hypothesis completely. If an insignificant $\mathrm{R}^{2}$ is produced by the model in both cases this supports the null hypothesis completely. If the analyses produces mixed results, this indicates that product density has an impact on motor carrier rates under one set of conditions but not the other.

\section{Hypothesis $\underline{3}$ Test}

Hypothesis 3 explores the idea that the value of a product is directly related to the RTM. As the product value per pound increases, the RTM increases. This hypothesis can be tested by examining the relationship between RTM and the value of the product per pound. If the alternative hypothesis is supported, the two variables, RTM and Value, should be highly correlated and regression analysis should produce an $\mathrm{R}^{2}$ value which is statistically significant. Simple linear regression analysis can be used 
to examine the relationship proposed. The computed coefficient of determination can describe the strength of the relationship.

\section{Hypothesis $\underline{4}$ Test}

Hypothesis 4 examines the issue of whether the type of equipment used to transport a shipment has any impact on the pricing behavior of motor carriers. The database indicates the type of trailer used to transport each shipment. Using this information, a 0 - 1 variable was created. Shipments coded 0 were those made in closed, general purpose vans. Shipments coded 1 were those made in any other type of trailer. To examine the issue of pricing differences, a $t-$ test of the RTM means of the two groups should identify any significance variation between the types of shipments.

\section{Hypothesis $\underline{5}$ Test}

Hypothesis 5 examines the impact of the region of origin on motor carrier pricing behavior. The RTM for shipments originating in the same region of the country are more likely to be similar. The RTM for shipments originating in different regions of the country are more likely to be different. This same relationship could be tested on the state level and the city level, but to do so would require extensive data manipulation. For that reason it has not be attempted. 
The individual shipments in the database come from one of nine regions. To test the hypothesis that the region of origin makes a difference in the RTM, a one-way analysis of variance should be performed. This analysis also determines the regional RTM variation in the data and the variation between the total RTM mean and the regional RTM means, using a Tukey's Studentized Range Test.

Hypothesis $6 \underline{\text { Test }}$

Hypothesis 6 examines the relationship between the population of an area where a shipment originates and the RTM. Population concentration is assumed to be a proxy measure of the economic activity within a particular area. The specific relationship to be tested is that as the population in a shipment origin area increases, the RTM will decrease. For individual shipments associated with a Ranally Metro Area (RMA), the population of the largest city within the RMA is known. For shipments not associated with RMA's, the population of the origin city itself is known. Based on this information each of the individual shipments in the database has been assigned to one of six population categories, specified in Table 3 .

Using this data, the relationship between origin point population and RTM can be determined and tested for statistical significance with regression analysis. If the two variables, RTM and population, are highly correlated this supports the alternate hypothesis. 
Hypothesis 7 Test

Hypothesis 7 tests the idea that the total expenses for shipments involving more than one motor carrier will be greater than those of a single motor carrier. If this hypothesis is true, the RTM for those shipments involving more than one motor carrier will be higher than the RTM for a single motor carrier. The database contains information necessary to determine whether a motor carrier which picked up a shipment is the same carrier that delivered it. A 0 - 1 variable was created to differentiate between single motor carrier shipments and those involving more than one motor carriers. If the pick-up and delivery motor carriers were not the same, a value of 1 was assigned to the variable. If the pick-up and delivery carriers were the same, a value of 0 was assigned to the variable.

This procedure divided the motor carriers into two different groups. The t-test statistic, calculated using the RTM means of the two groups and the difference in their standard deviation, is compared with the critical $t$ value to determine whether the means of the two groups are significantly different.

Hypothesis $\underline{8}$ Test

Hypothesis 8 addresses the issue of economies of scale in the motor carrier industry. If the alternate hypothesis is supported, the larger the motor carrier, the less the RTM will be. All motor carriers in the database were assigned a 
scale value from 1 to 4 based on their reported sales. A scale value 1 represents the lowest sales level while a scale value of 4 represents the highest sales level. The test used to investigate the effect of motor carrier size on the RTM is correlation and regression analysis.

\section{Hypothesis $\underline{9}$ Test}

Hypothesis 9 examines the proposition that a high level of service is associated with a high RTM, while a low level of service is associated with a low RTM. The reasoning behind this hypothesis is that it is more expensive for the motor carrier to provide superior service. The increased costs to the motor carrier will, in turn, lead to the charging of higher rates to recover the costs. All shipments in the database were assigned a scale value from 1 to 3 indicating the level of service they had received. Service was judged to be superior if the number of days between pick-up and delivery were less than the standard service days described in the measurement section of this chapter. In such cases the shipment was assigned a service variable scale value of 1 to indicate that the shipment had received superior service. Following the same convention, shipments which were judged to have received average service were assigned a service scale value of 2 . Those which received poor service were assigned a service scale value of 3. The impact of the level of service on the RTM can be tested by using correlation and regression analysis. This 
type of test can allow us to determine if the service received explains a significant amount of the variation in the RTM charged by unregulated motor carriers. 


\section{CHAPTER VI}

\section{DATA ANALYSIS}

\section{Introduction}

The data used to formulate the independent variables described in hypotheses one, two, three, six, eight, and nine are at a minimum interval-scaled, which means that the scaling level assumptions of all general linear models are satisfied. This indicates that a first step in a data analysis would be to construct a correlation matrix. A correlation matrix is useful in describing the relationships of the independent variables among themselves as well as the relationships of the independent variables with the dependent variables.

$$
\text { Prior to statistical testing of the individual }
$$

hypotheses, the database was analyzed to determine whether it contained both minimum charge and full charge shipments. Samuelson and Lerman (1977) in their classic study of freight rates discovered that some shipments are too small to be shipped under the standard rate structure. Samuelson and Lerman reported that small shipments are often transported under a flat rate or minimum charge rate structure. Ferguson and Glorfeld (1981) confirmed this finding and validated this approach to motor carrier freight 
rate modeling. The analysis of a database containing both minimum charge and conventionally priced shipments would not be a true test of motor carrier pricing behavior. The minimum charges for shipments are most likely determined by a combination of weight and distance criteria. The charges for conventional types of shipments are probably influenced by several other factors as well. It is these other factors which are the major subject of this study. Based on this line of reasoning it was decided that minimum charge shipments, if they were present in the database, would be removed prior to the tests of the individual hypotheses.

An extensive analysis of the database determined that shipments of less than 250 pounds generally moved under a flat rate or minimum charge rate structure. This pricing break point was identified by removing shipments from the database in 50 pound increments. The removal of shipments of weighing less than 50 pounds, those weighing less than 100 pounds, those weighing less than 150 pounds, and those weighing less than 200 pounds did not improve the explanatory power of a simple rate model. When shipments weighing less than 250 pounds were removed from the database the explanatory power of the model increased considerably.

To test the validity of this weight break point in the motor carrier pricing structure, two correlation matrices were constructed. The magnitudes of the correlation coefficients for the dependent and independent variables 
were compared. In all cases they were significantly larger for the data set with shipments of less than 250 pounds removed. This indicated that the full data set did contain minimum charge shipments which should be removed prior to hypothesis testing. Table 6 contains a summary of the correlation matrix developed from a smaller database created by removing shipments of less than 250 pounds. This database contains 3833 observations.

Table 6 reports the Pearson Product Moment Correlation Coefficients for each of the independent variable pairs. They are also reported for the dependent and independent variable pairs. The probabilities that the correlations are statistically significant, and the number of observations used to determine correlation, are also reported.

In the full database correlation matrix, it should be noted that the dependent variable, rate per ton-mile (RTM), is not correlated at a meaningful level with the independent variables truckload class (TLC); less-than-truckload class (LTLC), or product value (Value). In the reduced database the dependent variable, RTM, is significantly correlated with all of the independent variables in the database. The magnitudes of the correlations for Density and TLC as well as Density and LTLC are greater than for many of the other independent variable pairs. The relationship is consistent in the full and reduced databases. This relationship is expected because product density, as pointed out in Table 1, Chapter $\mathrm{V}$, is one of the attributes used by 
TABLE 6

CORRELATION MATRIX, REDUCED DATABASE

Variable

$\begin{array}{rllllllllllll} & 1 & 2 & 3 & 4 & 5 & 6 & 7 & 8 & 9 & 10\end{array}$

1. Distance -

2. Weight a -.222

b 01 *

c 3833

3. IIC

$\begin{array}{rrr}\text { a } & .079 & -133 \\ \text { b } & 01 \star & 01 \star\end{array}$

c 16451645

4 IIIC

$\begin{array}{cccc}\text { a } & 074 & -137 & 891 \\ \text { b } & .01 \star & 01 \star & .01 \star \\ \text { c } & 1613 & 1613 & 1613\end{array}$

5. Denselty a $-238 \quad 345-558-553 \quad-$

b 01* .01* .01* 01*

c $700 \quad 700 \quad 700,668$

6. Value a $-010 \quad-082 \quad 667 \quad .573 \quad-236$

b $.80 \quad 05 \quad .01 * \quad .01 * \quad 01 *$

c $700 \quad 1240 \quad 700 \quad 668 \quad 700$

$\begin{array}{rccccccc}\text { 7. Citysize a } & -.030 & 194 & -.022 & -.047 & 250 & -.089 \\ \text { b } & .10 & .01 * & .40 & .10 & .01 * & .05 \\ \text { c } & 3833 & 3833 & 1645 & 1613 & 700 & 700\end{array}$

8 carrsize a $338 \quad-.165 \quad-141 \quad-.172 \quad-.094 \quad-004 \quad-066$

b. 01* 01* 01* 01* 01* .95 01*

$\begin{array}{llllllll}\text { c } & 3833 & 3833 & 1645 \quad 1613 & 700 & 700 & 3833\end{array}$

9 Servzce a $\quad .388 \quad-269-111 \quad-.094 \quad-.234 \quad 059-035 \quad-059410$

b 01* 01* 01* .01* .01* .15 $35 \quad .01$ *

$\begin{array}{lllllllll}\text { c } & 3833 & 3833 & 1645 & 1613 & 700 & 700 & 3833 & 3833\end{array}$

10.RW a $\quad \begin{array}{lllllllllll}-428 & -.125 & -.155 & -.201 & -217 & .306 & -029 & -139 & -.095 & -\end{array}$

b .01* 01* 01* 01* .01* .01* .10 .01* .01*

$\begin{array}{llllllllll}\text { c } & 3833 & 3833 & 1645 & 1613 & 700 & 700 & 3833 & 3833 & 3833\end{array}$

$\begin{array}{lllllllllllllllllllll}11 . \text { Charge } & a & 091 & 316 & .200 & 248 & .148 & -028 & .059 & -288 & -.263 & -.128\end{array}$

b 05 01* .01* .01* 01* . .50 $01 * \quad .01 * \quad .01 * \quad .01 *$

$\begin{array}{lllllllllll}\text { c } & 3833 & 3383 & 1645 & 1613 & 700 & 700 & 3833 & 3833 & 3833 & 3833\end{array}$

$a=$ correlation coefficient; $b=$ significance level; c = sample size; $\star=$ p. < .01 . 
freight classification authorities to assign products to classes.

It has been reported that a large degree of correlation among independent variables damages the efficiency of regression models developed using the correlated variables. In cases where the correlation is very strong, it may render the regression models useless. Strong correlation between independent variables makes it difficult to identify significant relationships and it may make a regression model unstable.

The correlation between Density and TLC and Density and LTLC could be a serious problem if the correlations among the variables were large. The term large is, however, a relative rather than an absolute term. Most statistical texts define large correlations as those whose value is .7 or greater. The correlation which represents the relationship between Density and LTLC is -.55 . The correlation which represents the relationship between Density and TLC is -.56. In both cases, the value of these correlations is well below the value commonly considered to be large.

As expected, the independent variable, Value, is also significantly correlated with the independent variables, LTLC and TLC, in Table 6 . The value of the product, like the product density, is one of the product attributes used by product classification authorities to assign a product to a class. The correlations for Value and LTLC and Value and 
TLC are, as they are in the case of Density, below the level considered to be large. The correlation between value and LTLC is .57. The correlation between value and TLC is .67 . The charge for a shipment (Charge), the distance the shipment travels (Distance), and the weight of the shipment (Weight) are included in the correlation matrix reported in Table 6. These three shipment elements are not used to formulate any of the hypotheses tested, but they are used to compute the dependent variable, RTM. Their relationships with the other study variables are, therefore, useful in certain cases. In many transportation rate studies employing a modeling approach, Charge is used as the dependent variable in the model while Distance and Weight are frequently included as independent variables. Including these variables in the correlation matrix can be justified on the basis of the generalizability of the research results.

The signs of the correlations for Charge, Distance, and Weight are stable between the full and the reduced databases. The magnitude of the correlations does not increase significantly between the two, as in the case of RTM. In both the full and the reduced data sets, Charge and Distance are not significantly correlated with value (p. = .10) whereas Weight is significantly correlated with Value $(\mathrm{p} .=.05)$.

In addition to discussing the correlations between dependent and independent variables in hypotheses one, two, 
three, six, eight, and nine, the results of a simple linear regression procedure are also reported. This might appear to be redundant, because the coefficient of correlation reported in Table 6 can be used to compute the coefficient of determination produced by the linear regression procedure. The reason for reporting both of these statistics lies in their interpretation.

The value of the coefficient of correlation can fall at or between the values -1 and +1 . A plus or minus sign is attached to the coefficient of correlation, indicating whether the slope of the fitted regression line is positive or negative. The coefficient of determination, however, can only have a value which falls at or between 0 and 1 . It indicates the proportional reduction in the variability of the dependent variable attained by using information about the independent variable. Except for the values of 0 and 1, the value of the coefficient of correlation will always be larger than the value of the coefficient of determination. This relationship causes problems with the operational interpretation of the coefficient of correlation. For example, the coefficient of correlation value of .32 and the coefficient of determination value of .10 might represent the same relationship between two variables. The value of .32, however, gives the impression of a stronger linear association between the two variables.

Regression analysis is one of the best known and widely use types of statistical analysis. Linear regression is 
easily the most commonly employed form of analysis in transportation rate studies, and has one of the strongest theoretical bases of all of the statistical procedures available. For the above reasons regression analysis results are also reported for hypotheses one, two, three, six, eight and nine.

Simple linear regression is based on two assumptions. First, the relationship between two variables can be represented by a straight line. Second, the data being analyzed is normally distributed. If the analysis of a database determined that either of these assumptions are violated, the researcher is faced with one of two options. First, regression analysis can be abandoned and a search conducted for a more appropriate and usually more complex model. Second, some type of transformation can be used to make the data more appropriate for use with the regression model.

Transformations can, however, cause problems. The first approach may entail the development of a more complex model which yields better insights into the nature of the data. It may also lead to difficulties in estimating and interpreting the model parameters. Transformations may make the data more suitable for analysis with a simpler model, but there is the chance that fundamental relationships between variables might be obscured.

On the other hand, data transformations have benefits which sometimes outweigh their drawbacks. Transformations 
might enhance the nature of important relationships which were not evident in the original data set. Based on the level of theoretical support, the frequency of usage of the technique, and personal judgment about the nature of the database under study, the second approach is taken when variable relationships in the data set are suspected of being unduly influenced by nonlinearity or nonnormality.

When the decision is made to transform data, the researcher is faced with a number of choices which could affect the research results, such as selecting the variables to transform and the type of transformation to use.

A case can be made for the transformation of the dependent variable, the independent variable, or both the dependent and the independent variables. When the dependent variable alone is transformed, the model results might be improved, but care must be used in the interpretation of the result. For example, if the natural logarithm of the dependent variable is chosen as the method of transformation, the antilogarithm of the dependent variable logarithm must be determined to estimate the value of the dependent variable for a given value of the independent variable.

When both dependent and independent variables are transformed into their natural logarithmic forms, the coefficient for the independent variable estimates the percentage change in the independent variable per one percent change in the dependent variable. 
Three experimental transformations were performed on the data set for the dependent variable, the independent variable, and both the dependent and independent variables. The data was transformed to its natural logarithmic, polynomial, and reciprocal forms and tested in a simple regression model for explanatory power. In almost every case the regression model containing the natural logarithmic forms of both the dependent and independent, variables explained the most variation in the database. The regression model with only the independent variable transformed, however, produced results which are only marginally smaller. Because the interpretation of results is more straight forward, the latter transformation is reported, when appropriate, throughout the remainder of this research.

The data used to test hypotheses four and seven are binary in nature. In these hypotheses, the research area of interest is the RTM mean differences of the two groups defined by the binary variables. To determine whether the mean of the dependent variable, RTM, is significantly different for each of the two groups, t-tests are performed to test both hypotheses. The results of these tests are reported in the sections in which the hypotheses are discussed in detail. For the general information of the reader, the results achieved when Charge is specified as the dependent variable are also reported. 
Hypothesis five examines the differences in the dependent variable, RTM, for nine different regions of the country. The data used to test hypothesis five is nominal for the independent variable, Region, and interval for the dependent variable, RTM. The appropriate statistical technique in this case is to examine the variance in the dependent variable between the regions using a one-way analysis of variance (ANOVA) procedure. The results of this one-way ANOVA procedure are reported in the section which discusses hypothesis five in detail. The results achieved when Charge is specified as the dependent variable are also reported.

\section{Product Attributes}

The first four hypotheses to be tested involve the attributes of products. The effect of these attributes on the rate per ton-mile charged by motor carriers is the major relationship of interest. The specific product attributes tested are product class, product density, product value, and product special handling requirements. The data analysis for each of the four hypotheses, developed to determine the significance of the four product attributes, is reported in the following paragraphs.

\section{Hypothesis 1 Findings}

The first product attribute examined for its impact on RTM is product class. The full database has 5655 
observations. When shipments of less than 250 pounds are removed from the database, its size is reduced to 3833 observations. Within this reduced database, the TLC numbers are known for 1645 of the shipments and the LTLC numbers are known for 1613 of the shipments.

For analysis, each shipment in the reduced database is assigned a single product class number (Class). The product class number assigned (either the LTLC number or the TLC number) depends on the weight of the shipment. When the weight of a shipment is greater than or equal to the weight break point between TLC and LTLC, that shipment is assigned the TLC class number. When the weight of a shipment is less than the weight break point, that shipment is assigned the LTLC number.

The removal of the minimum charge shipments from the database greatly improves the correlation between RTM and TLC and RTM and LTLC. The relationships between variables in the reduced database are reported in Table 6 . When a simple regression model is constructed using RTM as the dependent variable and Class (either the LTLC or the TLC number but not both) as the independent variable, the results also improve dramatically for the reduced data set. The results of the simple regression model procedure for the reduced database of 1614 observations are reported in Table 7 below. Although the value of $R^{2}$ produced by the reduced database model is not large, it is statistically 
significant. The natural logarithmic form of Class (LClass) is also reported in Table 7 .

TABLE 7

REGRESSION ANALYSIS, HYPOTHESIS 1

RTM AND CLASS $(\mathrm{n}=1614)$

\begin{tabular}{lccccc}
\hline & a value & b value & F Value & Pr $>F$ & $R^{2}$ \\
\hline Class & 0.153 & 0.003 & 105.73 & 0.001 & 0.062 \\
LClass & -0.943 & 0.267 & 156.59 & 0.001 & 0.089 \\
\hline
\end{tabular}

It should be noted that a value of $R^{2}=.219$ is produced by transforming both the dependent and independent variables to their natural logarithmic forms. This large increase in the value of the $R^{2}$ statistic suggests that the relationships between RTM and Class and RTM and LClass are not fully captured by the restricted models', probably because the relationship is nonlinear or the data is not normally distributed.

When Charge is specified as the dependent variable, the simple regression model procedure produces an insignificant $\mathrm{R}^{2}$ value for the full database. When the reduced data set is used, a value of $\mathrm{R}^{2}=.014$ is produced. Although this $\mathrm{R}^{2}$ value is statistically significant, it might be considered 
trivial because the magnitude of the statistic is small. Transforming the dependent variable, Charge, and the independent variable, Class, fails to improve the predictive power of the simple regression model. These findings support the contention that the relationship between charge and Class is weak and linear.

Hypothesis $2 \underline{\text { Findings }}$

This hypothesis examines the impact of the product attribute, Density, on the rate per ton-mile charged by the motor carrier. An examination of the correlation matrix in Table 6 indicates that Density is significantly related to the RTM charged by motor carriers. The reduced data set correlation coefficient is more than twice as large as that produced by the full data set.

The signs of the correlations in both the full and reduced databases are negative. This consistency in the sign of the correlation supports the argument that the database is basically stable. It also indicates that as product density increases, RTM decreases.

The magnitude of the correlation coefficient is somewhat surprising. If the original hypothesis is supported, one side of the data distribution would be offset by the other side of the distribution. The magnitude of the correlation coefficient would, in this case, be near zero. This is not the case, and the possible reasons for this relationship are considered later in this section. 
The full database has 1240 observations for which product density information is available. A simple linear regression model procedure applied to this database produces a value of $\mathrm{R}^{2}=.009,(\mathrm{p} .=.01)$. Although this $\mathrm{R}^{2}$ value is significant, the usefulness of the model is questionable. The magnitude of the $R^{2}$ value might cause the model results to be considered trivial because it explains less than one percent of the total variation.

When the shipments of less than 250 pounds are removed from the database, its size is reduced to 700 observations. The simple linear regression model procedure for this reduced data set produces the results which are reported in Table 8 . While the results produced by both of the models are statistically significant, it is obvious by the magnitude of the $R^{2}$ values that the reduced database model fits the data better. The natural logarithmic form of the independent variable Density (LDensity) is also reported in Table 8. This data transformation more than doubles the size of the $R^{2}$ value.

The value of $\mathrm{R}^{2}$ can be increased dramatically by normalizing both the dependent and independent variables. When LogRTM and LDensity are used, the simple regression model for the full database produces a value of $R^{2}=.091$. For the reduced database the transformed variables produce a value of $\mathrm{R}^{2}=.127$. This finding would indicate that the relationship between Density and RTM is nonlinear in nature or that the assumption of data normality is violated. 
TABLE 8

REGRESSION ANALYSIS, HYPOTHESIS 2

RTM AND DENSITY $(n=700)$

\begin{tabular}{llcccc}
\hline & a value & b value & F Value & Pr $>$ F & $R^{2}$ \\
\hline Density & 0.393 & -0.004 & 34.49 & 0.001 & 0.047 \\
LDensity & 0.685 & -0.134 & 80.58 & 0.001 & 0.104 \\
\hline
\end{tabular}

In the hypothesis formulation stage of this research it was thought that the relationship between Density and RTM might be best described as being $U$ or $V$ shaped. To test this proposed relationship the database is split into two different groups of shipments. One group contains those products that have a product density which is less than the ideal product of 16.67 pounds per cubic foot. The second group contains those products which have a product density that is greater than or equal to the ideal product density. When the shipments of products with greater than ideal densities are analyzed using the simple linear regression model procedure, there is no significant relationship between product density and RTM. This finding is consistent within both normalized and untransformed databases. It is also consistent between the full and the reduced data sets. When the shipment of products with lighter than ideal densities are analyzed using the simple linear regression 
model procedure, there is a small but significant relationship between the normalized variables in the full database. In the reduced data set untransformed variables explain a small but significant amount of variation in the database.

The above results lead to the conclusion that product densities greater then the ideal product density of 16.67 pounds per cubic foot have no relationship to the rate charged by motor carriers. The shape of the curve which describes the relationship between RTM and Density is not, therefore, $U$ or $V$ shaped. It is more likely that only one arm of the $\mathrm{U}$ or $\mathrm{V}$ is captured in the data.

When Charge is specified as the dependent variable, a simple linear regression model procedure with Density as the independent variable produces values of $R^{2}=.027$ for the full database and $R^{2}=.022$ for the reduced database. When the dependent variable, Charge, and the independent variable, Density, are transformed into their natural logarithmic forms, the simple linear regression model for the full database produces a value of $R^{2}=.023$. For the reduced data set the transformed variables produce a value of $\mathrm{R}^{2}=.009$.

Charge, as a dependent variable, does a significantly better job of explaining variation when the database is split into light and heavy halves. This is true for both the full and the reduced databases. It is also true when 
normalized and untransformed data are used in the simple linear regression model.

Hypothesis $\underline{3}$ Findings

Hypothesis three examines the impact of the product attribute value on the rate per ton-mile charged by the motor carrier. The correlation matrix for the full database $(n=1240)$ indicates that the value of a product is not significantly correlated with the dependent variable, RTM. When the minimum weight shipments are removed from the data set $(n=700)$, the correlation coefficient for RTM and Value becomes highly significant $(r=.306, p<.01)$ as reported in Table 6. The sign of the correlation for product RTM and Value is positive in both the full and the reduced data set. This-indicates that the database is stable. A positive, significant correlation between Value and RTM in the reduced data set indicates as Value increases, the RTM charged by the motor carriers increases.

When a simple linear regression model procedure is applied to the full database, the model, as expected, produces insignificant results. When the reduced dataset is used, the simple linear regression model produces highly significant results. These results are reported in Table 9. It should be noted that the value of $R^{2}$ can be increased by normalizing both the dependent and independent variables. When the regression model LogRTM $=$ LValue is used, the full database produces a value of $\mathrm{R}^{2}=.091$. For 
the reduced data set the transformed variables model produces a value of $\mathrm{R}^{2}=.162$. In both cases the results are highly significant.

TABLE 9

REGRESSION ANALYSIS, HYPOTHESIS 3 RTM AND VALUE $(n=700)$

\begin{tabular}{lccccc}
\hline & a value & b value & F Value & Pr>F & $R^{2}$ \\
\hline Value & 0.272 & 0.001 & 72.13 & 0.001 & 0.094 \\
LValue & 0.277 & 0.058 & 94.90 & 0.001 & 0.120 \\
\hline
\end{tabular}

When Charge is designated as the dependent variable, the simple linear regression model procedure produces insignificant results for the full and reduced data sets. When Charge and Value are normalized by converting them to their natural logarithmic forms, the simple linear regression model for the full and reduced databases produces significant $R^{2}$ values. The magnitude of the values produced is, however, much less than those produced when LogRTM and LValue are used in a simple linear regression model. 
Hypothesis $\underline{4}$ Findings

The last of the product attribute variables examined for statistical significance involves the need of the product to be transported by special equipment. The nature of the product often has an impact on the type of vehicle used. For example, products with odd shapes, bulk liquids, or those which need refrigeration cannot be transported in a standard closed van.

A 0 - 1 variable (EqDummy) is used to study the impact special equipment usage on the RTM charged by motor carriers. When the product is transported in a standard closed van, an EqDummy value of 0 is assigned. When special equipment is used to transport the product, an EqDummy value of 1 is assigned. To test the hypothesis that the means of the RTM's for the two classes of shipments defined by EqDummy are equal, a t-test is used. The results of this analysis are reported in Table 10. The results achieved when the mean of Charge is tested for significant differences are also reported.

In the interest of consistency, the full data set and a reduced data set are examined. In both cases the computed t-test statistic supports the alternate hypothesis; the RTM means of the two groups are not equal. The RTM mean for shipments made in standard closed vans is significantly different than the RTM mean for shipments made with special equipment. This difference in the RTM mean for the two groups of shipments indicates that the use of special 
equipment does have a significant impact on motor carrier pricing behavior.

TABLE 10

T-TEST SUMMARY, HYPOTHESIS 4

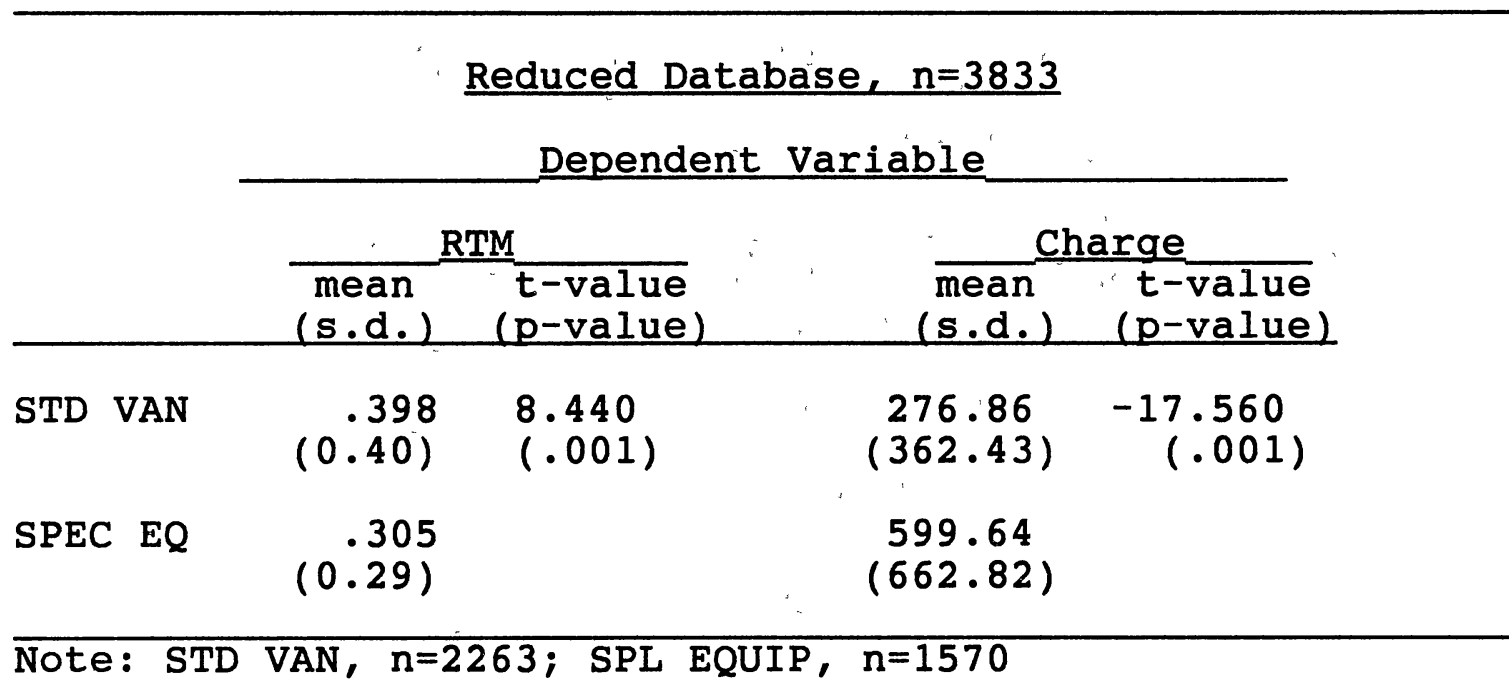

Although the RTM charged is affected by the use of special equipment, the direction of the effect is unexpected. When the original hypothesis was formulated it was reasoned that the use of special equipment would be more costly to the motor carrier. The RTM charged by the motor carrier would, therefore, have to be higher to recover the increased cost.

The data analysis indicates that the reverse of the hypothesis is true. The RTM for shipments made with special 
equipment is lower than the RTM for shipments made with standard equipment. There could be several reasons for this reversed relationship. It could be that low class, low value, and high density products are more likely to be shipped by special equipment. Another possible reason is that shipments requiring special equipment are more likely to move in larger lots or over longer distances.

Also reported in Table 10 are the results of t-tests used to determine whether the usage of special equipment has any effect when Charge is used in the data analysis. For both data sets the t-tests strongly support the alternate hypothesis. The mean of Charge for shipments made in standard closed vans is different from the means for shipments made with special equipment. The directions of the differences in these cases are in the direction proposed in the hypothesis.

\section{Geographic Attributes}

Hypotheses five and six were formulated to determine whether there are geographic factors underlying the rate structure of the motor carriers represented in the database. Hypothesis five examines the RTM differences for nine different regions (Region) in the United States. By using RTM as the dependent variable, the effect of differences in shipment distances and weight are neutralized. Under these conditions, any differences in the RTM between regions must occur for reasons other than the distance from the 
destination and the weight of the shipment. Hypothesis six examines the RTM differences for six different sized origin points (Citysize). Does the size of the origin point make any difference in the RTM charged?

\section{Hypothesis $\underline{5}$ Findings}

To determine whether the region of shipment origin has an impact on the RTM charged by motor carriers, a one-way ANOVA procedure is used. The null hypothesis tested is that there is no statistically significant difference in the RTM's for the nine identified regions (Region). In the interest of consistency, both the full and reduced data sets are examined. Results for the reduced database are reported in Table 11 on the following page. Both analyses produce results which are statistically significant at the .01 level. The results achieved when Charge is utilized as a dependent variable are also included in Table 11.

In both data sets the RTM for at least one of the regions is significantly different from the other regions. Judging by the increases in the magnitudes of the Fstatistics, the regional differences in RTM means are much more pronounced for the reduced database. When Charge is specified as the dependent variable, the one-way ANOVA procedure produces results which are much less robust. The F-statistics indicate that there are significant differences between regional charges made by motor carriers. The F- 
statistics are, however, much smaller in absolute value than when RTM is used as the dependent variable.

TABLE 11

ONE-WAY ANOVA; HYPOTHESIS 5

REGIONAL PRICE DIFFERENCES

$\begin{array}{cccccc}\begin{array}{l}\text { Dependent } \\ \text { Variable }\end{array} & \underline{\text { F Value }} & \underline{\mathrm{Pr}>\mathrm{F}} & \underline{\mathrm{R}} \underline{\underline{2}} & \underline{\text { d.f. }} \\ & 126.78 & 0.001 & .220 & 8,3824 \\ \text { Charge } & 11.24 & 0.001 & .023 & 8,3824\end{array}$

The above results indicate that at least one of the regions has an RTM which is different from that of the other regions. The results do not, however, identify the region or regions which are different. To identify the region or regions which have different or similar rate structures, a Tukey's Studentized Range Test is performed on both the full and reduced databases. The complete results of these tests are reported in Figure 2 and Figure 3. In the full database Tukey's results, there is considerable overlap between regions with similar rate structures. This overlap makes analysis of regional differences of means difficult. 
Dependent Puriable = RTY

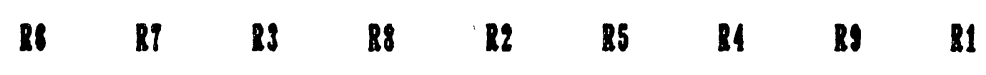

$\begin{array}{llllllllllll}\text { Yea1 } & (1.39) & (1.09) & (0.99) & (0.71) & (0.65) & (0.62) & (0.59) & (0.49) & (0.32)\end{array}$

Region a (344) (1124) (1089) (296) (805) (143) , (385), (1258) (231)

Dependeat Varlable $=$ Charse

\begin{tabular}{lllllllllll}
85 & 81 & 81 & $R 9$ & 83 & 86 & 88 & 89 & $R 2$ \\
\hline
\end{tabular}

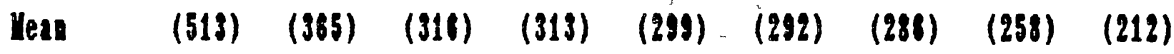

Replon I (143) (385) (213) (1258) (1089) (341) (296) (1124) (805)

Figure 2. Tukey's Studentized Range Test, Regional

Differences, Full Database.

Depeadent Varlable = BII

$\begin{array}{llllllllll}\text { R6 } & \text { R7 } & \text { B5 } & \text { B3 } & \text { R8 } & \text { R4 } & \text { R2 } & \text { R1 } & \text { R9 }\end{array}$

$\begin{array}{llllllllllllll}(0.95) & (0.56) & (0.40) & (0.29) & (0.28) & (0.29) & (0.24) & (0.28) & (0.22)\end{array}$

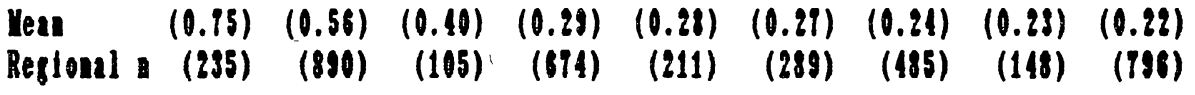

Dependeat Varlable $=$ Charse

\begin{tabular}{lllllllllll}
85 & 81 & 89 & 83 & 81 & 86 & 88 & 89 & $R 2$ \\
\hline
\end{tabular}

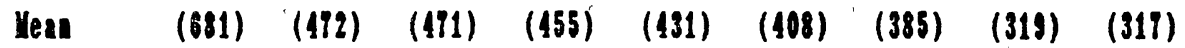

$\begin{array}{llllllllll}\text { Region I (105) (289) } & \text { (798) } & \text { (674) } & \text { (148) (235) } & \text { (211) } & \text { (890) } & \text { (485) }\end{array}$

Figure 3. Tukey's Student lzed Range Test, Reglonal Differences, Reduced Database. 
When shipments of less than 250 pounds are removed from the database, four clear, significantly different groups emerge. The RTM for regions five (MI, ND, SD, WI, and the MI Upper Peninsula), six (IA, KS, MO, and NE), and seven (AR, LA, OK, and TX) are all different from each other and from the remainder of the regions. The remaining six regions form a fourth group in which the RTM does not vary significantly. The RTM mean for the fourth group is, however, significantly different from the RTM for each of the other three regions.

The Tukey's test of the regional mean of Charge also produces results which are mixed. There are basically no differences between any of the regions except region 5, which stands alone. The reason for this regional difference in Charge is not clear, but fewer shipments come from this region than any other.

Discovering the factors which underlie the regional RTM differences would require extensive additional analysis. Such an effort is beyond the scope of the current research. At this point it is sufficient to say that significant regional differences exist in the RTM charged by motor carriers.

\section{Hypothesis $\underline{6}$ Findings}

Hypothesis six examines the impact of the independent variable, city size (Citysize), on the rate per ton-mile charged by the motor carrier. The correlation matrix for 
the full data set indicates that the size of the city from which a shipment originates is significantly correlated with the dependent variable, $\operatorname{RTM}(r=.038, \mathrm{p}<.01)$. When the reduced data set is used, the correlation for Citysize and RTM becomes insignificant $(r=-.029, \mathrm{p} .<.10)$, as reported in Table 6. The sign of the correlation between Citysize and RTM is positive in the full, but negative, in the reduced database.

When coding city sizes, a value of one, is assigned to the largest city and a value of six is assigned to the smallest city. Because of this coding scheme, a positive correlation indicates that as city size increases, the RTM goes down. This relationship supports hypothesis six, but the reversal of the sign between the full and reduced databases appears to be inconsistent.

One possible reason for this sign reversal can be discovered by looking at the correlation coefficients for Citysize and Weight. In both the full and reduced databases, Citysize and Weight are significantly correlated and the sign of the correlation is positive. This would indicate that the weight of the shipments from smaller cities is greater than the weight of those from larger cities. Weight is one of the three elements used to compute RTM. Therefore, the removal of the less than 250 pound shipments from the database gives more importance to the shipments from smaller cities. This could be the reason for 
the sign reversal between Citysize and RTM in the full and reduced databases.

For the full database, regression analysis results indicate that the size of the shipment origin point has a small, but significant, impact on the dependent variable, RTM. The simple linear regression model results for the reduced database are reported in Table 12 . In this case the size of the city has no significant impact, at the .05 percent level, on the RTM charged by motor carriers. The value of $\mathrm{R}^{2}$ has not increased significantly by normalizing the dependent and independent variables.

TABLE 12

REGRESSION ANALYSIS, HYPOTHESIS 6 RTM AND CITYSIZE $(n=3833)$

\begin{tabular}{lccccc} 
& a value & b value & F Value & Pr>F & $R^{2}$ \\
\hline Citysize & 0.382 & -0.008 & 3.14 & 0.077 & 0.001 \\
LCitysize & 0.393 & -0.035 & 9.16 & 0.003 & 0.002 \\
\hline
\end{tabular}

When Charge is designated as the dependent variable, the simple linear regression model procedure for the full database produces an $F$ value of 3.90 . This value is 
significant at the .05 percent level, but, based on the size of the $R^{2}$ value, .001 , the result is probably trivial.

When Charge and Citysize are normalized by converting them to their natural logarithmic forms, the simple linear regression model for the full data set produces insignificant results. Using the reduced data set, the simple linear regression model procedure produces significant results for both the natural and the normalized variables. The $F$ value computed using the natural variable values is 13.17 , while the $F$ value computed using normalized variable values is 15.26. Although both of these $F$ values are significant at the .01 percent level, the magnitude of the $\mathrm{R}^{2}$ statistic indicates that the results might be trivial.

\section{Carrier Attributes}

Hypotheses seven and eight are formulated to determine whether any geographic restrictions the motor carrier might face or size of the motor carrier make a significant difference in the rates charged. Hypothesis seven examines the differences in RTM means for two different groups of shipments. The first group of shipments consists of those shipments for which only one motor carrier is involved with the shipment from pick-up at origin to delivery at destination. The second group of shipments consists of those shipments which are originated by one motor carrier and delivered by a second motor carrier. It should be noted 
that single motor carrier shipments are not restricted to the larger motor carriers. A small regional motor carrier often makes both pick-up and delivery of shipments.

Hypothesis eight examines the RTM differences for four different sizes of motor carriers. Total annual sales figures are used to assign individual motor carriers to size classes. Does the size of the motor carrier make any difference in the RTM charged?

\section{Hypothesis 1 Findings}

The first motor carrier attribute variable examined for statistical significance involves interline shipments. A 0 - 1 variable (Interline) is used to study the relationship between RTM and multiple carrier involvement in a single shipment. If the shipment is picked up and delivered by the same motor carrier, the variable value is set at zero. When at least two motor carriers are involved in a single shipment, the value of the variable is set at one. A t-test is used for the proposition that the means of the RTM's for the two classes of shipments defined by the 0 - 1 variable are equal. The results of this analysis are reported in Table 13.

In the interest of consistency both the full database and a reduced database are examined. In the case of the full database, the computed t-test statistic supports the null hypothesis. It cannot be stated with any reasonable degree of certainty that the RTM of the two groups are 
different. The RTM for shipments made by two or more motor carriers is not significantly different from the RTM for shipments made by a single motor carrier. This lack of difference in the RTM for the two groups of shipments could indicate that motor carriers involved in interline shipments are willing to absorb any extra cost associated with their operation. When the reduced data set is analyzed, the difference in RTM for the two groups becomes statistically significant at the .01 level.

TABLE 13

T-TEST SUMMARY, HYPOTHESIS 7

Reduced Database, $n=3833$

Dependent Variable

\begin{tabular}{|c|c|c|c|c|}
\hline & \multicolumn{2}{|c|}{ RTM } & \multicolumn{2}{|c|}{ Charge } \\
\hline & $\begin{array}{l}\text { mean } \\
(\text { s.d. })\end{array}$ & $\begin{array}{l}\overline{t-v a l u e} \\
\text { (p-value) }\end{array}$ & $\begin{array}{c}\text { mean } \\
(\mathrm{s} . \mathrm{d} .)\end{array}$ & $\begin{array}{c}t-v a l u e \\
\text { (p-value) }\end{array}$ \\
\hline $\begin{array}{l}\text { SINGLE } \\
\text { CARRIER }\end{array}$ & $\begin{array}{l}.355 \\
(0.36)\end{array}$ & $\begin{array}{r}-2.749 \\
(.006)\end{array}$ & $\begin{array}{c}406.97 \\
(535.90)\end{array}$ & $\begin{array}{r}-0.769 \\
(.442)\end{array}$ \\
\hline
\end{tabular}

MULTIPLE $\quad .408$

CARRIERS $(0.37)$

427.30

(493.05)

Note: Single Carrier, $n=3438$; Multiple Carriers, $n=395$

Table 13 also reports the results of a reduced data set t-test using Charge to determine whether interline operations have any effect on motor carrier pricing 
behavior. The t-test fails to support the alternate hypothesis at a meaningful level of significance. The charge imposed by motor carriers for shipments involving interline operations is not different than the charge imposed for single carrier shipments. This relationship is also present in the full data set.

Normalizing the dependent variables, RTM and Charge, in both data sets, produces results which support the alternate hypothesis at the .05 level.

Hypothesis $\underline{8}$ Findings

Hypothesis eight examines the impact of the motor carrier attribute size on the rate per ton mile charged by the motor carrier. To examine this relationship, all of the motor carriers represented in the database are assigned to one of four classes. Class assignments are made on the basis of yearly sales, with carriers having the most sales assigned a class value of four. The specific carriers assigned to each carrier size class are listed in Table 4. The correlation coefficients for the full database indicate that the size of a motor carrier (Carrsize) is significantly correlated with the dependent variable, RTM, at the .05 percent level $(r=.031, p<.05)$. In the reduced data set the correlation for Carrsize and RTM, as reported in Table 6 , is significant at the .01 percent level $(r=-.139, p<.01)$. 
The sign of the correlation for Carrsize and RTM is positive in the full database and negative in the reduced database. The negative sign in the reduced database indicates that as the size of the motor carrier increases, the RTM, charged by the motor carrier decreases. This may indicate that there are economies of scale for the larger motor carriers which enable them to charge a lower RTM.

When a simple linear regression model procedure is applied to the full database of 5655 shipments, the results produced are not significant at the.01 percent level. The magnitude of the $\mathrm{R}^{2}$ statistic produced by this analysis is so small that it is meaningless. The above results indicate carrier size probably has no significant impact on the dependent variable, RTM, when minimum charge shipments are included in the database.

The reduced data set of 3833 observations is analyzed using simple linear regression; the results produced indicate that there is a significant relationship between motor carrier size and the RTM. The results of the linear regression procedure are reported in Table 14 .

In the case of the full database it should be noted that the value of $\mathbf{R}^{2}$ can be increased only slightly by normalizing the dependent and independent variables. For the reduced database, transformation of dependent and independent variables produces no significant change in the value of $R^{2}$. 
TABLE 14

REGRESSION ANALYSIS, HYPOTHESIS 8

RTM AND CARRIER SIZE $(n=3833)$

\begin{tabular}{lccccc}
\hline & a value & b value & F Value & Pr>F & $R^{2}$ \\
\hline Carrsize & 0.445 & -0.040 & 75.11 & 0.001 & 0.019 \\
LCarrsize & 0.407 & -0.084 & 73.78 & 0.001 & 0.019 \\
\hline
\end{tabular}

An examination of the correlation coefficients for the full database indicates that the size of a motor carrier is significantly correlated with the dependent variable, Charge, at the .01 percent level $(r=-.271, p<.01)$. The correlation for Carrsize and Charge, as reported in Table 6, is also significant at the .01 percent level $(r=-.288, p<$ $.01)$. The signs of the correlations for Carrsize and Charge in both databases are negative, which supports the contention that economies of scale might exist for larger motor carriers.

When a simple linear regression model procedure is applied to the full database, with Charge specified as the dependent variable, an $\mathrm{R}^{2}$ value of 073 results. When a simple linear regression model procedure is applied to the reduced data set, the $R^{2}$ value equals .081 . When the values for Charge and Carrsize are normalized by converting them to their natural logarithmic forms, the simple linear 
regression model for the full database produces no change in the $R^{2}$ value. Using the reduced database, the simple linear regression model procedure for the transformed variables produced a value of $\mathrm{R}^{2}=.093$.

The above results indicate that for the study of the impact of carrier size on rates, Charge rather than RTM might be selected as a dependent variable. More of the variation in motor carrier rates can be explained by motor carrier size if total charges are specified as the dependent variable.

\section{Service Attributes}

Hypothesis 9 is design to measure the impact of the service level provided by a motor carrier on the rates charged by that carrier. Service is assumed to be a function of the number of days a shipment is en route and the distance involved. There are two possible reasons the RTM charged by motor carriers who provide superior service might be higher than average. First, motor carriers providing superior service levels will more than likely incur increased costs. They will have to adjust their rates upward to recover these increased costs second, superior service might have a value to the shipper. The shipper might be willing to pay higher rates if fast service is beneficial to them. Knowing of this willingness of the shipper to pay higher rates for superior service, the motor 
carrier who provides superior service will set the RTM at a higher level.

Hypothesis 9 Findings

To determine whether the service level has an impact on the RTM charged, the correlation coefficients are examined as a first step. The correlations between Service and RTM are statistically significant in both the large $(r=.036, p$ $<.01)$ and the reduced data sets $(r=-.095, p<.01)$. The reversal of the correlation coefficient sign between the two databases is somewhat bothersome. One possible explanation for this sign reversal would be that when shipments were assigned to one of three service levels, the minimum charge shipments all ended up in the poor service category. This is an intuitively appealing explanation because it is almost certain that small (under 250 pound shipments) will have to be combined with many others before they are dispatched. The magnitude of the correlation increases significantly in the reduced database.

When a simple linear regression model procedure is applied to the full database, the resulting $R^{2}$ equals .001 . Service has a small but significant impact on the dependent variable, RTM, at the .01 percent level. The results of analyzing the reduced data set of 3833 shipments using the simple linear regression model procedure are reported in Table 15. 
TABLE 15

$$
\begin{gathered}
\text { REGRESSION ANALYSIS, HYPOTHESIS } 9 \\
\text { RTM AND SERVICE }(\mathrm{n}=3833)
\end{gathered}
$$

\begin{tabular}{llcccc}
\hline & a value & b value & F Value & Pr>F & $R^{2}$ \\
\hline Service & 0.465 & -0.042 & 35.07 & 0.001 & 0.009 \\
LService & 0.426 & -0.079 & 35.66 & 0.001 & 0.009 \\
\hline
\end{tabular}

In the full database, the value of $\mathrm{R}^{2}$ can be increased only slightly by normalizing the dependent and independent variables. When the dependent variable, RTM, and the independent variable, Service, are transformed into their natural logarithmic forms, the simple linear regression model for the full database produces a value of $R^{2}=.008$. For the reduced database the transformed variables produce a value of $\mathrm{R}^{2}=.001$. For the full database transformation the value of $R^{2}$ is small but significant at the .01 percent level. For the reduced database transformation the value of $\mathrm{R}^{2}$ is also small, but significant at the .05 percent level. When the dependent variable is specified as Charge rather than RTM, much more of the variation in rates can be explained by the service level offered by the motor carrier. By examining the correlation coefficients it can be seen that the correlations for Charge and Service in both the full $(r=-.288, p<.01)$ and reduced $(r=-.263, p<.01)$ 
databases are significant. The magnitude of the correlations indicate that the relationships between Charge and Service are important in both databases.

The signs of the correlations are consistently negative in both databases. This inverse relationship is as expected. Because service levels were coded, with one being good service and three being poor service, an inverse relationship indicates that shippers pay more for better service.

When a simple linear regression model procedure is applied to the full database, the model with Charge specified as the dependent variable has an $R^{2}=.083$. The above model results indicate that for the full database, Service has a significant impact on the dependent variable, Charge, at the .01 percent level. The simple linear regression model procedure for the reduced data set of 3833 shipments with Charge specified as the dependent variable produces an $R^{2}$ value of .069 .

In the case of the full database it should be noted that the value of $R^{2}$ can be increased by normalizing the dependent and independent variables. When the dependent variable, Charge, and the independent variable, Service, are transformed into their natural logarithmic forms, the simple linear regression model for the full database produces an value of $\mathrm{R}^{2}=.100$. For the reduced database the transformed variables produce a value of $R^{2}=.088$. For the 
full and reduced database transformations, the values of $R^{2}$ are significant at the .01 percent level.

\section{Data Analysis Summary}

The preceding pages of this chapter are concerned with the testing of individual hypotheses formulated through speculation about relationships between dependent and independent variables. In almost every case the independent variables have a significant relationship with the dependent variables. When such relationships exist, any change in the value of an independent variable has an impact on the value of the dependent variable. When all of the independent variables are considered individually, some of them contribute more than others in explaining the variation in the dependent variable. This leads to the conclusion that some of the independent variables are more important than others in explaining motor carrier pricing behavior. The question in this case becomes which of the independent variables are the most important.

The independent variables not only have relationships with the dependent variables, they also have relationships with each other. When two independent variables are closely related, it is obvious that it would not be necessary to use both of them to explain motor carrier pricing behavior. Which one of the two closely related variables to use, however, is not easily determined. The issue of which combination of independent variables best explains the 
pricing behavior of motor carriers in an unregulated environment is addressed below.

\section{Motor Carrier Rate Models}

When all of the independent variables are considered as candidates for inclusion in a motor carrier rate model, which of them contribute most and which least to explaining the variation in the dependent variable? Which of the independent variables can be omitted from a motor carrier rate model without harming the power of the model to explain motor carrier rates? Which form of the dependent variable should be used in a motor carrier rate model? To answer these questions, two motor carrier rate models are formulated using regression analysis procedures. The data set used to build these models is the reduced data set with shipments of under 250 pounds removed.

Two different dependent variables, RTM and Charge, are specified for use in rate model formulation. Fourteen independent variables are considered for inclusion in the motor carrier rate models. Six of these independent variables are Class, Density, Value, Citysize, Carrsize, and Service. An additional six independent variables are created by computing the natural logarithmic forms of the six variables previously listed. The reasons for this particular form of data transformation and justification for data transformation have been discussed previously. Transformed data often increases the explanatory power of 
models when the relationships between dependent and independent variables are non-linear in nature or when the data or the residuals are not normally distributed. These 12 independent variables were previously used to test six of the individual research hypotheses.

Two of the 14 independent variables considered for inclusion in the model are dummy variables. These variables identify shipments made with special equipment (EqDummy) and interline shipments (Interline). For these variables the database is divided into two groups and the observations in each of the groups are assigned values of 1 or 0 . Due to the nature of the data, the independent variable, Region, was not considered for inclusion in the motor carrier rate model.

Reduced Database Analysis

A first step in the construction of motor carrier rate models is to examine the correlation matrix for the two dependent variables and the 14 independent variables. When RTM is designated as the dependent variable, the correlation matrix shows that the relationships between RTM and nine of the 14 independent variables are significant at the p.>.01 level. In addition, three of the independent variables have relationships with RTM which are significant at the p.>.05 level. The only two variables which do not have significant relationships with RTM are Service and LService. This makes it unlikely that these two variables would be included in a 
rate model developed to explain motor carrier pricing behavior. The remaining 12 independent variables appear to be candidates for inclusion in a motor carrier rate model with RTM designated as the dependent variable.

When Charge is designated as the dependent variable, the correlation matrix shows that the relationships between Charge and 8 of the 14 independent variables are significant at the p.>.01 level. The relationship between RTM and LDensity is significant at the p.>.05 level. The relationships which are non-significant at the p.>.10 level are LClass, CitySize, LCitySize, Value, and Interline. The lack of correlation between Charge and the independent variables in these five cases would seem to excludes these variables as likely candidates for further consideration in the model building process.

The second step in the development of a motor carrier rate models involved a $t$ test examination of the means of the 14 independent variables. The General Linear Model Procedure of the SAS Statistical Analysis System was used to test the means of the independent variables for statistical significance. RTM and Charge were both used as dependent variables in the models and the results of both analyses are reported in Table 16 and Table 17. In this step of the model building process only 669 of the 3833 observations in the reduced dataset could be used. The SAS General Linear Model Procedure automatically eliminated observations with 
missing values for any of the 14 independent variables in the model.

TABLE 16

GENERAL LIINEAR MODEL REGRESSION RESULTS DEPENDENT VARIABLE， RTM

\begin{tabular}{|c|c|c|c|}
\hline Parameter & Estimate & $t$ value & Probability \\
\hline Intercept & -1.464 & -3.19 & $0.001^{*}$ \\
\hline Class & 0.000 & 0.02 & 0.982 \\
\hline LClass & 0.345 & 2.70 & $0.007^{*}$ \\
\hline Density & 0.002 & 1.37 & 0.170 \\
\hline LDensity & -0.025 & -0.68 & 0.494 \\
\hline Value & -0.001 & -1.52 & 0.129 \\
\hline LValue & -0.011 & -1.08 & 0.281 \\
\hline Citysize & 0.176 & 4.88 & $0.001^{*}$ \\
\hline LCitysize & -0.507 & -4.97 & $0.001^{*}$ \\
\hline Carrsize & 0.250 & 4.22 & $0.001^{*}$ \\
\hline LCarrsize & -0.535 & -4.24 & $0.001^{*}$ \\
\hline Service & 0.098 & 0.76 & 0.447 \\
\hline LService & -0.178 & -0.75 & 0.456 \\
\hline EqDummy & -0.076 & -3.26 & $0.001^{*}$ \\
\hline Interline & 0.073 & 1.89 & $0.059^{* *}$ \\
\hline $\begin{aligned}= & 0.269 \\
= & 669 ; \\
& \text { signifi } \\
& \text { signifi }\end{aligned}$ & $\begin{array}{l}\text { at } p_{.}>.01 \\
\text { at } p_{.}>.10\end{array}$ & & \\
\hline
\end{tabular}


TABLE 17

GENERAL LINEAR MODEL REGRESSION RESULTS DEPENDENT VARIABLE, CHARGE

\begin{tabular}{|c|c|c|c|c|c|}
\hline Parameter & & Estimate & & $t$ value & Probability \\
\hline Intercept & & 3945.131 & & 4.49 & $0.001^{*}$ \\
\hline Class & & 3.914 &. & 1.37 & 0.170 \\
\hline LClass & & -691.181 & & -2.83 & $0.005^{*}$ \\
\hline Density & . & 6.951 & & 3.02 & $0.003^{*}$ \\
\hline LDensity & & -228.961 & & -3.27 & $0.001^{*}$ \\
\hline Value & & -1.345 & & 1.42 & 0.157 \\
\hline LValue & & 39.907 & . & 1.98 & $0.048^{* *}$ \\
\hline Citysize & & -210.175 & & -3.04 & $0.003^{*}$ \\
\hline LCitysize & & 459.079 & 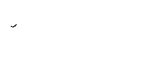 & 2.35 & $0.019^{* *}$ \\
\hline Carrsize & & 126.482 & & 1.12 & 0.264 \\
\hline LCarrsize & & -520.169 & & -2.16 & $0.032 * *$ \\
\hline Service & & -32.107 & & -0.13 & 0.896 \\
\hline LService & & -196.019 & & -0.43 & 0.668 \\
\hline EqDummy & & 178.151 & & 4.01 & $0.001^{*}$ \\
\hline Interline & & -179.919 & 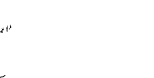 & -2.45 & $0.015^{* *}$ \\
\hline $\begin{aligned}= & 0.347 \\
& 669 ; \\
& \text { signifi } \\
& \text { signifi }\end{aligned}$ & $\begin{array}{l}\text { nt } \\
\text { nt }\end{array}$ & $\begin{array}{l}\text { at } p .>.01 \\
\text { at } p .>.10\end{array}$ & & & . \\
\hline
\end{tabular}

The parameter estimates, $t$ values, and probabilities reported in Tables 16 and 17 indicate that not all of the 14 independent variables are equally good candidates for 
inclusion in a motor carrier rate model. In the interest of statistical efficiency a model should contain as few independent variables as possible without compromising the power of the model to explain changes in the dependent variable. The non-significant variables can, in both cases, be omitted without harming the power of the model to explain motor carrier rates.

The next step in the model building process involves the use of the Stepwise Regression Procedure of the SAS System. Models with RTM and Charge specified as dependent variables and Class, LClass, Density, LDensity, Value, LValue, Citysize, LCitySize, Carrsize, LCarrsize, Service, LService, EqDummy, and Interline specified as independent variables are analyzed using the stepwise Regression Procedure. The significance level for independent variable entry into the model is set at the program default value of 0.15 percent. Using this procedure, the independent variables which contribute little to the explanatory power of the model are rejected. The results produced by these models are summarized in Table 18.

A second analysis is performed with Class and LClass eliminated from consideration as independent variables. The justification for this analysis is that Class and LClass are composite measures and their inclusion in a model restricts several other independent variables from being considered for entry into the model. The results of this analysis are reported in Table 19. 
TABLE 18

STEPWISE REGRESSION RESULTS*

Dependent Variable RTM

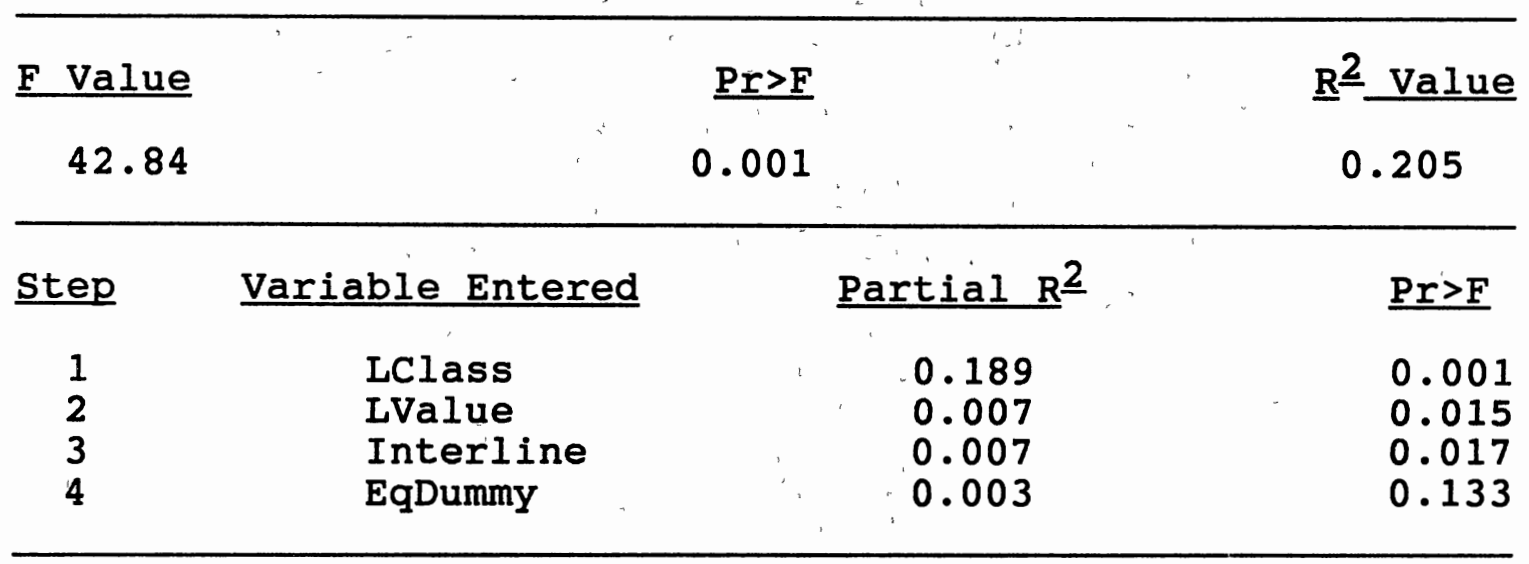

Dependent Variable Charge

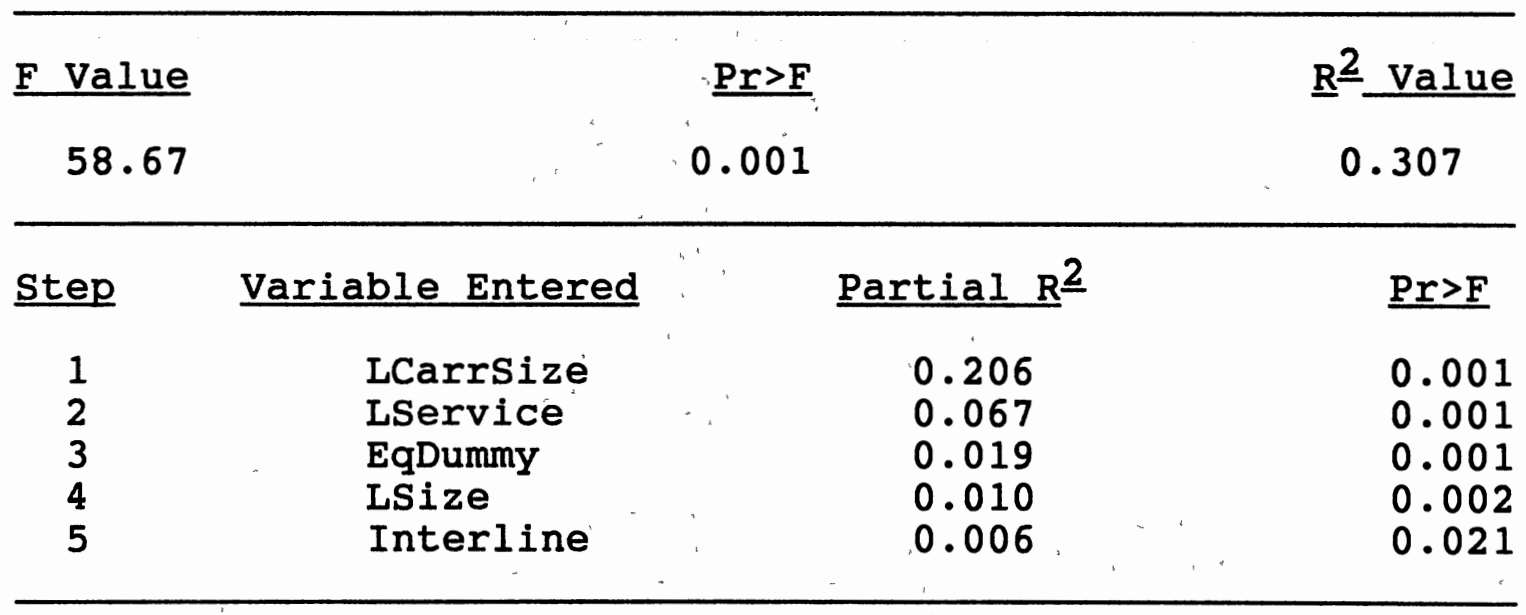

* Class and LClass considered for inclusion 
TABLE 19

STEPWISE REGRESSION RESULTS*

Dependent Variable RTM

\begin{tabular}{|c|c|c|c|c|}
\hline F Value & $\because$ & $\underline{P r}>F$ & & $\underline{\mathrm{R}} \underline{2}$ Value \\
\hline 28.92 & " & 0.001 & & 0.172 \\
\hline Step & Variable Entered & & Partial $\mathrm{R}^{2}$ & $\underline{P r}>F$ \\
\hline $\begin{array}{l}1 \\
2 \\
3 \\
4 \\
5\end{array}$ & $\begin{array}{l}\text { Worth } \\
\text { LDensity } \\
\text { Density } \\
\text { Interline } \\
\text { EqDummy }\end{array}$ & 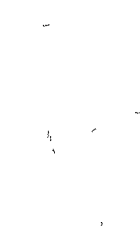 & $\begin{array}{l}0.133 \\
0.014 \\
0.015 \\
0.008 \\
0.004\end{array}$ & $\begin{array}{l}0.001 \\
0.001 \\
0.001 \\
0.011 \\
0.069\end{array}$ \\
\hline
\end{tabular}

Dependent Variable Charge

\begin{tabular}{|c|c|c|c|}
\hline F Value & \multicolumn{2}{|c|}{$\underline{\operatorname{Pr}>\mathrm{F}}$} & $\underline{\mathrm{R}} \underline{2}$ Value \\
\hline 44.61 & & & 0.311 \\
\hline Step & Variable Entered & Partial $\mathrm{R}^{2}$ & $\underline{\mathrm{Pr}>\mathrm{F}}$ \\
\hline $\begin{array}{l}1 \\
2 \\
3 \\
4 \\
5 \\
6 \\
7\end{array}$ & $\begin{array}{l}\text { LCarrSize } \\
\text { Service } \\
\text { EqDummy } \\
\text { CitySize } \\
\text { Interline } \\
\text { CarrSize } \\
\text { LCitySize }\end{array}$ & $\begin{array}{l}0.206 \\
0.064 \\
0.023 \\
0.010 \\
0.006 \\
0.003 \\
0.003\end{array}$ & $\begin{array}{l}0.001 \\
0.001 \\
0.001 \\
0.002 \\
0.014 \\
0.077 \\
0.094\end{array}$ \\
\hline
\end{tabular}

* Class and LClass not considered for inclusion.

In closing this chapter it should be reported that the values of the $\mathrm{R}^{2}$ statistic for the models can be improved substantially by including other variables in the analysis. For example, the value of the $\mathrm{R}^{2}$ statistic for the model with Charge reported above can be more than doubled if 
weight and distance variables are included in the model. A model which includes the natural logarithmic forms for the dependent as well as the independent variables also increases the explanatory power of the modeling process. 


\author{
CHAPTER VII \\ SUMMARY AND CONCLUSIONS \\ Introduction
}

This chapter consists of four major sections. The first section summarizes the research findings. The second section examines the limitations of the study. The third section discusses the implications of these research findings. The final section suggests areas where further research effort might be useful in expanding the body of knowledge in the field.

The major purpose of this study was to determine the factors, other than distance and shipment weight, that influence motor carrier pricing in an unregulated environment. A review of the literature revealed that distance and shipment weight were used as the principal independent variables in almost all motor carrier pricing studies. A mix of secondary independent variables were also included in those studies. However, the lack of consistency in secondary variable selection made it difficult to draw any general conclusions about the contribution these secondary variables made to the understanding of motor carrier pricing behavior. To examine the explanatory power of the secondary variables, shipment weight and distance 
were excluded from the current research effort. This research shows that, within the limits of the study, motor carrier pricing behavior was significantly influenced by several factors other than weight and distance.

\section{Research Findings Summary}

The attributes of the product being shipped were found to have an important impact on motor carrier pricing. Product class, a composite measure which contains many commodity attributes, significantly influenced motor carrier pricing behavior when a reduced database was examined. As the product class number increased, the RTM charged by the motor carrier also increased.

The density of the product, another product attribute measure, was found to be significantly related to the RTM charged under some conditions examined in the study. If the product was less dense than the ideal product density, higher transportation RTM's were paid for the shipment. If, however, the product was more dense than the ideal product density, there was no relationship present between transportation RTM's and product density.

Product value is also a product attribute measure. This variable produced the least consistent results in the study. Product value was significantly related to the RTM charged in only half of the situations studied. As the value of the product increased in the reduced dataset, the transportation RTM paid to the motor carrier also increased. 
When a particular shipment had characteristics which required the use of special equipment, the RTM charged by the motor carrier was different from that charged when standard equipment was used. This relationship was more pronounced when minimum weight shipments were removed from the dataset.

The removal of the minimum weight shipments from the dataset allowed the shipments which required the use of special equipment to have more influence on motor carrier pricing behavior. 'Special equipment shipments tend to be made in larger quantities. Therefore, the special equipment shipments make up a larger percentage of the reduced dataset and they would explain more of the motor carrier pricing behavior than they do in the full dataset.

Two geographic factors, region of origin and size of the origin city, were identified and their impact on motor carrier pricing behavior was evaluated. The region in which the shipment originated was found to have a significant influence on motor carrier pricing behavior. Six of the nine regions fell into a single pricing group. The prices charged by motor carriers for their services did not vary within this group of six regions. Pricing behavior of the motor carriers in the remaining three regions, the Northwest, Midwest, and Southwest, were found to be significantly different than that of the other pricing groups. 
The size of the city in which the shipment originated had a mixed influence on motor carrier pricing behavior. only in some cases did the city size have a small but significant impact on motor carrier pricing behavior. Under other conditions, shipments originating in cities of different sizes did not have significantly different pricing structures.

Two motor carrier attributes were examined to determine whether they had an impact on motor carrier pricing behavior. When the RTM's charged for shipments made by a single motor carrier were contrasted with the RTM's charged for shipments made by two or more motor carriers, the results produced were mixed in both the full and the reduced databases. The RTM's charged for shipments made by multiple carriers was generally higher, but the difference in means of the two groups was not statistically significant.

The size of the motor carrier was found to have a small but significant impact on the pricing behavior of the motor carriers. This was especially true in the reduced database. The larger the motor carrier, the lower its RTM. This supports the idea that there might be some economies of scale involved in larger motor carrier operations.

The final area investigated for its impact on motor carrier pricing behavior was the level of service offered by the motor carrier. The level of service had a direct, significant impact on the RTM charged in almost every case. The higher the level of service, the higher the RTM charged. 


\section{Limitations of the Study}

The major limitation of the study was that all of the shipments have a single destination. Although the shipments used in the study originated in 46 different states and hundreds of different cities, the single destination for all shipments was Tinker AFB, Oklahoma. The possibility exists that shipments destined for this single destination might have a unique pricing structure. If this were true, it would be unlikely that the study results could be generalized. Oklahoma generally imports finished goods and exports raw materials. The flow of freight into Tinker AFB would certainly be considered finished goods. Lack of a corresponding flow of raw materials in the opposite direction could cause an adverse effect on motor carrier prices. An imbalance in the flow of raw materials and finished goods would be reflected in the motor carrier rates.

A second limitation of the study was that it was not possible to gather data on numerous independent variables which had been used in past motor carrier pricing research. Although weight and distance were commonly used as independent variables in almost all studies, the selection of what might be classified as secondary independent variables usually depended on data availability. Data available also controlled the secondary independent variables selected for the current study. It appears that this was also true in many other previous motor carrier 
pricing studies. This lack of independent variable commonalty between studies makes it difficult to compare the results reported for one study with those reported for

others. Without a common use database it is unlikely that a general theory of motor carrier pricing behavior can ever be developed.

A third limitation of the study was caused by missing data. The original dataset contained information on over 15,000 motor carrier shipments inbound to Tinker AFB. When all of the observations with missing data were removed, the number of usable observations was reduced to just over 5600 . In some cases the database was further reduced because data was missing on variables added to the original database. For example, product density information was only available for 1200 of the shipments. The possibility exists that the observations studied do not represent the true population under consideration.

The fourth limitation of this study was that it involved military shipments only. The only disaggregated database readily available for public use was the database maintained by the Military Traffic Management Command. Information from this database was easily acquired under the provisions of the Freedom of Information Act. Motor carrier pricing information from non-public sources proved impossible to acquire. The possibility exists that the pricing behavior of motor carriers might be different when dealing with the government than it is when dealing with a 
private sector company. If this is the case, the study might not be applicable to the civilian sector.

A final limitation of the research involves the time period selected for study. The year of motor carrier shipments studied was carefully selected to allow initial deregulation pricing effects to diminish and to coincide with the only two other empirical studies done in the area. It is quite possible that as the motor carriers gained experience in the services pricing area the factors they consider in setting their prices have changed.

\section{Implications of the Study}

This research effort helps overcome some of the limitations of motor carrier pricing studies done using the case study and the survey approach. As pointed out earlier in this paper, there is always a chance that the group surveyed or the subject of the case study do not truly represent the feelings of the population of interest. For example, it has been widely reported in the motor carrier industry literature that a group of surveys and case studies show motor carrier service to small communities had declined in the decade following the deregulation the of the motor carrier industry. There is a second group of surveys and case studies, however, which show that motor carrier service levels to small communities have improved or, at a minimum, are no lower than they were before July of 1980. There are also conflicting case study and survey results in the areas 
of large and small shippers, overall service levels, and motor carrier pricing.

As long as there is a lack of unanimity in the results produced by case studies and surveys in the area of motor carrier pricing behavior, it is unlikely that a general theory of motor carrier pricing behavior can be formulated and tested. A large scale empirical study will always be necessary to resolve conflicts produced by the case studies and surveys and to confirm the conclusions reached by research efforts based on these techniques.' This study serves as a check on survey and case study findings in the nine areas where motor carrier pricing behavior was tested. The research also gives those researchers interested in the area of motor carrier pricing a deeper understanding of the nature of motor carrier pricing in an unregulated environment. Since deregulation of the motor carrier industry in 1980, this is only the third major pricing study done which is based on a large disaggregated dataset. The lack of empirical studies has been a major shortcoming in the area of motor carrier rate research. Although a single research effort fails to completely overcome the serious deficiency caused by the lack of empirical studies in motor carrier pricing behavior, it does add a great deal to the pool of knowledge about the subject.

By excluding shipment weight and distance as possible independent variables considered for inclusion in a motor carrier rate model, other independent variables are given 
the opportunity to explain more of the pricing behavior of motor carriers. This research identifies the most important of these secondary independent variables and defines the conditions under which they are important. By focusing on these secondary variables, the current research enriches the understanding of motor carrier pricing behavior. Although the amount of motor carrier pricing behavior explained by many of these secondary variables is small, it is in almost all cases significant. This study widens the field of independent variables which future motor carrier pricing researchers will be able to consider for inclusion in motor carrier rate models.

By examining the actual motor carrier pricing structure of the major industry in central oklahoma, a motor carrier pricing benchmark is set for all other firms located in the area. Local firms can compare their transportation rates to those paid by Tinker AFB. This will give these local firms a good idea if the rates they are paying are reasonable. The motor carrier pricing information will also be useful to governmental and non-governmental agencies in their attempts to attract industries to the local area. A great deal of effort is expended by economic development agencies to gather information about their area for prospective industrial relocation candidates. It can only make the informational packet more impressive if a complete analysis of inbound motor carrier rates can be included. 
Finally, this study of motor carrier pricing behavior identifies a public use database that has been completely neglected in the past. The research shows that the database can be used successfully to investigate the area of motor carrier pricing behavior. This might be the most important aspect of the study. In the past motor carrier rate research has been severely hampered by the lack of a large, public use database containing disaggregated data. This deficiency has been identified repeatedly in the motor carrier pricing literature.

\section{Future Research Efforts}

The study needs to be expanded to other Air Force Logistical Centers located throughout the United States. There are centers located in California, Utah, Texas, Ohio, and Georgia. Motor carrier shipment data for these destinations are in the public domain and easily accessible. It also needs to be expanded to examine shipments made by other branches of the armed services. Are the motor carrier price structures for other destinations comparable to Tinker AFB and are they comparable to each other? This expansion from a single destination study to one involving multiple destinations would overcome the limitations of a single destination study and validate the current research. If the study is expanded into a multiple destination study, than sampling of the available data should be considered. 
An additional study needs to be done using Tinker AFB data from a later time period. Data from the 1988 - 1989 time period is readily available and complete at this time. A study which replicates the current study and uses a different time period database would assure that the findings of the first study are stable over time.

The final area where additional research needs to be conducted is in the area of non-governmental motor carrier traffic. A study needs to be conducted using civilian traffic, disaggregated data, and the same variables used in the current research. This type of research project would answer the questions which are sure to arise about the similarity of governmental and civilian motor carrier shipments. 


\section{LITERATURE CITED}

Allen, B. J. (1981). The nature, effectiveness and
importance of motor carrier service obligations.
American Economic Review, $\underline{71}(2), 110-115$.

Allen, B. W., Lonergan, S., \& Plane, D. (1978). Examination of the unregulated trucking experience in New Jersey. Washington, DC: Office of University Research, U. S. Department of Transportation.

Altschiller, D. (1982). Transportation in America. New York: H. W. Wilson.

American Enterprise Institute (1980). Regulatory reform for motor carriers: An analysis of pending leglislation. Washington, DC: The Institute.

American Gas Association (1987). 1987 Gas facts. Arlington, VA: The Association.

American Trucking Associations (1974). Accounting for motor carrier operating rights. Washington, DC: Financial Accounting Foundation, The Associations.

American Trucking Associations (1979a). Trucking regulation: In the public interest. In Papers on vital transportation issues, 2,7-8. Washington, DC: The Associations.

American Trucking Associations (1979b). American trucking trends: 1978-1979. Washington, DC: The Associations.

American Trucking Associations (1980). 1980 Financial analysis of the motor carrier industry. Washington, DC: The Associations .

American Trucking Associations (1981). American trucking trends: 1979-1980. Washington, DC: The Associations.

American Trucking Associations (1983a, December 5) . Court asked to curb ICC antitrust action. Transport Topics, 1 .

American Trucking Associations (1983b, December 19). DOT urges end to joint ratemaking. Transport Topics, 1, 26 . 
American Waterways Operators (1972). United for action. Washington, DC: The Operators.

American Waterways Operators (1981). The barge and towing industry - A statistical profile. Washington, DC: The Operators.

AMOCO Educational Services (1983). Oil on the move. Chicago: American Oil Company.

Association of American Railroads (1973). Railroads in the cost spiral. Washington, DC: The Association.

Association of American Railroads (1978). Basic provisions of the railroad revitalization and regulatory reform act of 1976. Washington, DC: The Association.

Association of American Railroads (1983). Yearbook of railroad facts (1983 ed.). Washington, DC: The Association.

Association of American Railroads (1984). The economic abz's of the railroad industry. Washington, DC: The Association.

Backman, J. (1983). Price practices and price polocies. New York: Ronald Press.

Ballou, R. H. (1987). Basic business logistics. Englewood Cliffs, NJ: Prentice-Hall.

Barrett, C. (1972). The theory and practice of carrier rate-making. Transportation and Distribution

Management, $12(10)$.

Becht, J. E. (1970) • A geography of transportation and business logistics. Dubuque, Iowa: William C. Brown.

Beilock, R. (1985). Is regulation necessary for value-ofservice pricing? Rand Journal of Economics, 16(1), 93102 .

Beilock, R., \& Freeman, J. (1982): Carrier and shipper perceptions of motor carrier deregulation in Flordia. In Proceedings of the Transportation Research Forum, 23, 250-257.

Beilock, R., \& Freeman, J. (1984). Deregulated motor carrier service to small communities. Transportation Journal, $\underline{23}(4), 80-81$. 
Beilock, R., \& Freeman, J. (1987). The effect on rate levels and structures of removing entry and rate cControls on motor carriers. Journal of Transport Economics and Policy, $\underline{21}(2), 167-188$.

Beilock, R., \& Shonkwiler, J. S. (1982). An analysis of rate variation across time for identical hauls of unregulated commodities. In Proceedings of the Transportation Research Forum, 23, 300-305.

Berkowitz, E. N., Kerin, R. A., Rudélius, W. (1989). Marketing (2nd ed.). Homewood, IL: Richard D. Irwin.

Bernstein, G. W. \& \& Dajani, J. S. (1979). Modal-split models of air and truck competition. In Proceedings of the Transportation Research Forum, 20, 106-115.

Binkley, J., \& Harrar, B. (1981). Major determinants of ocean freight rates for grain: An economic analysis. American Journal of Agricultural Economics, 63, 47-57.

Blair, R. D., Kaserman, D. L., \& McClave, J. T. (1986). Motor carrier deregulation: The Flordia experiment. Review of Economics and Statistics, 68(1), 159-164.

Borts, G. H. (1954). Increasing returns in the railway industry. The Journal of Political Economy, 62, 316333 .

Bowers, E. W. (1986; January 6). Truckers face more deregulation. Traffic World, 4-5 (year end review).

Bowersox, D. J. (1978), Logistical management (2nd ed). New York: MacMilian.

Boyer, K. D. (1978). How similar are motor carrier and rail rate structures?: The value-of-service component. In Proceedings of the Transportation Research Forum, 19, 523-531.

Breen, D. A, \& Allen, B. J. (1980). Common carrier obligations of motor carrier service to small rural communtities. Quarterly Review of Economics and Business, 20 (4), 86-106.

Burck, C. G. (1978, December 18). Truckers roll toward deregulation. Fortune, 75-85.

Burke, J. L. (1964). Oil-pipelines' place in the transportation industry. ICC Practitioners' Journal, $31,(3), 788$.

Calmus, T. W (1969). Full costs versus incremental costs: Again. Transportation Journal, $\underline{9}(2), 31-36$. 
Casavant, K. L. (1979). Issues in freight transportation regulation: Discussion. American Journal of

Agricultural Economics, 61, 1012-1013.

Chagnon, P. R. (1980, June). Competition and regulated rates:-Can they co-exist? TRANSLOG, $2-4$.

Chiang, Y., Roberts, P. O., \& Ben-Akiva, M. (1981). Development of a policy sensitive model for forcasting freight demand. Washington, DC: Assistant secretary for Policy and International Affairs, U. S. Department of Transportation.

Chow, G. (1978). The status of economies of scale in regulated trucking: A review of the evidence and future directions. In Proceedings of the Transportation Research Forum, 19, 365-373.

Chow, G. (1980a) . Studies of interstate trucking regulation: A critique. Transportation Journal, 19(4), 23-32.

Chow, G. (1980b). Motor carrier rate bureaus: Shippers' vs. carriers' views. Journal of Purchasing and Materials Management, $16(1), 21-24$.

Chow, G. (1980c). The impact of state regulation on motor carrier performance. Logistics and Transportation Review, 16(3), 209-223.

Clark, J.M. (1940). Toward a concept of workable competition. American Economic Review, $\underline{30}(2), 241-256$.

Corsi, T. M., \& Roberts, M. J. (1982). Patterns of discrimination in the collective ratemaking system. In Proceedings of the Transportation Research Forum, 23, 621-630.

Cort C. J. (1970). The economic regulation of the road transportation industry. Washington, DC: International Bank for Reconstruction and Development.

Cover, V., \& Cutler, H. (1959)." Government procurement of and provision of transportation services. Washington, DC: U. S. Department of Commerce.

Coyle, J. J. (1965). Cost of service pricing in transportation: Some reflections. Quarterly Review of Economics and Business, $\underline{5}(1), 63-74$.

Coyle, J. J. (1966, September 15). Dissimilar pricing: A logical approach to regulated rates. Public Utilities Fortnightly, 32-45. 
Coyle, J. J., \& Bardi, E. J. (1984). The management of business logistics ( $3 \mathrm{rd}$ ed.). Saint Paul, MN: West.

Coyle, J. J., Bardi, E. J., \& Cavinato, J. L. (1986). Transportation (2nd ed.). Saint Paul, MN: West.

Davis, G. M. (1987). Unresolved issues in U.S. trucking regulatory modernization debate. Transportation Practitioners' Journal, 163-176.

Davis, G. M., \& Combs, L. J. (1975). Some obversations concerning value of service pricing in transportation. Transportation Journal, 14(3), 49-58.

Department of Defense (1955). Department of defense experience under section 22 of the interstate commerce act. Washington, DC: U. S. Department of Defense.

Department of Transportation (1972). Executive briefing: Transportation regulatory modernization and assistance leglislation. Washington, DC: Office of the Secretary, U. S. Department of Transportation.

DeVany, A. S., \& Saving, T. R. (1977). Product quality, uncertainty, and regulation: The trucking industry. American Economic Review, 67, 583-594.

Dillon, W. R., Madden, T. J., \& Firtle, N. H. (1987). Marketing research in a marketing environment. St. Louis: Times Mirror/Mosby.

Doyle, J. R. (1969, Janurary 11). National transportation pricing policy. Traffic World, 74 .

Dun's Review (1980, October). Private trucking: Low profile giant, 124 .

Due, J. W., \& Clower, R. W. (1966). Intermediate economic analysis (5th ed.). Homewood, IL: Richard D. Irwin.

Duncan, T. (1984, February). The pickings are good for fleets that tailor services. Fleet Owner, 93.

Economist, The (1978). Uneasy riders. The Economist, $\underline{275},(7136), 86$.

Edwards, F. K. (1969). The role of transportation costs and market demand in railroad rate making. Transportation Journal, $\underline{9}(1), 45-49$.

Enis, C. R., \& Morash, E. A. (1987). Some aspects of motor carrier size, concentration tendencies, and performance after deregulation. Akron Business and Economic Review, 17, 82-94. 
Fair, M. L, \& Williams, E. W. Jr. (1975). Economics of transportation and logistics. Dallas, TX: Business Publications.

Fair, M. L., \& Williams, E. W. Jr. (1981). Transportation and logistics. Plano, TX: Business Publications.

Farmer, R. N. (1964). The case for unregulated truck transportation. Journal of Farm Economics, $46(2), 398-$ 409 .

Federal Highway Administration (1972). Annual truck weight study. Washington, DC: U. S. Department of Transportation.

Felton, J. R. (1978). The cost and benefits of motor trucking regulation. Quarterly Review of Economics and Business, $18(2), 7-20$.

Ferguson, W. (1982). Life after deregulation: The motor carrier environment. International Journal of Physical Distribution and Materials Management, 12(4), 44-51.

Ferguson, W., \& Glorfield, L. W. (1981). Modeling the present motor carrier rate structure as a benchmark for pricing in a new competitive environment. Transportation Journal, $\underline{21}(2)$, 59-66.

Fisher, R. H. (1980, July). Automated traffic management in the $1980^{\prime} \mathrm{s}$. TRANSLOG, 4 .

Friedlaender, A. F. (1969). The dilemma of freight transportation requlation. Washington, DC: Brookings Institution.

Friedlaender, A. F., \& Simpson, R. (1978). Alternative scenarios for federal transportation policy: Freight policy models. Washington, DC: Office of University Research, U. S. Department of Transportation.

Friedlaender, A. F., \& Spady, R. H. (1981). Freight transportation regulation: Equity, efficiency and competition in the rail transportation industries. Cambridge, MA: M.I.T. Press.

Fruin, J. E. (1981). Impacts on agriculture of deregulating the transportation system: Discussion. American Journal of Agricultural Economics, 63, 923-925.

Gatty, B. (1983). Turmoil in trucking. Nation's Business, $71(10), 57-60$. 
Glaskowsky, N. A. (1986). Effects of deregulation on motor carriers. Westport, CT: Enos Foundation For Transportation.

Goodrich, C. (1960). Government promotion of american canals and railroads 1800-1890. New York: Columbia University Press.

Griffith, T. F., Daniel, N. E., Shrock, D. L., \& Farris, M. T. (1983). Inbound freight and deregulation: A management opportunity. Journal of Purchasing and Materials Management, $19(3), 16-21$.

Hall, R. W. (1985). Dependence between shipment size and mode in freight transportation. Transportation Science, $19,436-444$.

Handling and Shipping Management (1982, Month and Date*). Shippers roundtable airs transportation concerns. Handling and Shipping Management, 16-18.

Harper, D. V. (1959). Economic regulation of the motor carrier industry by the states. Urbana, IL: University of Illinois Press.

Harper, D. V. (1966). Price policy and procedure. New York: Harcourt, Brace, Jovanovich.

Harper, D. V. (1978). Transportation in america: Users, carriers, government. Englewood Cliffs, NJ: PrinticeHall.

Harper, D. V. (1980). The federal motor carrier act of 1980: Review and analysis. Transportation Journal, $\underline{20}(1), 5-33$.

Harper, D. V. (1982). Transportation in america (2nd ed.). Englewood Cliffs, NJ: Printice-Hall.

Harper, D. V. (1982). Consequences of reform of federal economic regulation of the motor carrier industry. Transportation Journal, $\underline{21}(4), 35-58$.

Harper, D. V. (1983). The marketing revolution in the motor trucking industry. Journal of Business Logistics, $\underline{4}(1), 35-49$.

Harper, D. V., \& Johnson, J. C. (1987). The potential consequences of deregulation of transportation revisited. Land Economics, 63(2), 137-146.

Hazard, J. L. (1955) . Crisis in coastal shipping. Austin, TX: Bureau of Business Research, University of Texas. 
Hazard, J. L. (1977) . Transportation: Management, economics, policy. Cambridge, MD: Cornell Maritime Press.

Healy, K. T. (1961). The effects of scale in the railroad industry. New Haven, CT: Committee on Transportation, Yale University.

Hillen, P. G. (1984, December). Deregulation's impact on the DOD. TRANSLOG, 1-5.

Hoover, H. (1985). Pricing behavior of deregulated motor common carriers. Transportation Journal, 25(2), 55-61.

Hudson, W. J., \& Constantin, J. A. (1958). Motor transportation: Principals and practices. New York: Ronald Press Company.

Hunt, S. D., Muncy, J. A., \& Ray, N. M. (1981). Alderson's general theroy of marketing: A formalization. In B. M. Enis \& K. J. Roering (Eds.), Review of Marketing, 269. Chicago: American Marketing Association.

Inland Waterway Commission (1912). Inland waterway commission report. Washington, DC: U. S. Government Printing Office.

ICC (1965). Profile of motor carriers of property subject to ICC regulation. Washington, DC: Bureau of Economics, The Commission.

ICC (1979a). Economic impact of new motor carrier entry for the transportation of government traffic. Washington, DC: Office of Policy and Analysis, The Commission.

ICC $(1979 \mathrm{~b})$. Initial report of the motor carrier task force. Washington, DC: Motor Carrier Task Force, The Commission.

ICC (1980). Annual report, 1980. Washington, DC: The Commission.

ICC (1977). 91st Annual Report. Washington, DC: U. S. Government Printing office.

Johnson, A. M. (1956). The development of american petroleum products. Ithaca, NY: Cornell University Press.

Johnson, A. M. (1967) Petroleum pipelines and public policy, 1906-1959. Cambridge, MA: Harvard University Press . 
Johnson, J. C., \& Wood, D. F. (1986). Contemporary physical distribution and logistics (3rd ed.). New York:

MacMillan.

Jones, J. R. (1979). United states department of transportation industrial shipper survey, plant level. Washington, DC: U. S. Government Printing office.

Jones, R. M. (1940). Land grant railroad rates. The George Washington Law Review, $\underline{8}$, 933-938.

Jordan, W. A. (1970). Airline regulation in america. Baltimore, MD: John Hopkins University Press.

Karolevitz, R. F. (1966). This was trucking. Seattle, WA: Superior Publishing.

Keyes, L S. (1980). Regulatory reform in air cargo transportation. Washington, DC: American Enterprise Institute.

Klaus, P. G. (1981). Trucking deregulation-the west german experience. In Proceedings of the Transportation Research Forum, 22, 47-54.

Krielel, W. R., \& Baumel, C. P. (1979). Issues in freight transportation regulation. American Journal of Agriculture Economics, 61, 1003-1009.

Krielel, W. R., \& Baumel, C. P. (1983). Issues in freight transportation regulation: Reply. American Journal of Agriculture Economics, 65, 629-632.

Labich, K. (1985, November 11). Blessings by the truckload. Fortune, 138 .

Leftwich, R. H. (1970). The pricing system and resource allocation (4th ed.). Hinsdale, IL: Dryden Press.

Levin, R. (1978) . Allocation of surface freight transportation: Does rate regulation really matter? Bell Journal of Economics, $9,18-45$.

Levine, H. A. (1973). A historical analysis of the criteria to determine the revenue needs of motor common carriers. ICC Practitioners' Journal, 40 , (2).

Lieb, R. C. (1981). Transportation: The domestic system (2nd ed.). Reston, VA: Prentice-Hall.

Lockley, L. C. (1949). Theories of pricing in marketing. Journal of Marketing, $\underline{13}, 364-366$. 
Locklin, D. P. (1966). Economics of transportation (6th ed.). Homewood, IL: Richard D. Irwin.

Lovelock, C. H. (1984). Services marketing. Englewood Cliffs, NJ: Prentice-Hall.

Lowe, J. C., \& Moryadas, S. (1975). The geography of movement. Boston, MA: Houghton Mifflin.

Lucas, B. (1979, August) . Traffic managers face change. TRANSLOG, 2-4.

Luna, C. (1971). The handbook of transportation in america. New York: Popular Library.

Machalaba, D. (1985, December 18). More companies push freight haulers to get better rates, service. Wall Street Journal, 1 .

Maister, D. H. (1978). Regulation and the level of trucking rates in canada: Additional evidence. Transportation Journal, $18(2), 49-62$.

Maister, D. H. (1979). Regulation and the level of trucking rates in canada. In Proceedings of a Workshop on Motor Carrier Economic Regulation. Washington, DC: National Acadeny of Sciences.

Manalytics, Inc. (1978). A Comparison of Motor Carrier Freight Charges in Differing Regulatory Jurisdictions. Washington, DC: U. S. Department of Transportation.

McCormick, C. J. (1980, April) . Joint Conference Report, Part III. Traffic Ouarterly, 243.

McMullen, B. S., \& Schary, P. (1986). Intrastate regulation and interstate motor carriers. In Proceedings of the Transportation Research Forum, 27, 193-197.

McRae, J. J., \& Prescott, D. M. (1979). The effects of regulation on the canadian common carrier industry. Ottawa, Canada: The Economic Council of Canada.

Mentzer, J. T., \& Gomes, R (1986). Deregulation of the motor carrier industry: A retrospective analysis. International Journal of Physical Distribution and Materials Management, $16(7), 46-58$.

Mertins, H. (1972). National transportation policy in transition. Lexington, MA: D. C. Heath.

Meyer, J. R., Peck, M. J., Stenson, J., \& Zwick, C. (1959). The economics of competition in the transportation industries. Cambridge, MA: Harvard University Press. 
Miklius, W. (1969). Economic performance of motor carriers operating under the agricultural exemption ( Marketing Research Report No. 838). Washington, DC: U. S. Depatrment of Agriculture.

Miklius, W., \& Casavant, K. L. (1975). Stability of motor carriers operating under the agricultural exemption. Washington, DC: U. S. Depatrment of Agriculture.

Monroe, A. (1986, Janurary 13). McClean trucking files for chapter 11, will halt operations, liquidate assets. The Wall Street Journal, 5.

Moody's Transportation Mamual (1987).

Moore, T. G. (1972). Freight transportation regulation: Surface freight and the interstate commerce commission. Washington, DC: American Enterprise Institute.

Moore, T. G. (19.76). Trucking requlation: Lessons from europe. Washington, DC: American Enterprise Institute.

Moore, T. G. (1983). Rail and truck reform - the record so far. Regulation, $\underline{7}(6), 34-39$.

Morehouse, J. E. (1983). Operating in a new logistics era. Harvard Business Review, 61(5), 18-19.

Morse, L. W. (1980). Practical handbook of industrial traffic management (6th ed.). Washington, DC: The Traffic Service Corporation.

Morton, A. L. (1971). Competition in the intercity freight market: A waybill study of the motor carrier industry. Washington, DC: Office of Systems Analysis, U. S. Department of Transportation.

Mossman, F. H., \& Morton, N. (1957). Principles of transportation. New York: Ronald Press.

National Commission on Productivity/Council of Economic Advisers (1978). Improving railroad productivity. Washington, DC: U. S. Government Printing Office.

Nelson, J. C. (1936). The motor carrier act of 1935. The Journal of Political Economy, 44(4), 464-504.

Nelson, J. C. (1942). New concepts in transportation regulation. In Transportation and National Policy, Report of the National Resources Planning Board, 197237. Washington, DC: U. S. Government Printing Office. 
Nelson, J. C. (1945). Federal requlatory restrictions upon motor and water carriers. Washington, DC: Board of Investigation and Research, U. S. Government Printing office.

Nelson, J. C. (1959). Entry into domestic surface transportation under the interstate commerce act. Washington, DC: U. S. Department of Commerce.

Nelson, J. C. (1965). The effects of entry control in ssurface transportation in transportation economics. New York: National Bureau of Economic Research.

Nelson, J. C. (1971). Toward rational pricing policies. In E. W Williams, Jr. (Ed.), The future of american transportation, 115-154. Englewood Cliffs, NJ : Prentice-Hall.

Nelson, J. C. (1976). The economic effects of transportation deregulation in australia. Transportation Journal, $\underline{16}(2), 48-71$.

Nelson, J. C. (1987). Politics and economics in transportation Regulation and deregulation - a century perspective on the ICC's role. Logistics and Transportation Review, 23(1), 5-32.

New York Times (1934, August 24). Railmem foresee truck control act. The New York Times, 23.

Nupp, B. (1963). Control over entry as an economic and regulatory problem. ICC Practitioners' Journal, 30, (4).

Oil and Gas Journal (1985). Oil and gas journal databook. Tulsa, Oklahoma: Pennwell Publishing.

Olsen, J. E. (1972). Price discrimination by regulated motor carriers. American Economic Review, 62(3), 395402 .

Owen, W. (1964). Strategy for mobility. Washington, DC: Brookings Institute.

Owen, B., \& Braeutigum, R. (1978). The regulation game. Cambridge, MA: Ballinger Publishing.

Paden, D. L. (1982, May 17). Post-mc act finds shippers most concerned about carrier rates. Transport Topics, 2 .

Paxton, D. S. (1981). Changes in intercity truckload cost and service, 1950-1980. In Proceedings of the Transportation Research Forum, 22, 508-515. 
Pegrum, D. F. (1952). The economic basis of public policy for motor transportation. Land Economics, 28, 244-263.

Pegrum, D. F. (1963). Transportation: Economics and public policy. Homewood, IL: Richard D. Irwin.

Pegrum, D. F. (1973). Transportation: Economics and public policy (3rd ed.). Homewood, IL: Richard D. Irwin.

Posner, R. A. (1971). Taxiation by regulation. Bell Journal of Economics and Management Science, $\underline{2}, 22-50$.

Phillips, C. F (1969). The Economics of regulation (rev. ed.). Homewood, IL: Richard D. Irwin.

Pustay, M. W. (1985). Reform of entry into motor carrier markets: Was the motor carrier act of 1980 necessary? Transportation Journal, 25(1), 11-24.

Rakowski, J. P. (1981). The trucking industry in the united states: A study of transportation policy in transition. Traffic Quarterly, 35, 623-638.

Ranson, C. R., \& Sheldon, G. H. (1980). Advancing competitive policy in the leglislative arena: Flordia's experience. University of Flordia Law Review, 32, 877-897.

Roberts, M. J. (1965). Transportation costs, pricing and regulation. In Transportation Economics, 3-37. New York: National Bureau of Economic Research.

Salop, S., \& Stiglitz, J. (1979). Bargins and rip offs: A model of monopolistically competitive price dispersion. Review of Economic Studies, 44, 493-510.

Sampson, R. J. (1966). The case for full cost ratemaking. ICC Practitioners' Journal, 33 (3), 49-95.

Sampson, R. J., \& Farris, M. T. (1966). Domestic transportation: Practice, theory, and policy. Boston, MA: Houghton Mifflin.

Sampson, R. J., \& Farris, M. T. (1971). Domestic transportation: Practice, theory, and policy (2nd ed.). Boston, MA.: Houghton Mifflin.

Sampson, R. J., \& Farris, M. T. (1975). Domestic transportation: Practice, theory, and policy (3rd ed.). Boston, MA.: Houghton Mifflin.

Sampson, R. J., \& Farris, M. T. (1979). Domestic transportation: Practice, theory, and policy (4th ed.). Boston, MA: Houghton Mifflin. 
Sampson, R. J., Farris, M. T., \& Shrock, D. L. (1985) . Domestic transportation: Practice, theory, and policy (5th ed.). Boston, MA: Houghton Mifflin.

Samuelson, R. D., \& Lerman, S. R. (1977). Modeling the Freight Rate Structure. In Proceedings of the Transportation Research Forum, 18, 387-396.

Sargious, M., \& Tam, T. (1985). Modelling rail and truck freight rates in canada. Logistics and Transportation Review, 21(2), 173-184.

Schneider, L. M. (1985). New era in transportation strategy . Harvard Business Review, 63(2), 118-126.

Shirley, R. E. (1969). Analysis of motor carrier cost formulae developed by the interstate commerce commission. Transportation Journal, $\underline{8}(3), 21-27$.

Sloss, J. (1970) . Regulation of motor freight transportation: A quantitative evaluation of policy. Bell Journal of Economics and Management Science, 1 , 327-366.

Snitzler, J. R., \& Byrne, R. J. (1958). Interstate trucking of fresh and frozen poultry under agricultural exemption (Marketing research report No. 224). Washington, DC: U. S. Department of Agriculture.

Snitzler, J. R., \& Byrne, R. J. (1959). Interstate trucking of frozen fruit and vegetables under agricultural exemption (Marketing research report No. 316). Washington, DC: U. S. Department of Agriculture.

Snow, J. W. (1977) . The problem of motor carrier regulation and the ford administration's proposal for reform in regulation of entry and pricing in truck transportation. In P. W. MacAvoy \& J. W. Snow (Eds.), Ford administration papers on regulatory reform. Washington, DC: American Enterprise Institute.

Spady, R. H., \& Friedlaender, A. F. (1978). Hedonic cost functions for the regulated trucking industry. Bell Journal of Economics, 9 , 159-179.

Stern, G. L (1972). Traffic: Clear signals for higher profits. Harvard Business Review, $\underline{50}(3), 72-82$.

Sugrue, P. K., Ledford, M. H. \& Glaskowsky, N. A. Jr. (1982). Operating economies of scale in the U. S. long-haul common carrier, motor freight industry. Transportation Journal, 22(1), 27-41. 
Taft, C. A. (1961). Commercial motor transportation (3rd ed.). Homewood, IL: Richard D. Irwin.

Taft, C. A. (1969). Commercial motor transportation (4th ed.). Homewood, IL: Richard D. Irwin.

Taft, C. A. (1978). Management of physical distribution and transportation. Homewood, IL: Richard D. Irwin.

Taft, C. A. (1980). Commercial motor transportation (6th ed.). Centerville, MD: Cornell Maritime Press.

Tausz, A (1985). Deregulation down under. Distribution, $\underline{84}(8), 104$.

Taylor, R. H. Jr. (1982). Viewing the motor carrier act of 1980 with 20/20 hindsight. In Annual Proceedings of the National Council of Physical Distribution Management, 1, 209-217.

Traffic Management (1985a). Truckers face hard economic times. Traffic Management, $\underline{24}(8), 13$.

Traffic Management (1985b). TL trucking services. Traffic Management, 24 (12), 55-56.

Traffic Management (1985c). One of the biggest truckers in the west has shut down. Traffic Management, $\underline{24}(12), 2$.

Traffic Management (1986). What's in store for logistics professionals. Traffic Management, $\underline{25}(8), 62-66$.

Traffic World (1983, December 26). Truck industry on recovery route. Traffic World, 14 .

Traffic World (1984, January 30). GAO says motor carrier act of 1980 putting downward pressure on rates. Traffic World, 41 .

Traffic World (1986, March, 17). Hall's motor is latest forced to file for chapter 11 reorganization. Traffic World, 1 .

Transportation Association of America (1979). Transportation facts and trends (15th ed.). Washington, DC: The Association.

Transportation Association of America (1980) . Transportation facts and trends (16.th ed.). Washington, DC: The Association.

Transportation Association of America (1981). Transportation facts and trends (17th ed.). Washington, DC: The Association. 
Transportation Policy Associates (1985). Transportation in america (3rd ed.). Washington, DC: The Associates.

Trayer, H. W. (1954). The four wheel drive story. New York: McGraw-Hill.

United States Congress (1961). Report on national transportation policy. Washington, DC: Senate Committee on Interstate and Foreign Commerce, 87th Congress, 1st Session, January 3rd, 1961.

United States Department of Transportation (1975) - $\underline{A}$ statement of national transportation policy. Washington, DC: U. S. Government Printing office.

United States Motor Carrier Ratemaking Study Commission (1983). Collective ratemaking in the trucking ndustry. Washington, DC: The Commission.

Wall Street Journal (1979, October 23). Senator Cannon warns ICC to go cautiously in deregulation of the trucking industry. Wall street Journal, 7 .

Walters, L. L. (1987). Federal and state transportation policies: Mostly about motor carriers. Logistics and Transportation Review, 23(1), 57-64.

Whipple, G. D., Casavant, K. L., \& Mittelhammer, R. (1981). An evaluation of state regulation of primary agricultural motor carriers in washington. In proceedings of the Transportation Research Forum, 22, 25-32.

Wilcox, C. (1966). Public policies toward business (3rd ed.). Homewood, IL: Richard D. Irwin.

Williams, E. W. Jr. (1958). The regulation of rail-motor rate competition. New York: Harper Brothers.

Williamson, K. C., Singer, M. G., \& Peterson, R. A. (1983). The impact of regulatory reform on U.S. for-hire freight transportation: The users perspective. Transportation Journal, $22(4), 44$.

Williamson, K. C., Singer, M. G., \& Bloomberg, D. L. (1985). The impact of regulatory reform on U.S. for-hire freight transportation: The carriers perspective. Transportation Journal, 24(4), 28-51.

Wilson, G. (1962). Essays on some unsettled questions in the economics of transportation. Bloomington, IN: Bureau of Business Research, Indiana, University. 
Wolbert, G. S. (1979). United states oil pipelines: An examination of how oil pipelines operate and the current public policy issues concerning their ownership. Washington, DC: American Petroleum Institute.

Wood, D. F., \& Johnson, J. C. (1989) . Contemporary transportation. New York: MacMillan.

Wyckoff, D. D. (1974). Which truckers compete with us? Modern Railroads, 24(11), 65 .

Wyckoff, D. D., \& Maister, D. H. (1975). The owneroperator: Independent trucker. Lexington, MA: D. C. Heath. 


\section{VITA}

Russell W.' Jones

Candidate for the Degree of

Doctor of Philosophy

Thesis: MOTOR CARRIER PRICING IN AN UNREGULATED ENVIRONMENT

Major Field: Business Administration

Biographical:

Personal Data: Born in Shawnee, Oklahoma, January 17, 1934, the son of Clarance $C$. and Lucy L. Jones.

Education: Graduated from Shawnee Senior High School, Shawnee, Oklahoma, in May, 1951; received Bachelor of Science Degree in Business Administration from Oklahoma State University in May, 1955; received Master of Science Degree in Business Administration from Boston University, Boston, Massachusetts in May, 1977; completed requirements for the Doctor of Philosophy degree at Oklahoma State University in December, 1992

Professional Experience: Twenty three years of operational experience as an officer in the United States Air Force between 1955 and 1978; three years of operational supervisory experience in the motor carrier industry between 1978 and 1981; Teaching Assistant, Department of Marketing, Oklahoma State University, August, 1986 to May, 1987; Instructor, Department of Marketing, University of Central Oklahoma, August, 1988 to present. 